\title{
II. DAS FINNISCHE STRAFRECHT UND DESSEN GESAMTREFORM
}





\title{
Neues in der finnischen Strafrechtswissenschaft und in den allgemeinen Lehren des finnischen Strafrechts
}

\begin{abstract}
I. Zur Einführung
Wenn jegliche sich mit der Kriminalität befassende Forschung zum Bereich der Kriminalwissenschaften gerechnet wird, so sind die die Kriminalität betreffenden Rechtsvorschriften das Objekt der Strafrechtswissenschaft. Mit den allgemeinen Lehren des Strafrechts sind hier die allgemeinen Voraussetzungen der strafrechtlichen Verantwortlichkeit gemeint, kurz die Straftatlehre. Sie ist der typische Bereich der Strafrechtsdogmatik. Das strafrechtliche Sanktionensystem werde ich hier nicht behandeln. Zu Anfang möchte ich jedoch die Wechselwirkung zwischen den verschiedenen Teilkomplexen des Strafrechtssystems und den verschiedenen, diese untersuchenden Bereichen der Kriminalwissenschaften betonen.

Die Betrachtung der Situation des finnischen Strafrechts und der finnischen Strafrechtswissenschaft ist insofern ein aktuelles Anliegen, als gegenwärtig die Gesamtreform unseres Strafgesetzes, das am 19. Dezember 1989100 Jahre alt geworden ist, vorbereitet wird und eine Regierungsvorlage, die die erste Phase der Reform der Strafgesetzgebung zum Inhalt hat (Nr. 66/1988), gerade mit gewissen Änderungen vom finnischen Reichstag verabschiedet worden ist. ${ }^{1}$ An jenem Tage wurde das Werk „Strafrechtliche Abhandlungen VI. Zum Jubiläum des Strafrechts im Jahr 1989“"veröffentlicht, das zahlreiche Artikel über die Vergangenheit, Gegenwart und Zukunft der strafrechtlichen Forschung enthält. Anlaß für das Jubiläum bildete indes nicht nur das 100jährige Bestehen des Strafgesetzes, sondern auch der Umstand, daß seit der Geburt von Jaakko Forsman (1839-1899), dem „Vater“ des finnischen Strafgesetzes, 150 Jahre und seit der Geburt von Brynolf Honkasalo (1889-1973), einem anderen bedeutenden finnischen Strafrechtsgelehrten, 100 Jahre vergangen sind.
\end{abstract}

$1 \quad$ Siehe Gbl. Nrn. 769-834 vom 24.8.1990. 


\section{II. Über die Entwicklungstendenzen der (Straf-) Rechtswissenschaft}

Die Strafrechtswissenschaft ist ein Sektor der Rechtswissenschaft, und daher kann man annehmen, daß sich in ihrer Entwicklung dieselben Tendenzen ausdrücken wie in der Rechtswissenschaft allgemein. Der Hauptstrom der Rechtswissenschaft und ihres traditionellen Kerngebiets, der Rechtsdogmatik, hat seine Richtung relativ wenig geändert, und auch die Grundzüge der Forschung auf diesem Gebiet scheinen sich selbst im Laufe von Jahrhunderten kaum wesentlich gewandelt zu haben. Dementsprechend erweisen sich die Errungenschaften der rechtlichen Begriffs- und Systembildung als langlebig. Hierfür ein Beispiel aus dem Bereich des Strafrechts:

Welzel hat in einer Abhandlung aus dem Jahre 1966 über die Entwicklung der deutschen Strafrechtsdogmatik in den letzten 100 Jahren festgestellt, daß sich bereits im ersten Drittel unseres [20.] Jahrhunderts in der Klassifizierung der allgemeinen Voraussetzungen der strafrechtlichen Verantwortlichkeit die Einteilung zwischen Tatbestandsmäßigkeit, Rechtswidrigkeit und Schuld abgezeichnet hat. Er hielt die Anerkennung eines solchen dreiteiligen Straftatbegriffs für den wichtigsten strafrechtsdogmatischen Fortschritt der letzten zwei, drei Generationen. ${ }^{2}$ Die Dreiteilung machte sich u.a. auch Honkasalo in seinen Ende der vierziger Jahre verfaßten Lehrbüchern über die allgemeinen Lehren des finnischen Strafrechts zu eigen, ${ }^{3}$ und ein solcher Straftatbegriff gilt nach wie vor als Ausgangspunkt der modernen finnischen Straftatlehre. ${ }^{4}$

Trotz der relativen Stabilität der Rechtswissenschaft sind auch in ihr verschiedene Entwicklungstendenzen und Lehrkonstruktionen $\mathrm{zu}$ beobachten. Das begriffsjuristische Denken deutscher Provenienz bewahrte seine beherrschende Stellung in Finnland bis in die fünfziger Jahre hinein. Von da an begannen zwei neue Richtungen des Rechtsdenkens Anhänger zu finden: zum einen die analytische Rechtswissenschaft, für die eine besondere Weise der Begriffsanalyse kennzeichnend ist, und zum anderen der Rechtsrealismus, bei dem die Berücksichtigung der Rechtswirkungen von Auslegungen betont wird. Impulse

2 Welzel, JuS 1966, 421.

3 Siehe Honkasalo, Suomen rikosoikeus. Yleiset opit I-II (Das finnische Strafrecht. Allgemeine Lehren I-II), 2. Aufl. Hämeenlinna 1965 und 1967.

4 Siehe z.B. Jescheck, Uusi rikosoppi ja sen käytännön merkitys Saksan liittotasavallassa (Die neue Straftatlehre und ihre praktische Bedeutung in der Bundesrepublik Deutschland), Lakimies 84 (1986), S. 468, 469, der es als Vorzug des dreiteiligen Straftatbegriffs ansieht, daß die strafbare Tat unter verschiedenen Aspekten betrachtet, d.h. auf verschiedenen Ebenen beurteilt wird. 
für diese neuen Denkkonstruktionen kamen in erster Linie aus den übrigen nordischen Ländern. Die genannten Tendenzen hatten einen besonders deutlichen Einfluß auf die zivilrechtliche Forschung, während die finnische Strafrechtsdogmatik ihre der deutschen Tradition folgende stark begriffliche Prägung bewahrte.

Gegen Ende der 60er, Anfang der 70er Jahre geriet die juristische Forschung in das Kreuzfeuer heftiger Kritik. Den Kritikern zufolge sollte man sich in der Rechtswissenschaft nicht mit juristischen Fragestellungen - mit der Klärung des Inhalts der Rechtsvorschriften (der Auslegung) und Systematisierung begnügen, sondern von zentraler Bedeutung sei es, die rechtlich geregelten Phänomene mit Hilfe der Methoden der empirischen Sozialwissenschaften zu erforschen. Die Grenze der Rechtswissenschaft zur soziologischen und politischen Forschung sei zu durchstoßen.

Die strafrechtliche Forschung ist für gewöhnlich besonders empfänglich für solche Forderungen; hatte ja schon die sog. soziologische Strafrechtsschule, die sich gleichzeitig mit der Entstehung der Kriminologie Ende des 19. Jahrhunderts entwickelte, für mehrere Jahrzehnte einen starken Einfluß auf das kriminalpolitische Denken ausgeübt. Seit dieser Zeit hält man es für wichtig, die Verbindungen der Strafrechtsdogmatik zur gesellschaftlichen Wirklichkeit und zu den diese untersuchenden Kriminalwissenschaften zu berücksichtigen.

Eine bedeutende Richtung, die in der letzten Zeit Einfluß genommen hat, wird als alternative Rechtslehre bezeichnet; sie hat Verbindungspunkte zu der amerikanischen Bewegung der Kritischen Rechtsforschung (Critical Legal Studies). Auch weist sie gemeinsame Züge mit dem Zweig auf, der das Erbe des skandinavischen Realismus fortsetzt und für den die Herausstellung der realen Argumentation (reella överväganden) kennzeichnend ist. Die alternative Rechtslehre ist bestrebt, auf die Herausforderung zu antworten, die der Wohlfahrtsstaat und die ihm eigenen rechtlichen Regelungen stellen. Die Rechtsvorschriften des Wohlfahrtsstaates sind häufiger und offener als zuvor an Ziele und Interessen gebunden, und dementsprechend hat man sich in der rechtlichen Argumentation immer mehr auf die Folgen der Entscheidungsalternativen (vom Standpunkt gewisser Ziele oder Werte aus gesehen) zu stützen. ${ }^{5}$

5 Siehe eingehender z.B. Tuori, Vaihtoehto ja kritiikki, suppea vai laajennettu doktriini (Alternative und Kritik, enge oder erweiterte Doktrin), in: Hirvonen / Tuori (Hrsg.), Oikeus, kieli ja kritiikki (Recht, Sprache und Kritik), Helsinki 1990, S. 49. 


\section{III. Über die kriminalpolitische Ausrichtung in der Strafrechtswissenschaft}

In diesem Zusammenhang ist es nicht möglich, die Wirkung der oben genannten Entwicklungstendenzen auf die Strafrechtswissenschaft eingehend $\mathrm{zu}$ analysieren. Meine Absicht ist indes zu zeigen, daß sich in der finnischen Strafrechtswissenschaft und in dem Teilgebiet der Strafrechtsdogmatik bemerkenswerte Wandlungen vollzogen haben und vollziehen und daß diese Veränderungen vor dem Hintergrund der allgemeinen Entwicklung der Rechtswissenschaft und der Kriminalwissenschaften zu sehen sind.

In erster Linie ist eine verstärkte kriminalpolitische Ausrichtung der Strafrechtswissenschaft festzustellen. Die Voraussetzungen für diese Ausrichtung sind durch mehrere Umstände geschaffen worden, die zeitlich in den 70er Jahren anzusiedeln sind. Oben habe ich die Diskussion über die Neubewertung der Aufgaben und Methoden der Rechtswissenschaft erwähnt, die zu Anfang der 70er Jahre geführt wurde. Zur gleichen Zeit wurde auch über die Zielsetzung und die Wertziele der Kriminalpolitik intensiv diskutiert. Im Jahre 1972 ist mit der Einsetzung des Strafrechtskomitees die Arbeit zur Gesamtreform der Strafgesetzgebung aufgenommen worden.

Ein Schwerpunkt in den Äußerungen der Vertreter der Strafrechtswissenschaft und allgemeiner der Kriminalwissenschaften in den 70er und 80er Jahren betraf die Grundlagen einer der Rationalität verpflichteten Kriminalpolitik - in erster Linie für die Ausarbeitung der Gesetze, insbesondere zur Gesamtreform der Strafrechtsgesetzgebung. Das grundlegende Dokument ist der Bericht des Strafrechtskomitees. ${ }^{\mathbf{6}}$

Ich stelle an eine rationale Kriminalpolitik u.a. folgende Anforderungen. ${ }^{7}$

- Das gesamte Strafrechtssystem hat für die Leitung des Verhaltens der Menschen, für die Entscheidung von Konfliktsituationen und für die Bekämpfung von im Rahmen der Gesellschaft unerwünschten Erscheinungen nur begrenzte Bedeutung. Dementsprechend sollte man danach streben, den relativen Anteil des Strafrechts an der sozialen Kontrolle im Hinblick auf andere Mittel zu verringern.

6 Siehe Komiteanmietintö 1976:72. Rikosoikeuskomitean mietintö (Komiteebericht 1976:72. Bericht des Strafrechtskomitees), Helsinki 1976 (1977).

7 Siehe auch meine früheren Ausführungen hierzu; z.B. Lahti, Festschrift för Jescheck, Bd. II, 1985, S. 871. 
- Man ist der Ansicht, daß das wichtigste utilitaristische Ziel des Strafrechts, die generalpräventive Wirkung, am besten dadurch erreicht wird, daß man zum einen für Effektivität des offiziellen Überwachungsapparats sorgt (in erster Linie durch ein hohes Entdeckungsrisiko für den Straftäter) und zum zweiten sicherstellt, daß das Strafrecht in seiner Gesamtheit seine Glaubwürdigkeit bei der Aufrechterhaltung der Rechtsordnung bewahrt und seine die Gesellschaftsmoral festigende Aufgabe behält.

- Hinsichtlich des gerade Gesagten ist anzunehmen, daß das Repressionsniveau, d.h. in erster Linie die Anwendung von Freiheitsstrafen, gesenkt werden kann, ohne daß dadurch die generalpräventive Wirkung des gesamten Strafrechtssystems merklich geschwächt würde.

- Neben den utilitaristischen Zielen des Strafrechtssystems (zu denen außer der Generalprävention noch vor allem die Spezialprävention zu zählen ist) sind auch in differenzierterer Weise als bisher die die Kriminalpolitik lenkenden Werte (Grundsätze) zu berücksichtigen, vor allem die Werte der Gerechtigkeit und Humanität sowie die konkreteren Rechtsprinzipien.

- Die genannten Ziele und Werte der Kriminalpolitik sind hinsichtlich der einzelnen Ebenen / Teile des Strafrechtssystems in unterschiedlicher Weise von Bedeutung, zum Beispiel je nachdem, ob die Existenzberechtigung des gesamten Strafrechtssystems zur Diskussion gestellt ist, ob es um die Begründbarkeit einzelner Kriminalisierungen und die Strenge der festzulegenden Strafandrohungen geht (d.h. welche Taten zu bestrafen sind und gegebenenfalls mit welcher Sanktion), ob die Prinzipien, die die Verhandlung strafrechtlicher Sachen (den Strafprozeß) betreffen, oder die bei der Festsetzung der Sanktionen zu befolgenden Prinzipien in Frage stehen.

- Deutlicher als früher ist man sich dessen bewußt, daß Struktur und Funktion des Strafrechtssystems auch von der verstärkten Beachtung der Menschenrechte und den internationalen Abkommen und Gebräuchen bestimmt werden.

In der praktischen Umsetzung der Kriminalpolitik, d.h. bei der Ausarbeitung der Gesamtreform der Strafgesetzgebung durch die 1980 vom Justizministerium eingesetzte Projektorganisation (dem sog. Strafgesetzprojekt) hat der Schwerpunkt bislang auf den Kriminalisierungen gelegen. Die erste und die zweite Phase dieser Reformarbeit betreffen insgesamt etwa zwei Drittel des Besonderen Teils des neuen Strafgesetzes. ${ }^{\mathbf{2}}$ In der dritten Ausarbeitungsphase

8 Siehe Hallituksen esitys (Regierungsvorlage) Nr. 66/1988 zur Verwirklichung der ersten Phase der Gesamtreform der Strafgesetzgebung mit der Änderung des Strafgesetzes und einiger anderer Gesetze und Rikoslain kokonaisuudistus II. Rikoslakiprojek- 
des Projekts, die 1989 begonnen hat, richtet sich das Hauptaugenmerk auf die Fragen der Reform des Sanktionensystems.

\section{IV. Über die neueste theoretische Ausrichtung in der Strafrechtsdogmatik}

Während bei der anstehenden Reform der Strafgesetzgebung vorrangig die Forderungen im Blickpunkt stehen, die an einen rationalen Gesetzgeber zu stellen sind, werden in der Strafrechtsdogmatik nach den Worten des Schweden Nils Jareborg die an den rationalen Richter oder allgemeiner an den Gesetzesanwender zu stellenden Forderungen behandelt.' Was ist rationales Verhalten in der Rolle des Richters oder des Anklägers? Bei der Beantwortung dieser Frage nehmen die allgemeinen Lehren des Strafrechts (und des Strafprozeßrechts) eine Schlüsselstellung ein.

Die allgemeinen Lehren des Strafrechts und die mit ihnen zusammenhängende theoretische Forschung haben in den vergangenen Jahrzehnten bei uns - von der jüngsten Entwicklung einmal abgesehen - nur relativ wenig Beachtung gefunden. Diese Beobachtung bewog Eero Backman zu der Feststellung:

Das Kartenhaus der traditionellen strafrechtlichen Begriffsjuridik ist umgestoßen worden. Seine Karten liegen jedoch noch auf dem Tisch. ...eine Strafrechtsdogmatik, die sich aktiv der gesellschaftlichen und allgemein metajuristischen Gebundenheit der Begriffe bewußt ist, steht in der Anfangsphase ihrer Entwicklung. ${ }^{10}$

Danach hat sich die Situation weitgehend gewandelt. Zum einen sind zwei für die theoretischen Grundlagen der Strafrechtsforschung bedeutsame Werke erschienen: die Dissertationen (Habilitationsschriften) von Tapio LappiSeppälä und Dan Frände aus den Jahren 1987 bzw. 1989. ${ }^{11}$ Außerdem haben viele junge Forscher ihre strafrechtstheoretisch orientierten Lizentiatsarbeiten abschließen oder ihre Dissertationen weitgehend ausarbeiten können. Einige

tin ehdotus (Die Gesamtreform des Strafgesetzes II. Entwurf des Strafgesetzprojektes), Helsinki 1989.

9 Siehe Jareborg, Brotten I. Grundbegrepp. Brotten mot person (Die Straftat I. Grundbegriffe. Straftaten gegen die Person), 2. Aufl. Lund 1984, S. 16-81.

10 Backman, Havaintoja suomalaisen rikosoikeudellisen tutkimuksen metodien kehityksestä (Beobachtungen zur Entwicklung der Methoden der finnischen rechtswissenschaftlichen Forschung), in: Lahti / Rehbinder (Hrsg.), Oikeustieteen tila ja tulevaisuus (Zustand und Zukunft der Rechtswissenschaft), Vaasa 1985, S. 106, $108 \mathrm{f}$.

11 Siehe Lappi-Seppälä, Rangaistuksen määräämisestä I. Teoria ja yleinen osa (Über die Strafbemessung I. Theorie und Allgemeiner Teil), Habilitationsschrift, Vammala 1987, und Frände, Den straffrättsliga legalitetsprincipen (Das strafrechtliche Legalitätsprinzip), Habilitationsschrift, Ekenäs 1989. 
dieser Forschungsergebnisse werden in dem eingangs erwähnten Werk „Zum Jubiläum des Strafrechts im Jahr 1989“" vorgestellt. ${ }^{12}$

Zum zweiten ist in den letzten Jahren eine rege Diskussion über die Stellung der allgemeinen Lehren der verschiedenen Rechtsbereiche und besonders der sog. Rechtsprinzipien im Rechtssystem entstanden. Unter anderem ist die Frage aufgeworfen worden, welches die Bedeutung der zu den allgemeinen Lehren zu zählenden Grundbegriffe und Rechtsprinzipien zum einen für die Ausgestaltung der Grundstrukturen des Rechtsbereichs und zum zweiten für die juristische Argumentation sei. ${ }^{13}$

Zum dritten hat die von dem Strafrechtsprojekt eingesetzte Arbeitsgruppe für allgemeine Lehren in den letzten zwei Jahren die Fragen der Straftatlehre behandelt und vorläufige Entwürfe ausgearbeitet. Ich nehme also an, daß es schon recht bald möglich sein wird, unter besseren Voraussetzungen Gesamtentwürfe und -vorlagen über die Struktur der Straftat (den theoretischen Straftatbegriff) zu erstellen, die zeitgemäß sind und auf einem einheitlichen, konsequenten Denken basieren.

Als nächstes möchte ich kurz die neueste finnische Strafrechtsforschung charakterisieren und danach (V.-VIII.) die aktuelle Problematik der allgemeinen Lehren des Strafrechts von meinem eigenen Standpunkt aus umreißen.

Die Schriften von Lappi-Seppälä und Frände sind schwerpunktmäßig rechtstheoretisch (-philosophisch) orientiert. Lappi-Seppäläs Werk enthält - als Hintergrund für seine juristische Systematisierung und Auslegung traditioneller Art - eine auf Rechts- und Moralphilosophie gestützte Analyse sowie eine geschickte Auswertung von kriminologischem und kriminalpolitischem Material. Der Opponent von Frändes Dissertation, Lars D. Eriksson, bezeichnete die von ihm geprüfte Arbeit als eine in gewissem Sinne sozialphilosophische Arbeit, bei der die Regel-Prinzip-Diskussion eine bedeutende Stellung einnehme. Eriksson war sogar der Ansicht, daß Frändes Dissertation Ausdruck des sich in der Rechtsforschung gerade vollziehenden grundlegenden Paradigmenwechsels sei. ${ }^{14}$

12 Siehe Lahti (Hrsg.), Rikosoikeudellisia kirjoitelmia VI. Rikosoikeuden juhlavuonna 1989 (Strafrechtliche Abhandlungen. Zum Jubiläum des Strafrechts im Jahr 1989), Vammala 1989.

13 Siehe z.B. Tuori, The General Doctrines in Public Law, Scandinavian Studies in Law 31 (1987), S. 175, und Frände (Anm. 11), Abschnitt II.4.

14 Eriksson, Dan Frändes legalitetstregler - och opponentens bekymmer (Dan Frändes Legalitätsregeln - und die Sorgen des Opponenten), Oikeus 1989:1, S. 63. 
$\mathrm{Zu}$ den Forschungsaufgaben dieser Schriften: Lappi-Seppälä verfolgte das Ziel, anhand von Rechtsquellen die Zahl der Auslegungsalternativen in der Weise zu begrenzen, daß die Gesetzesanwendung - die Strafbemessung - in optimaler Weise die materiellen wie auch die formellen Forderungen des Rechtsschutzes erfüllt. Frändes Werk hingegen hat als zentrales Anliegen, zu zeigen, daß die vier Unterregeln des strafrechtlichen Gesetzlichkeitsprinzips das Rückwirkungsverbot, das praeter-legem-Verbot sowie besonders das Analogieverbot und das Bestimmtheitsgebot - von den Rechtsprinzipien (den „Daumenregeln“) gestützt werden und daß sie damit alle zum Strafrechtssystem gehörenden bindenden Vorschriften darstellen.

In Lappi-Seppäläs Schrift ist u.a. sein für die Theoriebildung der Strafbemessung aufgestelltes Argumentationsmodell von Interesse, in welchem er versucht, die allgemeinen und tatbestandsbezogenen Voraussetzungen der Strafbarkeit auf die präventiven, d.h. die die Kontrollierbarkeit des Verhaltens betreffenden Wirkungen der legislativen Entscheidung zurückzuführen. Neben der Präventivwirkung sind gleichzeitig das Präventionsinteresse (die Schädlichkeit des Tattyps) und die Beschränktheit der zur Kontrolle zur Verfügung stehenden Hilfsmittel (welche zu einer strengen Abwägung der Kontrollierbarkeit zwingt) zu berücksichtigen.

Ähnliche Gedankengänge finden sich in mehreren Beiträgen zu dem Werk „Zum Jubiläum des Strafrechts im Jahr 1989“. Nach Ari-Matti Nuutila bestimmt sich der Inhalt des zentralen Prinzips im Strafrecht - der Möglichkeit, anders zu handeln - durch eine Abwägungsoperation, bei der zum einen die relative Effizienz des Reaktionssystems zur Verwirklichung rationaler gesellschaftlicher Ziele und zum anderen die an die Gerechtigkeit und Humanität des Systems zu stellenden Forderungen berücksichtigt werden. ${ }^{15}$

Eine rechtstheoretisch ähnliche Argumentation findet sich in der Festschrift auch in den Aufsätzen von Timo Tuovinen über das Notwehrrecht und von Jaakko Jonkka über das Beweisrecht. ${ }^{16}$ Kimmo Nuotio, der in seinem Beitrag die Fragen der strafrechtlichen Kausalität und der objektiven Zurechenbarkeit untersucht, kommt zu folgendem Schluß: Im modernen Strafrecht wird die

15 Nuutila, Toisintoimimismahdollisuus Serlachiuksella ja Honkasalolla - tavoitteita ja arvoja (Die Möglichkeit des Anders-Handelns bei Serlachius und Honkasalo - Ziele und Werte), in: Rikosoikeuden juhlavuonna 1989 (Anm. 12), S. 342, 362.

16 Tuovinen, Hätävarjelun ja rikoslainsäädännön luonne (Der Charakter der Notwehr und der Strafgesetzgebung), in: Rikosoikeuden juhlavuonna 1989 (Anm. 12), S. 439, und Jonkka, Syytekynnyksestä (Uber die beweismäßigen Voraussetzungen för die Anklageerhebung), in: Rikosoikeuden juhlavuonna 1989 (Anm. 12), S. 129. 
Dogmatik immer deutlicher an ihre straftheoretischen und kriminalpolitischen Grundlagen gekoppelt. ${ }^{17}$

Obwohl die oben erläuterten Auffassungen in mancher Beziehung in die gleiche Richtung gehen, darf man nicht annehmen, daß in der jungen Forschergeneration nur eine einzige kriminalpolitische oder rechtstheoretische Denkweise repräsentiert sei. So hat sich zum Beispiel Panu Minkkinen in seiner Lizentiatsarbeit über Schuldfähigkeit und soziale Kontrolle die sog. kritische Theorie zu eigen gemacht und gibt an, theoretische Impulse u.a. von der Schule der Critical Legal Studies, dem Strukturalismus und der Rechtssemiotik erhalten zu haben. ${ }^{18}$

\section{$V$. Die allgemeinen Lehren des Strafrechts und die Gesamtreform der Strafgesetzgebung}

Die die allgemeinen Lehren des Strafrechts betreffenden Gesetzesänderungen sollen in der Endphase der Gesamtreform vorgenommen werden. Ein solcher Zeitplan ist aus mehreren Gründen problematisch. Zum einen ist es das vorrangige Ziel der gesamten Reform, eine Neubewertung der Frage vorzunehmen, welche Taten zu bestrafen sind und gegebenenfalls mit welcher Sanktion. Die Regeln und Prinzipien der Lehre von der Straftat bestimmen im wesentlichen die Grenzen zwischen strafbarem und nicht strafbarem Verhalten. Zum Beispiel haben die Antworten auf die Fragen, welcher Inhalt dem Vorsatz zu geben oder in welchem Umfang der sog. untaugliche Versuch zu bestrafen sei, eine maßgebliche Auswirkung auf den Bereich der Strafbarkeit.

Zum zweiten muß bei der Reform der Vorschriften über bestimmte Straftaten die Antwort auf die Frage antizipiert werden, in welcher Form die allgemeinen Voraussetzungen der strafrechtlichen Verantwortlichkeit später im Gesetz definiert werden oder welchen Inhalt sie sonst erhalten.

Dabei wird schon aus praktischen Gründen vorausgesetzt, daß die Straftatlehre möglichst weitgehend ihren bisherigen Inhalt behält. Mit anderen Worten: Die bei der Ausarbeitung des Gesetzes angewandte Verfahrensweise trägt dazu bei,

17 Nuotio, Ennalta arvattavuuden merkityksestä Brynolf Honkasalon kausaalisuus- ja rikosopin kannalta (Die Bedeutung der Vorhersehbarkeit vom Standpunkt der Kausalitäts- und Straftatlehre Brynolf Honkasalos), in: Rikosoikeuden juhlavuonna 1989 (Anm. 12), S. 309, $340 \mathrm{f}$.

18 Minkkinen, „Ymmärrystä vailla“. Syyntakeisuus ja sosiaalinen kontrolli (,Der eigenen Sinne nicht mächtig“. Zurechnungsfähigkeit und soziale Kontrolle), Kriminologische Lizentiatsarbeit, Rechtswissenschaftliche Fakultät der Universität Helsinki 1989 (unveröffentlicht). 
eine dynamische Entwicklung der Straftatlehre zu erschweren. Allerdings erleichtert der Umstand, daß in unserem Strafgesetz aus dem Jahre 1889 nur wenige allgemeine Voraussetzungen der strafrechtlichen Verantwortlichkeit festgelegt sind, die Weiterentwicklung des Rechtssystems in einer von dem neuen legislativen Recht unabhängigen Weise.

Zum dritten hat der Aufschub der Behandlung der allgemeinen Lehren zur Folge, daß in der Anfangsphase der Strafgesetzreform kein gründlich durchdachtes, in sich folgerichtiges Konzept für den Inhalt vorliegt, der den Grundbegriffen und Rechtsprinzipien der Straftatlehre zu geben ist. Außerdem kommt erschwerend hinzu, daß das Strafrechtskomitee in seinem Grundsatzbericht diese Fragen nur recht knapp abgehandelt hat. ${ }^{19}$

Wenn man über die allgemeinen Lehren des neuen Strafgesetzes nachdenkt, tauchen insbesondere zwei Fragen auf. Die erste lautet: In welchem Maße sind in dem neuen Gesetz die Grundbegriffe und Rechtsprinzipien der allgemeinen Lehren zu definieren? Noch wichtiger ist die zweite Frage: Welche Forderungen sind an die Begriffs- und Systembildung des Strafrechts zu stellen? Die Stellungnahme hierzu setzt die Erwägung voraus, ob man bei der Ausgestaltung der Basisstrukturen des Strafrechts ganz neuartige Fragestellungen übernehmen sollte.

Der Bericht des Strafrechtskomitees gibt dieser Überlegung eine gewisse Richtschnur. Zum einen ist nach Meinung des Komitees die möglichst vollständige und genaue Festlegung der allgemeinen Lehren des Strafrechts wünschenswert; damit würde man die Vorhersehbarkeit und den Rechtsschutz fördern, und eine solche Vorgehensweise wäre auch hinsichtlich der Gewaltenteilung zwischen Reichstag und Gerichtswesen wünschenswert. ${ }^{20}$ Nach Ansicht des Komitees sprechen also das strafrechtliche Gesetzlichkeitsprinzip und die hinter diesem stehenden Werte für eine weitgehende Regelung der allgemeinen Lehren im Strafgesetz. ${ }^{21}$

Zum zweiten ist an dem Bericht des Strafrechtskomitees bemerkenswert, daß an mehreren Stellen die straftheoretischen und kriminalpolitischen Verbindun-

19 Siehe Komiteebericht 1976:72 (Anm. 6), S. 95-132.

20 Siehe Komiteebericht 1976:72 (Anm. 6), S. 95 f.

21 Desgleichen Norges offentlige utredninger (NOU) 1983:57. Straffelovgivningen under omforming (Norwegische öffentliche Untersuchungen 1983:57. Die Strafgesetzgebung im Wandel), Oslo 1983, S. 118, und Statens offentliga utredningar (SOU) 1988:7. Frihet från ansvar (Offentliche Untersuchungen des Staates 1988:7. Ausschluß der strafrechtlichen Verantwortlichkeit), Stockholm 1988, S. 12. Vgl. Frände (Anm. 11), S. $213 \mathrm{f}$. 
gen der allgemeinen Lehren betont werden. Zum Beispiel werden die beiden Grundprinzipien des Strafrechts - neben dem Gesetzlichkeitsprinzip auch das Schuldprinzip - in dem Bericht vorrangig mit der Rechtssicherheit (der Vorhersehbarkeit) oder mit damit eng verbundenen Werten, aber auch mit Zweckargumenten bezüglich der Generalprävention begründet. ${ }^{22}$ Die unabdingbare Voraussetzung für die Überzeugungskraft einer solchen parallelen Begründung ist, daß mit Generalprävention in erster Linie die sog. Integrationsprävention gemeint ist, d.h. die die Moral- und die sozialen Normen aufrechterhaltende oder stärkende Wirkung des Strafrechts. ${ }^{23}$

\section{VI. Über die Vorbilder der neuen Strafrechtsdogmatik}

Die Anstöße des Berichts des Strafrechtskomitees für die Entwicklung der finnischen Strafrechtsdogmatik sind durch Angaben über ausländische Vorbilder auf dem Gebiet der Strafrechtsdogmatik zu ergänzen. Wie oben (II.) deutlich geworden ist, hat die deutsche Lehre seit alters her einen großen Einfluß auf das finnische Denken hinsichtlich der Voraussetzungen der strafrechtlichen Verantwortlichkeit gehabt.

Für die deutsche, kontinentaleuropäische Tradition werden Konstruktivität (Begrifflichkeit) und theoretischer Charakter als kennzeichnend angesehen, während das angloamerikanische Denken praxisnäher ist und die Bedeutung des Gerichtsverfahrens (und damit des Beweisrechts) hervorhebt. Die genannte Konstruktivität ist u.a. in dem weitgehend differenzierten (,analytischen"), hierarchischen Straftatbegriff im Gegensatz zu der ,holistischen“ Straftatstruktur zu sehen. ${ }^{24}$

Im neueren westdeutschen Schrifttum wird indes mit Bedauern festgestellt, daß sich zwischen Theorie und Praxis eine immer größer werdende Kluft auftut. ${ }^{25}$ Jescheck warnt vor der Gefahr einer auf zu abstrakte Schemata beschränkten Strafrechtsdogmatik. Nach seiner Meinung haben die Forderungen nach Systematik bei Bedarf zurückzutreten, und maßgebend ist eine solche Lösung der Sachfrage, die die besonderen Merkmale des Einzelfalls berück-

22 Komiteebericht 1976:72 (Anm. 6), S. 97, 109. Vgl. Frände (Anm. 11), S. 205, 214.

23 Siehe Komiteebericht 1976:72 (Anm. 6), S. 65.

$24 \mathrm{Zu}$ diesen Charakterisierungen siehe Hassemer, Rechtfertigung und Entschuldigung im Strafrecht. Thesen und Kommentare. In: Eser / Fletcher (Hrsg.), Rechtfertigung und Entschuldigung, Bd. I, 1987, S. 175.

25 So z.B. Schönke / Schröder, Strafgesetzbuch. Kommentar, 23. Aufl. 1988, S. V. 
sichtigt. Auch kriminalpolitische Wertentscheidungen müssen auf die Systembildung des Strafrechts einen Einfluß haben können. ${ }^{\mathbf{2 6}}$

Natürlich bestehen nach wie vor Differenzen zwischen den verschiedenen Rechtssystemen. Das skandinavische Strafrechtsdenken ist im allgemeinen weniger konstruktiv gewesen als das deutsche und weist diesbezüglich Verbindungspunkte zur Tradition der Common-law-Länder auf. Zum Beispiel hat Andenaes bei der Präsentation des ersten Teilberichts der norwegischen Strafrechtskommission bemerkt, daß der Kommission theoretische Konstruktionsfragen, die jeglicher praktischen Bedeutung entbehren, fremd gewesen seien und daß überhaupt für das skandinavische Rechtsdenken die praktische Ausrichtung kennzeichnend sei. $^{27}$

In den letzten Jahrzehnten hat sich der Einfluß des Strafrechts und der Strafrechtswissenschaft der übrigen skandinavischen Länder auf Finnland verstärkt, zum Teil im Zuge der allgemeinen rechtlichen Kooperation und der Harmonisierung der Gesetzgebung zwischen diesen Ländern. Bei der Ausarbeitung der anstehenden Gesamtreform der Strafgesetzgebung sind in den Rechtsvergleich der allgemeinen Lehren und damit als Impulse in recht gleichwertigem Verhältnis dreierlei Elemente einbezogen worden: das skandinavische Element, das des deutschsprachigen Kontinentaleuropa und das der Common-lawLänder.

\section{An die Begriffs- und Systembildung des reformierten Strafrechts zu stellende Forderungen}

Aus dem oben (V.) Gesagten läßt sich zunächst folgern, daß man in dem neuen Strafgesetz die allgemeinen Lehren in stärkerem Maße als bisher und nach Möglichkeit mit exakteren Definitionen regeln wird. Der Anteil der Rechtspraxis und der Rechtswissenschaft bei der Bestimmung der Straftatlehre (des Rechtssystems) wird also abnehmen. Den die allgemeinen Voraussetzungen der strafrechtlichen Verantwortung bestimmenden Vorschriften kann jedoch kein allzu präziser Inhalt gegeben werden, ohne daß das Verallgemeinerungsniveau der Vorschriften in nachteiliger Weise sinken würde. In einigen Fällen kann jedoch eine Regelung in Frage kommen, die den Geltungsbereich der allgemeinen Lehren einschränkt.

26 Jescheck, Lehrbuch des Strafrechts. Allgemeiner Teil, 4. Aufl. 1988, S. 175 f. und dort zitiert Roxin, Kriminalpolitik und Strafrechtssystem, 2. Aufl. 1973.

27 Andenaes, Normierung der Rechtswidrigkeit als Strafbarkeitsvoraussetzung im neuen norwegischen Strafgesetzbuch?, in: Eser / Fletcher (Hrsg.) (Anm. 24), S. 437, 440. Der betreffende Bericht der Kommission ist NOU 1983:57 (Anm. 21). 
Die Ungenauigkeit der Vorschriften wird auch dadurch verursacht, daß bei der Definition der Straftatvoraussetzungen möglichst weitgehend eine Bindung an bestimmte, aus der Sicht der einheimischen Rechtstradition und des Rechtsvergleichs noch entwicklungsbedürftige oder umstrittene Lehrkonstruktionen vermieden werden soll. Die Tatsache, daß über eine Frage in der Rechtspraxis oder der Rechtswissenschaft Meinungsverschiedenheiten bestehen, reicht indes allein als Argument gegen eine Legaldefinition nicht aus, sondern kann eher ein für diese sprechender Grund sein. Zum Vergleich sei erwähnt, daß in das Strafgesetz von 1889 - entgegen dem Entwurf von 1875 - nur sehr wenige Legaldefinitionen aufgenommen wurden, und eine wichtige Begründung für diese Zurückhaltung die „Unreife“ vieler wissenschaftlicher Ergebnisse jener Zeit war. ${ }^{28}$

Zum zweiten nehme ich an, daß unsere Strafrechtsdogmatik außer aus den deutschsprachigen Ländern immer mehr Impulse von den Denkmodellen empfängt, die von den skandinavischen Ländern und vielleicht auch von den Common-law-Ländern ausgehen, die praktischer orientiert sind als die deutsche Tradition. Der Begriffsapparat und die Systematik der Strafrechtsdogmatik müssen eine ausreichend starke Verbindung zur praktischen Realität besitzen. Auf diese Weise gelangt man zu einer engeren Wechselwirkung zwischen Theorie und Praxis, wie es der folgende Ausspruch von Olavi Heinonen, dem Präsidenten des Obersten Gerichtshofs, anzudeuten scheint:

Das System der allgemeinen Lehren, vor allem die Struktur der Straftat, und viele der zu den allgemeinen Lehren gehörenden Theorien befinden sich auf einem solch hohen Abstraktionsniveau, daß von den Entscheidungen konkreter Rechtsfälle offenbar auch in Zukunft keine entscheidende Hilfe für die Entwicklung der allgemeinen Lehren erwartet werden kann. ${ }^{29}$

Verstärkte Praxisnähe bedeutet die Nichtbeachtung oder eingeschränkte Behandlung solcher rechtsdogmatischen Fragen, deren Lösung weder in der einen noch in der anderen Richtung eine nennenswerte Bedeutung im Hinblick auf die Folgewirkungen, in erster Linie die Strafbarkeit, hat.

Wenn man den Zusammenhang der Strafrechtsdogmatik mit der praktischen Realität betont, setzt man eine Definition der Begriffe z.B. der Straftatlehre in

28 Hierüber zusammenfassend Tulenheimo, Tuleeko uuden rikoslakimme pyrkiä ratkaisemaan n. k. teoreettisia kysymyksiä? (Sollte unser neues Strafgesetz bestrebt sein, theoretische Fragen zu lösen?), Lakimies 28 (1930), S. 200.

29 Heinonen, Lainkäyttö rikosoikeuden kehittämisessä, Rikosoikeudellisia kirjoitelmia V. Sylvi Inkeri Anttilalle 29.11.1986 omistettu (Weiterentwicklung des Strafrechts durch die Rechtsanwendung, in: Strafrechtliche Schriften V. Sylvi Inkeri Anttila gewidmet am 29.11.1986), Vammala 1986, S. 35, 50. 
der Weise voraus, daß sie ohne unangemessene Schwierigkeiten in der Praxis angewendet werden können. Den strafprozessualen, in erster Linie beweisrechtlichen Gesichtspunkten ist Aufmerksamkeit zu widmen. Die Verstärkung dieses Aspekts scheint einer der Hintergrundfaktoren für die Veränderung der Rechtspraxis bei der Abgrenzung von Vorsatz und Fahrlässigkeit seit Ende der siebziger Jahre gewesen zu sein. ${ }^{30}$

Zum dritten nehme ich an, daß die Begriffs- und Systembildung der allgemeinen Lehren des Strafrechts in zunehmendem Maße auf die Erwägung kriminalpolitischer Ziele und Werte gestützt wird oder daß man sich zumindest in deutlicherer Weise als bisher des Zusammenhangs zwischen Struktur und Funktion des strafrechtlichen Systems und Kriminalpolitik (und Moral) bewußt wird.

Als erster Exponent einer solchen Denkweise wird Claus Roxin angesehen. ${ }^{31}$ Für den Klassiker der Strafrechtswissenschaft Franz von Liszt, der um die Jahrhundertwende gewirkt hat, bestand noch zwischen Strafrecht und Kriminalpolitik ein unübersteigbarer Grenzwall. ${ }^{32}$ Nach Roxin ist die Kriminalpolitik nicht nur bei Entscheidungen über Kriminalisierungen oder bei der Festlegung strafrechtlicher Sanktionen von Bedeutung, sondern auch für die Strafrechtsdogmatik.

\section{Strafrechtsdogmatik und Kriminalpolitik}

Wie sieht eine Strafrechtsdogmatik aus, die sich der Ziele und Werte der Kriminalpolitik bewußt ist? Auf diese Frage gibt es zumindest bis heute noch keine eindeutige Antwort, und viele stehen der Fragestellung als solcher kritisch gegenüber.

Ich klassifiziere die oben (IV.) erläuterten Auffassungen von Lappi-Seppälä und Nuutila als kriminalpolitisch orientierte Strafrechtsdogmatik. Dagegen scheint z.B. Frände einer Verwertbarkeit der Kriminalpolitik in der Strafrechtsdogmatik recht skeptisch gegenüberzustehen: Nach seiner Ansicht ist

30 Zu dieser Praxis siehe besonders Träskman, Kan gärningspersonens uppsåt bevisas med hållpunkter i sinnevärlden? - Skuld och ansvar. Straffrättsliga studier tillägnade Alvar Nelson (Kann der Vorsatz des Täters mit Anhaltspunkten in der Welt der Sinne bewiesen werden? in: Schuld und Verantwortung. Strafrechtliche Studien, Alvar Nelson gewidmet), Uppsala 1985, S. 56.

31 Siehe besonders Roxin (Anm. 26) und Schünemann (Hrsg.), Grundfragen des modernen Strafrechtssystems, 1984.

32 von Liszt, Über den Einfluß der soziologischen und anthropologischen Forschungen auf die Grundbegriffe des Strafrechts, in: Strafrechtliche Aufsätze und Vorträge, Bd. II, 1905, S. 74, 80 . 
schon die Ausdehnung des Begriffs Kriminalpolitik über die Kriminalisierungsentscheidungen des Gesetzgebers hinaus problematisch; in der Systematisierung der Strafrechtsdogmatik seien die kriminalpolitischen Ziele überhaupt nicht von Belang und auch bei der Auslegung nur in sehr begrenztem Maße. ${ }^{33}$

In diesem Zusammenhang begnüge ich mich damit, meine eigenen Auffassungen in den Grundzügen kurz zu umreißen und anhand einiger Beispiele zu veranschaulichen. Zunächst einmal fasse ich den Begriff Kriminalpolitik sehr weit - viel weiter als zum Beispiel Frände. Bei der Bestimmung des Inhalts der allgemeinen Lehren des Strafrechts sind die rechtlichen Folgen ihrer Anwendung ebenso zu berücksichtigen wie die Ziele (und Interessen) sowie die Werte (und Prinzipien), von denen die Kriminalpolitik allgemein geleitet wird.

Die Anwendung des Wortes „Politik“ darf unter den zuletzt genannten Aspekten nicht nur Argumente vom „policy“-Typ umfassen, sondern auch solche vom ,principle“-Typ im Sinne von Dworkin. ${ }^{34}$ Mit anderen Worten: Ich fasse ebenso zur Zweck- wie zur Wertrationalität zählende Argumente ins Auge. ${ }^{35}$ Mit der Differenzierung zwischen kriminalpolitischen Zwecken und Werten wird die Spannung zwischen Zweckmäßigkeitsaspekten (utilitaristischen Aspekten) einerseits und den Aspekten der Gerechtigkeit und Humanität andererseits ausgedrückt - eine Spannung, die in der Geschichte des Strafrechts seit je bestanden hat. ${ }^{36}$

Wie oben (V.) bei der Erläuterung der Stellungnahmen des Strafrechtskomitees festgestellt wurde, lassen sich die Gesichtspunkte der Zweckmäßigkeit und der Gerechtigkeit zumindest bis zu einer gewissen Grenze als parallele und einander ergänzende Aspekte begründen. Als Mittel zur Beseitigung des Widerspruchs diente die Betonung, daß die Zweckprinzipien (vor allem)

33 Frände, Straffrättsdogmatik och kriminalpolitik (Strafrechtsdogmatik und Kriminalpolitik ), Oikeustiede - Jurisprudentia XVIII, Vammala 1985, S. 5, insb. S. 29, 37, 46, 48.

34 Siehe Dworkin, Taking Rights Seriously, London 1977, S. 22-28.

$35 \mathrm{Zu}$ dem Begriffspaar zweck- / wertrational siehe ursprunglich Weber, Wirtschaft und Gesellschaft, Studienausgabe, Tubingen 1985, S. 12. Eine entsprechende Differenzierung - goal / rightness reasons - bei Summers, Two Types of Substantive Reasons: The Core of a Theory of Common-Law Justification, Cornell Law Review 1978, 707.

36 Siehe Lahti, Festschrift für Jescheck, S. 883-889; vgl. Schünemann (Anm. 31), S. 45-64, Terminus „Zweckrationalismus“, der sprachlich nur auf Zweckmäßigkeitsaspekte hinweist. 
Argumente der legislativen Ebene und die Wertprinzipien Argumente der Rechtsprechungsebene sind. ${ }^{37}$

Diese Zweiteilung ist auch in den Straftheorien sichtbar geworden, wo man seit alters her die Präventions- und die Vergeltungstheorie voneinander unterschieden hat. In der modernen Diskussion wird allgemein die Ansicht vertreten, daß die Vergeltung ihre die Existenz des Strafrechtssystems begründende Funktion verloren habe. Statt dessen spricht man von den die Anwendung des Strafrechts begrenzenden Werten der Gerechtigkeit und der Humanität. $\mathrm{Zu}$ diesen zählen u.a. die Prinzipien der Gleichberechtigung und der Vorhersehbarkeit (der Rechtssicherheit) ebenso wie die Prinzipien der Billigkeit; dabei geht es wesentlich um die Beachtung der Rechte des Individuums.

Die Funktion der strafrechtlichen Begriffs- und Systembildung kann leicht als eine technische, das Wissensinteresse stützende Funktion verstanden werden: Die Systematik vermittelt Wissen über die Voraussetzungen der strafrechtlichen Verantwortlichkeit und erleichtert die Entscheidung von konkreten Fällen. ${ }^{38}$ Ich bin der Ansicht, daß diese Aufgabe mit Wertprinzipien verbunden ist, weil durch eine begriffliche Ordnung und konsequente und klare Systematik eine Willkür vermeidende Abwägung der Strafbarkeit und damit Gleichberechtigung und Vorhersehbarkeit in der Strafrechtsprechung ermöglicht wird. In der Beschleunigung der prozessualen Behandlung verwirklicht sich wiederum ein utilitaristischer Zweck. Die oben (VII.) besonders betonte Praxisnähe des Strafrechtssystems steht ebenso in einem Zusammenhang mit den Wertund Zweckargumenten.

Die materiellen Prinzipien des Strafrechts haben einen besonders deutlichen Zusammenhang mit den Werten und / oder Zielen der Kriminalpolitik. Die beiden zentralen Prinzipien - das Gesetzlichkeits- und das Schuldprinzip werden seit alters her an erster Stelle auf die Rechtssicherheit zurückgeführt und auf eng damit verbundene Werte, da mit Hilfe dieser Prinzipien die Anwendung des Strafrechts eingeschränkt wird. Oben (IV. und V.) sind jedoch auch im Hintergrund zu diesen Prinzipien denkbare (parallele) Zweckargumente zur Sprache gekommen. In der deutschen Rechtsliteratur wird die Meinung vertreten, daß die Schuld als Kategorie der strafrechtlichen Verantwortlichkeit völlig auf die Integrationsprävention zurückführbar sei: Zwischen Schuld und Prävention bestehe kein Widerspruch, da durch die Befolgung des

37 Siehe z.B. Lappi-Seppälä (Anm. 11), S. 265, Fletcher, ZStW 101 (1989), S. 803, 813 f.; Tuori (Anm. 5), S. 73 f.

38 Hierzu siehe z.B. Frände (Anm. 33), S. 32-38. 
Prinzips der individuellen Schuldzurechnung die Rechtsordnung aufrechterhalten werde (,Rechtsbewährung“) ${ }^{39}$

Bei der strafrechtlichen Begriffs- und Systembildung läßt sich auch in der Weise argumentieren, da $\beta$ der Rechtssicherheit und den entsprechenden Werten der prima-facie-Vorrang eingeräumt wird, daß aber bei der Bestimmung von einzelnen Kategorien der Verantwortlichkeit in gewissen Grenzfällen Präventionsaspekten der Vorrang zuerkannt wird. ${ }^{40}$ Im geltenden finnischen Recht läßt sich dieses Denken an der Einstellung zur strafrechtlichen Relevanz der Trunkenheit veranschaulichen: Gewicht und Bedeutung des Schuldprinzips sind hinsichtlich einer im Zustand der Trunkenheit begangenen Tat im Verhältnis zu den Präventionsaspekten verringert worden (siehe Strafgesetz Kapitel $3 \S 4$ Abs. 2). ${ }^{41}$

Bei einer solchen Argumentation muß die Gewichtung der Präventionsaspekte zu einer generalisierenden Schlußfolgerung führen: Wie verwirklichen sich unter Anwendung der Voraussetzungen der strafrechtlichen Verantwortlichkeit in bestimmten Fällen die Präventionszwecke? Die Beantwortung dieser Frage obliegt an erster Stelle dem Gesetzgeber und an zweiter Stelle dem Präjudizien schaffenden Obersten Gerichtshof.

Eine Analyse der Präjudizien des Obersten Gerichtshofs läßt uns erkennen und beurteilen, in welchem Umfang die Präventionsargumente auf die Auslegung der heutigen, überwiegend ungeschriebenen Kategorien der Verantwortlichkeit eingewirkt haben. Ich begnüge mich hier mit zwei exemplarischen Beobachtungen. Als ich die Entwicklung der Rechtspraxis bei der Abgrenzung von Mittäterschaft und Beihilfe zur Straftat untersuchte, bemerkte ich, daß sich der Bereich der Mittäterschaft im Verhältnis zur Beihilfe ständig ausdehnte. In der rechtswissenschaftlichen Literatur begründen Richter, die diese Tendenz befürworten, ihren Standpunkt mit präventiven Argumenten, und zwar ausdrücklich mit der Abschreckungswirkung des Vorrangs der Mittäterschaft. ${ }^{42}$ Als zweites Beispiel möchte ich die Änderung der Rechtspraxis (siehe OGH

39 Siehe z.B. Achenbach, in: Schünemann (Anm. 31), S. 135-151. Vgl. Schünemann (Anm. 31), S. 153-195; Fletcher, ZStW 101 (1989), S. 814-818.

$40 \mathrm{Zu}$ dieser Begründung hinsichtlich der beweismäßigen Anforderungen an die Anklage siehe Jonkka (Anm. 16). Allgemein siehe Alexy, Archiv für Rechts- und Sozialphilosophie, Beiheft 25 (1985), S. 13-29.

41 Zu dieser Frage siehe Lappi-Seppälä (Anm. 11), S. 414-418.

42 Siehe Lahti, Om gränsdragning mellan medgämingsmannaskap och medhjälp till brott (Über die Grenzziehung zwischen Mittäterschaft und Beihilfe zu einer Straftat), Tidskrift utgiven av Juridiska Föreningen i Finland 1989, S. 100-118, sowie die dort befindlichen Hinweise auf die Stellungnahmen von Soukka und Ukkonen. 
1985 II 134) in der Einstellung zu charaktergestörten (psychopathischen) Straftätern erwähnen: Eine sich als Asozialität manifestierende Charakterstörung führt für sich allein nicht mehr zu der in StrG Kap. 3 § 4 (im Vergleich zu $\S 2)$ bezeichneten Strafmilderung wegen verminderter Zurechnungsfähigkeit. Aus den in der rechtswissenschaftlichen Literatur vorgebrachten Standpunkten kann man als Hintergrund dieser Änderung die Betonung der Spezialprävention (der Unschädlichmachung) erkennen. ${ }^{43}$

Bei der kritischen Beurteilung einer solchen Tendenzwende in der Rechtspraxis sollte man die Überzeugungskraft der sich auf die Prävention gründenden Argumente einmal von der die Prävention betreffenden sozialwissenschaftlichen Forschung her und andererseits aus dem Blickwinkel der Abwägung verschiedener Prinzipien überprüfen. ${ }^{44}$ Besonders bei der Beurteilung der Voraussetzungen für die Anwendung des Strafrechts - d.h., wenn zu erwägen ist, oh in die Rechte eines Individuums auf sehr empfindliche Weise eingegriffen werden soll - ist entsprechend dem im Strafrecht geltenden Gesetzlichkeitsprinzip die Bedeutung des Wertes der Rechtssicherheit zu unterstreichen, und zwar auch dann, wenn durch das Zur-Verantwortung-Ziehen und durch die Auferlegung von Sanktionen vorbeugende Ziele angestrebt werden. Bei der Einschätzung der Rechtssicherheit sind z.B. die die Zurechnungsunfähigkeit und die verminderte Zurechnungsfähigkeit betreffenden Normen in erster Linie als rechtsstaatlicher Schutzwall gegenüber übermäßiger Anwendung von Repression anzusehen. Diese Normen dürfte man also im Geiste des Wohlfahrts- oder Sicherheitsstaates nicht nur als Kriterien für die Auswahl zweckmäßiger Sanktionen auslegen. ${ }^{45}$

Dem oben Gesagten zum Trotz bin ich der Ansicht, daß auch bei der Festlegung der allgemeinen Voraussetzungen der strafrechtlichen Verantwortlichkeit die verschiedenen die Kriminalpolitik steuernden Werte und Ziele möglichst weitgehend zu berücksichtigen sind. Ohne in eine detaillierte Analyse einzutreten, einige Thesen hierzu: Alle Voraussetzungen der strafrechtlichen Ver-

43 Siehe z.B. Lahti u.a., Syyntakeettomuuden määräytyminen ja kriminaalipotilaat (Die Bestimmung der Zurechnungsunfähigkeit und Kriminalpatienten), Helsinki 1987, S. 7, $11,48,50,105$ et passim.

44 Siehe auch Lahti (Anm. 42), S. 116 f; Ders., Straffrättsliga reaktioner för psykiskt störda lagöverträdare - ett korreferat (Strafrechtliche Reaktionen gegen psychisch gestörten Gesetzesbrecher - ein Korreferat), Nordisk Tidsskrift for Kriminalvidenskab 1989, S. 166-169.

45 Hierzu siehe die kritische Analyse bei Minkkinen (Anm. 18), Kapitel 3. Siehe auch Naucke, JuS 1989, 862, der die Gesetzlichkeit der Kriminalpolitik gegenüberstellt; mit anderen Worten: Das Gesetzlichkeitsprinzip darf ihm zufolge kein dem Oberbegriff der Kriminalpolitik unterzuordnender Wert sein. 
antwortlichkeit sind in der Weise aufzubauen, daß gewährleistet ist, daß die individuelle Zurechnung nicht $\mathrm{zu}$ als ungerecht empfundenen Resultaten führt, daß für die Zurechnung auch präventive Gesichtspunkte eine Rolle spielen und daß bei der strafrechtlichen Zurechnung Raum für Entscheidungen verbleibt, die sich an Billigkeit und Humanität orientieren (die Achtung der Menschenrechte einbegriffen). ${ }^{46}$

Diese Werte und Ziele der Kriminalpolitik stehen in einem engen Zusammenhang mit den Prinzipien, die bei der Strafbemessung und der Wahl der Sanktionsart zu befolgen sind. So erfolgt z.B. das Vermeiden unbilliger Entscheidungen in der Hauptsache im Rahmen des Sanktionensystems.

Der Umstand, daß man sich der Ziele und Werte der Kriminalpolitik in der Strafrechtsdogmatik so deutlich bewußt ist, erleichtert m.E. die Beurteilung der Frage, in welchem Umfang und in welcher Weise die Voraussetzungen der strafrechtlichen Verantwortlichkeit (und die diese betreffenden Begriffe und Prinzipien) den Veränderungen, die die Entwicklung der Kriminalität und die allgemeinen gesellschaftlichen Entwicklungen mit sich bringen, anzupassen sind und angepaßt werden können. Ebenso ist es leichter geworden anzuerkennen, daß auch das Strafrecht seiner Natur nach dynamisch ist und daß das Strafrechtssystem in seiner Gesamtheit für eine notwendige Spezifizierung und Entwicklung offen ist. Ein Beispiel hierfür: Ich halte aufgrund der gesellschaftlichen Entwicklung die Einführung der strafrechtlichen Verantwortlichkeit von juristischen Personen für ein legitimes Mittel des Strafrechts, auch wenn die Straftatlehre dann in einer vom Prinzip der Individualschuld abweichenden Weise aufgebaut werden muß. ${ }^{47}$

46 Siehe auch Lahti, Festschrift für Jescheck, S. 883-889.

47 Siehe Oikeushenkilön rangaistusvastuu. Rikoslakiprojektin ehdotus (Die strafrechtliche Verantwortlichkeit der juristischen Person. Entwurf des Strafgesetzprojektes), Helsinki 1987. 

8.

\title{
Die Gesamtreform des finnischen Strafgesetzes: Zielsetzung und Stand der Reformarbeit bis 1991 - insbe- sondere im Blick auf die erste Phase der Gesamtreform
}

\author{
I. Die Situation bei der Ausarbeitung \\ der Gesamtreform des Strafgesetzes \\ 1. Die bisherigen Dokumente der \\ Ausarbeitung der Strafgesetzreform
}

Die zur Zeit betriebene Gesamtreform des Strafgesetzes (1889) befindet sich seit 1972 in Ausarbeitung. In jenem Jahr wurde ein Komitee eingesetzt mit der Aufgabe, eine gesamtheitliche Grundrevision des Strafgesetzbuches auszuarbeiten. Auf der Grundlage des Berichts dieses Strafrechtskomitees (Komiteebericht 1976:72) und der über den Bericht erstellten Gutachten wurde die Reform in einer vom Justizministerium im Jahre 1980 eingesetzten speziellen Projektorganisation (dem sog. Strafgesetzprojekt) fortgesetzt. ${ }^{1}$ Aus der Arbeit des Strafgesetzprojektes sind hauptsächlich die bis Ende 1990 entstandenen Entwürfe hervorgegangen:

„Gesamtreform des Strafgesetzes I“ (1984) und ergänzender Entwurf über die Bewirtschaftungsdelikte und den Schmuggel (1986);

„Gesamtreform des Strafgesetzes II“ (1989);

„Über die Alternativen zur Freiheitsstrafe“ (1987) und damit verbundener Entwurf über das Absehen von strafrechtlicher Verfolgung und Verurteilung (1988); sowie

„Die strafrechtliche Verantwortung der juristischen Person“ (1987).

Von diesen Entwürfen des Strafgesetzprojektes haben die im ersten Punkt genannten, d.h. das ungefähr ein Drittel des Besonderen Teils des neuen Strafgesetzes umfassende „Paket eins“ der Strafgesetzreform, zu legislativen Maßnahmen geführt: Auf der Grundlage der Regierungsvorlage (Nr. 66/1988) wurde am 24. August 1990 ein die erste Phase der Gesamtreform umfassender

1 Über die Reformarbeit bis Mitte der 80er Jahre siehe näher Pekka Koskinen: Strafrechtsreform in Finnland: Zielsetzung und Stand. In: Albin Eser / Karin Cornils (Hrsg.), Neuere Tendenzen der Kriminalpolitik. Max-Planck-Institut für ausländisches und internationales Strafrecht, Freiburg i.Br. 1987, S. 83-105. 
Komplex von Gesetzen verabschiedet (Nrn. 767-834/90), die am 1. Januar 1991 in Kraft traten. Von dem Strafgesetz sind somit elf Kapitel völlig reformiert worden, und zwar die Vorschriften über die Vermögensdelikte (d.h. Eigentumsdelikte und sog. Delikte des Geschäftsverkehrs) sowie die die Wirtschaftsdelikte betreffenden Vorschriften.

Die elf völlig reformierten Kapitel des Strafgesetzes sind die folgenden:

Kapitel 28. Über Diebstahl, Unterschlagung und unbefugter Gebrauch

Kapitel 29. Über die Delikte gegen die öffentliche Wirtschaft

Kapitel 30. Über die Gewerbedelikte

Kapitel 31. Über Raub und Erpressung

Kapitel 32. Über die Hehlereidelikte

Kapitel 33.Über die Fälschungsdelikte

Kapitel 35. Über die Sachbeschädigung

Kapitel 36. Über Betrug und sontige Untreue

Kapitel 37. Über die Zahlungsmitteldelikte

Kapitel 39. Über die Delikte des Schuldners

Kapitel 46. Über die Bewirtschaftungsdelikte und den Schmuggel

Die Ausarbeitung dieser Kapitel wurde zwischen drei vom Strafgesetzprojekt eingesetzten Arbeitsgruppen aufgeteilt: Der Arbeitsgruppe für Eigentumsdelikte oblagen die Entwürfe zu den Kapiteln 28, 3132 und 35, der Arbeitsgruppe für Delikte des Geschäftsverkehr die Kapitel 33 36, 37 und 39 und der Arbeitsgruppe für Wirtschaftsdelikte die Entwurfe zu den Kapiteln 29, 30 und 46.

$\mathrm{Zu}$ bemerken sind die besonderen Charakteristika der Fälschungs- und Geldfälschungsdelikte. Die Fälschungsdelikte stellen von ihrer Natur her in erster Linie Delikte dar, die mit dem Nachweis eines Sachverhalts verbunden sind und gehören genaugenommen nicht zu den Vermögensdelikten. In der Praxis stehen die Fälschungsdelikte in einem engen Zusammenhang mit den Betrugsdelikten und die Vorschriften über die Geldfälschungsdelikte verbindet mit den übrigen Vorschriften über die Zahlungsmitteldelikte das Bestreben nach Sicherung des Geldverkehrs.

Der Entwurf über das Absehen von strafrechtlicher Verfolgung und Verurteilung, welcher auf den das Sanktionensystem betreffenden Entwürfen des Strafgesetzprojekts basierte, führte zu den am 23. März 1990 verabschiedeten Gesetzen (300-303/90), die am 1. Januar 1991 in Kraft traten. Auf dem Ent- 
wurf des Projekts betreffend die Alternativen zur Freiheitsstrafe basiert zudem das am 14. Dezember 1990 verabschiedete Gesetz über die Erprobung des gemeinnützigen Dienstes (1105/90), das ebenfalls am 1. Januar 1991 in Kraft trat. Es war indes von einem besonderen, vom Justizministerium eingesetzten Komitee in die Form eines Vorschriftenentwurfs gebracht worden. ${ }^{2}$

\section{Zukunftsaussichten der Strafgesetzreform}

Bei der Ausarbeitung der Fortsetzung zu der bereits verwirklichten Strafgesetzreform ist die Situation folgende: Über den Entwurf betreffend die strafrechtliche Verantwortung der juristischen Person sind die Gutachten eingeholt worden, und aufgrund eines revidierten Entwurfes sollte die Regierungsvotlage im Jahre 1992 dem Parlament eingereicht werden. Die zweite Phase der Gesamtreform der Strafgesetzgebung - d.h. in etwa das zweite Drittel von der den besonderen Teil des neuen Strafgesetzes umfassenden Reform - ist aufgrund der erteilten Gutachten in einen revidierten Entwurf zu einer Regierungsvorlage entwickelt worden, und die Regierungsvorlage sollte während des Jahres 1992 dem Parlament eingereicht werden.

In den Arbeitsgruppen des Strafgesetzprojektes ist man zur dritten Phase des Projekts fortgeschritten: Auszuarbeiten sind die Regelung der allgemeinen Voraussetzungen der strafrechtlichen Verantwortung - der allgemeinen Lehren -, die umfassende Reformierung des Sanktionensystems sowie die Revision der übrigbleibenden Kapitel des Strafgesetzes. Das Ziel ist, am Ende des Projekts ein sämtliche Phasen der Reform umfassendes, formell völlig neues Strafgesetz zu erlassen.

Ich nehme an, daß die Gesamtreform nach über 20jähriger Arbeit frühestens im Jahre 1994 abgeschlossen sein wird, wenn seit dem Inkrafttreten unseres Strafgesetzes hundert Jahre vergangen sein werden. Als 1980 das Strafgesetzprojekt eingesetzt wurde, schätzte man, daß die Arbeit im Jahre 1984 abgeschlossen sein würde!

2 Über die erwähnten und anderen Reformen des Sanktionensystems siehe näher Tarja Pellinen: Das strafrechtliche Sanktionensystem Finnlands im Umbruch. In: Raimo Lahti / Kimmo Nuotio / Panu Minkkinen (Hrsg.), Criminal Policy and Sentencing in Transition; Kriminalpolitik und Strafzumessung im Umbruch. Helsinki 1992, S. 89103. 


\section{II. Über die kriminalpolitischen Ausgangspunkte der Strafgesetzreform}

\section{Bedeutung der Bewußtwerdung der Ausgangspunkte für die Reform}

Die erste Phase der Strafgesetzreform ist vor ihrem Hintergrund und vor der Gesamtheit der Reform zu sehen. Ich halte es also für wichtig, daß man sich dessen bewußt ist, von welchen Zielen und Werten diese Reform geprägt wird und, allgemeiner, welches die Ziele und Werte sind, von denen die Funktion des strafrechtlichen Systems gesteuert wird. So ist es zum Beispiel für die strafrechtliche Systematisierung und Auslegungsargumentation von Nutzen, sich darüber eine Auffassung zu bilden, durch welche (Rechts-)Prinzipien und Interessen sich diese Werte und Ziele konkretisieren. Die legislativen Lösungen, die man sich in der zu analysierenden Teilreform zu eigen gemacht hat, sind leichter zu verstehen - und auch leichter zu kritisieren -, wenn man sich über die Ausgangspunkte und Linien der Gesamtreform des Strafgesetzes im klaren ist. ${ }^{3}$

\section{2. Über die Wirkungsweisen des Strafgesetzes, insbesondere über die Generalprävention und die Symbolfunktion}

$\mathrm{Zu}$ den kriminalpolitischen Ausgangspunkten der Strafgesetzreform gehören der begründete Glaube an die generalpräventive Wirkung (die Generalprävention) des strafrechtlichen Systems sowie die Pflege der Gerechtigkeit und Humanität dieses Systems.

Das Strafrechtskomitee ${ }^{4}$ war der Ansicht, daß die Wirkungsweisen des Strafgesetzes vielschichtig seien und daß sich die erfolgreiche Funktion des strafrechtlichen Systems auf mehrere Wirkungsweisen gründe. So wird in dem Bericht zum Beispiel eine direkte Kopplung der Generalprävention mit der Abschreckungswirkung der Strafe oder mit der Strenge der Strafdrohungen und der Strafpraxis abgelehnt. Das Gelingen der Kriminalitätsbekämpfung setzt auf der einen Seite effektive Prävention von Deliktmöglichkeiten voraus und zum anderen, daß das gesamte offizielle Kontrollsystem unter den Bürgern

3 Vgl. dazu Lahti: Zur Entwicklung der Kriminalpolitik in Finnland. In: Festschrift für Hans-Heinrich Jescheck zum 70. Geburtstag. Zweiter Halbband. Duncker \& Humblot, Berlin 1985, S. 871-892 (872-881) und idem: Neues in der finnischen Strafrechtswissenschaft und in den allgemeinen Lehren des finnischen Strafrechts. ZStW 1991, S. 521-540 (535-540).

4 Zum folgenden siehe Komiteebericht 1976:72, bes. 2. Kapitel. 
seine Akzeptanz bewahrt (was u.a. bedeutet, daß diese in die Funktionsfähigkeit des Systems und die Gerechtigkeit der Tätigkeit vertrauen). Das Strafrechtskomitee vertrat auch die Ansicht, daß die im Strafgesetz gesetzten Geund Verbote namentlich in der Weise von Bedeutung sind, daß sie die autoritative Mißbilligung der Gesellschaft ausdrücken und man mit ihrer Hilfe auf die Einstellungen, Werthaltungen und Auffassungen der Bürger einwirken kann. In dieser Äußerung finden sich zwei Umstände definiert: zum einen wird die expressive Aufgabe des Strafrechts, die Symbolfunktion, präzisiert, und zum anderen findet der Glaube Ausdruck, daß man mit einer solchen mißbilligenden Wertung auf die Motivation und das Verhalten der Menschen einwirken kann. Der Wirkungsmechanismus der letztgenannten Generalprävention wird vor allem als ein mittelbarer gesehen, d.h. mit den Ge- und Verboten des Strafgesetzes werden die das Verhalten der Menschen regulierenden Moralund Sittennormen aufrechterhalten und gestärkt.

\section{3. Über das Verhältnis der Strafgesetzgebung zu den Prinzipien der Gerechtigkeit und Rechtssicherheit}

Die Strafgesetzgebung und vor allem die Kriminalisierungsbeschlüsse stehen auch mit der Frage nach der sozialen Gerechtigkeit und damit nach den Kriterien der Akzeptanz des offiziellen Kontrollapparats in Verbindung.

Siehe folgendes Zitat aus der Regierungsvorlage Nr. 66/1988 S. 9: „In der Strafgesetzgebung ist anzustreben, die Interessen der einzelnen Gesellschaftsgruppen unpartiisch zu berücksichtigen." Genauer zu derselben Frage siehe den Komiteebericht 1976:72, S. 47: Die Gesamtreform des Strafgesetzes eigne sich zur Erwägung dessen, ,wie das strafrechtliche System in seiner Gesamtheit die wichtigen Werte und Interessen der einzelnen Gesellschaftsgruppen schützt, wie es das in der Gesellschaft herrschende Wertesystem widerspiegelt und stützt sowie wie die strafrechtlichen Folgen und Nachteile die einzelnen Gesellschaftsgruppen betreffen."

Dem Wert der Gerechtigkeit wurde bereits bei der Erlassung des Strafgesetzes (1889) eine zentrale Stellung gegeben, wie sich aus der folgenden Äusserung des ,Vaters“ des Strafgesetzes - Jaakko Forsmans - zeigt:

Wenn die Gerechtigkeit - in dem Maße wie sie in den mangelhaften menschlichen Verhältnissen möglich ist - aufhört, die oberste Richtschnur des Gesetzgebers und Rechtsprechers zu sein, gerät man in unsichere Wasser, wird von jedem Wind und jeder Strömung abgetrieben. ${ }^{5}$

Als Gegengewicht zu den utilitaristischen Zielen der Kriminalpolitik - von denen also die Generalprävention das wichtigste ist - sind Garantien zu schaf-

5 Forsman: Sveitsin uusi rikoslainehdotus (Der neue Strafgesetzentwurf der Schweiz). Tidskrift, utgifven av Juridiska Föreningen i Finland 1898, S. 177-192 (180). 
fen, mit denen der Rechtsschutz des Tatverdächtigen gewährleistet wird. Die Regulierung und Bestimmung dieser Rechtsschutzgarantien gehört zu mehreren Rechtsbereichen, zum Straf- und Strafprozeßrecht ebenso wie zum Verfassungsrecht und zum internationalen Recht.

In den Begründungen der ersten Phase der Strafgesetzreform wird angemerkt, daß es zu den Aufgaben der Strafgesetzgebung gehöre, die Rechtssicherheit zu mehren. Dies wird, wie weiter unten (IV.2-3) genauer zu erörtern ist, am deutlichsten in dem Versuch ersichtlich, die Bedeutung des strafrechtlichen Gesetzlichkeitsprinzips und des Wertes der im Hintergrund dieses Prinzips stehenden Vorhersehbarkeit in einigen Lösungen zu verstärken.

\section{Der Schwerpunkt der Strafgesetzreform}

Die Betonung der Symbolfunktion des Strafrechts, die oben in der Erläuterung zum Bericht des Strafrechtskomitees zum Tragen kommt und die in erster Linie mit dem Kriminalisierungsprinzipien zusammenhängt, wird bei der Wahl der Schwerpunkte der Strafgesetzreform ebenso wie in den weiter unten (IV) genauer $\mathrm{zu}$ behandelnden Entscheidungen über die Kriminalisierungsprinzipien und die Struktur des Strafgesetzes sichtbar. Das Hauptaugenmerk der gesamten Reform richtet sich auf die Strafvorschriften: auf die abdeckende und einheitliche Beurteilung dessen, was zu bestrafen ist und mit wie strengen Strafen. Daraus erklärt sich die zeitliche Planung der Ausarbeitung in der Weise, daß in der Anfangsphase das Gewicht fast ausschließlich auf den besonderen Teil des neuen Strafgesetzes gelegt wurde.

\section{Die mit der Verwirklichung der Ziele der Strafgesetzreform zusammenhängenden Probleme und die Mittel ihrer Lösung}

\section{Das strafrechtliche System und die übrigen Mittel der Kriminalpolitik}

a) Zwischen der Realisierung der ersten Phase der Strafgesetzreform und den in ihrem Hintergrund stehenden kriminalpolitischen-Ausgangspunkten tut sich, einer kritischen Einschätzung zufolge, eine ziemliche Kluft auf. Ist ein Strafrecht dabei zu entstehen, das nur symbolisch ist, und wird damit auf lange Sicht die Glaubwürdigkeit des gesamten strafrechtlichen Systems untergraben?

$\mathrm{Zu}$ einer solchen Kritik siehe besonders die Thesen von Winfried Hassemer. ${ }^{6}$ Kernpunkt seiner Kritik ist, daß bei dem Wandel des Strafrechts von punktförmiger Repres-

6 Hassemer: Symbolinen rikosoikeus ja oikeushyvien suojelu. Oikeus 1989, S. 388-400 (finnisch); Symbolisches Strafrecht und Rechtsgüterschutz. Neue Zeitschrift für Straf- 
sion konkreter Rechtsverletzungen in ein umfassende Mittel der Prävention von Problemsituationen folgenderlei Strafvorschriften geschaffen würden: Ihre Schutzobjekte seien unbestimmte gemeinschaftliche Rechtsgüter, sie bauten auf abstrakter Gefährdung auf und für ihre Anwendung in der Praxis seien keine realen Voraussetzungen gegeben. Anzumerken ist, daß diese Kritik die Symbolfunktion des Strafrechts an sich akzeptiert; die latenten Funktionen der Normen dürfen nur nicht mehr wiegen als die manifest ausgedrückten. ${ }^{7}$

Ich möchte mich zuerst dem in dieser Kritik geäußerten Vorwurf zuwenden, wonach man sich mit Kriminalisierung begnüge, ohne hierfür Alternativen zu erwägen oder ohne sich um die Voraussetzungen der Funktion des strafrechtlichen Systems zu kümmern. In dem Bericht des Strafrechtskomitees ist die Empfehlung zu lesen, daß der relative Anteil des strafrechtlichen Systems bei der Bekämpfung abzulehnender Verhaltensformen im Vergleich zu anderen Mitteln eher zu verringern als zu erhöhen sei. Des weiteren sei bei der Erwägung einzelner Kriminalisierungen neben der Evaluierung der Nachteiligkeit und Vorwerfbarkeit der betreffenden Verhaltensformen mit Hilfe von systematischen Vorteilsvergleichen abzuwägen, ob der Bedarf besteht, auf das Strafrecht zurückzugreifen. ${ }^{\mathbf{8}}$

b) Als das Justizministerium im Jahre 1983 bekräftigte, daß die Gesamtreform des Strafrechts in kleinen Teilreformen erfolge, äußerte es die Ansicht, daß der dringlichste Reformbedarf bei den Regelungen betreffend die Delikte gegen die öffentliche Wirtschaft und die wirtschaftlichen Gesetze (Wirtschaftsdelikte) und betreffend die sogenannten Delikte des Geschäftsverkehrs bestehe. Eine vom Ministerium eingesetzte Arbeitsgruppe zur Klärung der Wirtschaftskriminalität arbeitete eilig ihre Vorschläge zur Vorbeugung von Delikten in diesem Gebiet sowie zur Entwicklung der Kontroll- und Ermittlungsorganisation aus. In dieser Phase wurde also zur gleichen Zeit an der Reformierung der Vorschriften über die Wirtschafts- und Geschäftsverkehrsdelikte als auch an der Effektivierung der sonstigen Bekämpfung dieser Delikte gearbeitet. ${ }^{9}$

Nachdem die erste Phase der Strafgesetzreform nun abgeschlossen worden ist, mit anderen Worten: nachdem die neuen Vorschriften über die Wirtschafts-,

recht 1989, S. 553-559 (deutsch). Siehe auch den Artikel von Hassemer in diesem Band,Criminal Law Theory in Transition - Strafrechtstheorie im Umbruch, S. 113-125.

7 Zu ähnlicher, in Finnland geäusserter Kritik siehe bereits Lars D. Eriksson: Straffrättskommitténs anatomi (Die Anatomie des Strafrechtskomitees). Oikeus 1977, S. 72-80 (77-79).

8 Siehe Komiteebericht 1976:72, bes. S. 39, 41, 46-50 und 64.

9 Siehe auch Lahti: Concept and Principles of Economic and Business Criminal Law. National Report. Revue Internationale de Droit Pénal (RIDP) 1983, S. 249-262. 
Geschäftsverkehrs- und Eigentumsdelikte in Kraft getreten sind, kann man feststellen, daß von den Vorschlägen der Arbeitsgruppe zur Klärung der Wirtschaftskriminalität nur sehr wenige zu weiteren Maßnahmen geführt haben. So sind die zur Verbesserung der Vorbeugung, Kontrolle und Ermittlung der neuen Subventions-, Buchführungs- und Schuldnerdelikte vorgebrachten Vorschläge überwiegend nicht verwirklicht worden, und auch die materiellen Gesetze aller dieser Bereiche sind lückenhaft und zumindest teilweise veraltet.

In dem Tätigkeitsbericht der Zentralkriminalpolizei (ZKP) vom Jahre 1989 wird eine starke Verlagerung des Schwerpunktes bei der Bekämpfung von Wirtschaftsdelikten auf die Vorbeugung empfohlen: „Wenn man berücksichtigt, daß die Polizei in der Hauptregel nicht die Kontrollbehörde in den Bereichen sein kann, in denen die Wirtschaftsdelikte begangen werden, so setzt das Gelingen der Bekämpfung dieser Kriminalität den ganzheitlichen Einsatz der Gesellschaft voraus. - Die Bekämpfung der Kriminalität ist durch Entwicklung der Gesetze, der Untersuchungstätigkeit, der Kooperation der Behörden, der strafrechtlichen Ermittlung usw. zu verbessern." In demselben Bericht wird festgestellt, daß im Jahre 1989 der Mangel an Ressourcen für die Prüfung der Buchführungen der schlimmste Engpaß bei der Ermittlung von Wirtschaftsdelikten gewesen sei. Auf die Ineffizienz in der Kontrolle der Konkursverfahren im Vergleich vor allem zu Schweden hat u.a. Olavi Heinonen hingewiesen ${ }^{\mathbf{1 0}}$. Das von der Arbeitgruppe zur Klärung der Wirtschaftskriminalität (1983) vorgeschlagene, die Konkursquarantäne betreffende Gesetz über das Verbot von Geschäftshandlungen $(1059 / 85)$ ist zwar verabschiedet, aber bislang nur wenig angewendet worden: bis Ende 1989 in nur 24 Fällen.

Ein Mittel, um der an der symbolischen Natur des Strafrechts geäußerten Kritik entgegenzutreten, besteht darin, zu verlangen, daß die strafrechtliche Regulierung der wirtschaftlichen Beziehungen in Übereinstimmung gebracht wird mit der gleichzeitig gesamtheitlich zu entwickelnden materiellen Gesetzgebung und den Maßnahmen zur Bekämpfung der Delikte.

\section{Die Grenzen des Strafrechts}

a) Die oben erläuterte Kritik impliziert auch ganz allgemein Zweifel an der Brauchbarkeit straf- und strafprozeßrechtlicher Regelungen in Fällen, wo sich die Schutzobjekte des Strafrechtes nicht auf die traditionellen Rechtsgüter beschränken (d.h. auf die die Privatpersonen meist unmittelbar betreffenden Rechte, Werte oder Interessen) und die Strafbarkeit weiter auf die Formen der Gefährdungshaftung ausgedehnt wird. Diese Kritik läßt sich also zurückführen auf die Grenzbedingungen des Rechtsbereichs.

10 Heinonen: Velkojia loukkaava omaisuuden ottaminen osakeyhtiöstä. (Das die Gläubiger verletzende Entnehmen von Eigentum aus Aktiengesellschaften.) Defensor Legis 1985, S. 275-285 (276). 
Hassemer präzisiert die oben erwähnte Kritik durch die Äußerung, daß das Strafrecht in seiner rechtsstaatlich-liberalen Form sich denkbar schlecht als Flankendeckung für politische Ziele, zur Steuerung von Problemsituationen und zur Vorbeugung von Gefahrenssituationen in großem Maßstab eignet. Entsprechend kritisiert er vor allem die Vorschriften, die anhand von Rechtsschutzbegründungen die abstrakte Gefährdung kriminalisieren. ${ }^{11}$

Der inflatorische Gebrauch des Strafrechts ist vom prinzipiellen Standpunkt auch in folgender Weise kritisiert worden: Die von dem Strafrechtskomitee betonte, durch die Normen des Strafgesetzes auszudrückende autoritative Mißbilligung (siehe oben II.2) wirke umso schwächer, je umfangreicher der Bereich des strafbaren Verhaltens sei. ${ }^{\mathbf{1 2}}$

In beiden angesprochenen Beziehungen sah das Strafrechtskomitee in den Kriminalisierungen den Wandel voraus, der später in der ersten Phase der Strafgesetzreform und in dem Entwurf zur zweiten Phase seinen Ausdruck fand. Auf der anderen Seite richtete das Komitee seine Aufmerksamkeit auch auf die Begrenztheit der strafrechtlichen Steuerungsressourcen und auf die an die strafrechtliche Regulierung zu stellenden speziellen, in erster Linie auf Rechtsschutzgründen basierenden Bedingungen. ${ }^{13}$

Die verstärkte Stellung des Strafrechts bei der Regulierung wirtschaftlicher Beziehungen (erste Phase der Strafgesetzreform) oder beim Umweltschutz und der Förderung der Arbeitssicherheit (zweite Phase der Reform) ist also auch aufgrund der Grenzbedingungen des Rechtsbereichs problematisch. Die im Hintergrund der Strafgesetzreform stehenden kriminalpolitischen Ausgangspunkte (siehe oben II) haben jedoch zu einer dynamischen Entwicklung des Strafrechts u.a. in diesen Bereichen geführt und damit auch zu einer teilweisen Neugestaltung der Kriminalisierungsprinzipien (siehe weiter unten IV.1).

b) Den Grenzbedingungen des Strafrechts ist in der Arbeit des Strafgesetzprojektes durchaus Aufmerksamkeit gewidmet worden. Zunächst einmal ist der Geltungsbereich des Strafgesetzes meines Erachtens recht maßvoll in die Richtung der gemeinschaftlichen Rechtsgüter und der Betonung der Gefährdungshaftung erweitert worden - zumindest im Vergleich zu den denkbaren extremen Alternativen. So ist zum Beispiel die von dem Strafrechtskomitee behandelte sog. Lebenssphären-Analyse behutsam angewendet worden (wenn

11 Eine ähnliche Kritik hat u.a. auch Nils Jareborg vorgebracht. Siehe Jareborg: Brotten. Första häftet. (Straftaten. Erster Band.) 2. Aufl. Stockholm 1984, S. 38-39 und 170-171.

12 Siehe auch im allgemeinen Pekka Koskinen / Terttu Utriainen: The Legal and Practical Problems Posed by the Difference between Criminal Law and Administrative Penal Law. RIDP 1988, S. 173-188.

13 Siehe Komiteebericht 1976:72, bes. S. 50, 57 und 59. 
auch, wie gesagt, auf Arbeitsverhältnisse und Umweltfragen). ${ }^{14}$ Bei der Erweiterung der Kriminalisierungen und der Anwendung der LebenssphärenAnalyse besteht die Gefahr, daß man die Bedeutung des Strafrechts bei der Förderung gesellschaftspolitischer Ziele überschätzt und die speziellen Züge der strafrechtlichen Regulierung vernachlässigt.

Wegen des Bewußtseins um die Grenzen des Strafrechts hat es die Arbeitsgruppe für Wirtschaftsdelikte im Strafgesetzprojekt nicht für angebracht gehalten, die mit dem Verkauf von Wertpapieren verbundenen spekulationsartigen Delikte im Strafgesetz zu regulieren, bevor nicht die materiellen Gesetze und ein funktionsfähiges Kontrollsystem zustande gebracht worden sind. In diesem Sinne ist auch die Kontrolle der Wettbewerbsbeschränkungen durch den Erlaß eines neuen materiellen Gesetzes sowie durch gesamtheitliche Effektivierung des Kontroll- und Sanktionensystems strenger gestaltet worden.

Die Vorschriften über die Bewirtschaftungsdelikte (StG Kapitel 46) sind maßgeblich gebunden an die in diesen bezeichneten Gesetze, d.h. an die Bewirtschaftungsgesetze; entsprechend ist die Kontrolle der Befolgung dieser Gesetze abhängig davon, welch spezielle Kontroll- und Ermittlungsorganisation auf ihnen basierend geschaffen worden ist.

In den Fällen, wo eine reformierte, ins Strafgesetz übertragene Strafvorschrift in einem engen Zusammenhang mit einem außerhalb des Strafgesetzes befindlichen Gesetz und einem von diesem regulierten Kontroll- und Sanktionensystem steht - wie im Fall des Vermarktungsdeliktes (StG 30:1) -, hat man den Schwerpunkt der Kontrolle nicht auf das strafrechtliche System verlagern wollen. In derartigen Fällen ist der Strafprozeß nach wie vor ein selten anzuwendendes Mittel im Vergleich zu den übrigen Mitteln administrativer Art, und im allgemeinen sollten nur schwere Gesetzesverstöße zu einem Strafprozeß führen. Dabei ist es wichtig, dafür zu sorgen, daß die Kriterien der Selektierung zum Strafprozeß einheitlich und auch ansonsten kriminalpolitisch akzeptierbar sind. Auch bei der Anwendung von herkömmlichen Strafvorschriften hat man häufig wegen der neuen Vorschriften über das Absehen von Strafverfolgung in entsprechender Weise den zweckmäßigen Einsatz der Ressourcen des strafrechtlichen Systems zu erwägen.

c) Es ist kriminalpolitisch sehr problematisch, wenn eine Strafvorschrift in akzentuierter Weise eine sog. Effektivierungskriminalisierung zur Erreichung gewisser gesellschaftspolitischer oder administrativer Ziele darstellt und wenn bei der Anwendung dieser Vorschrift die sonstigen, aufgrund derselben Tat zu

14 Siehe Komiteebericht 1976:72, S. 50-56. Über die Charakterisierung dieser Lebenssphären-Analyse siehe z.B. Lahti: RIDP 1983 (Anm. 9), S. 250-251. 
verhängenden Sanktionen als deutlich milder empfunden werden. In der ersten Phase der Strafgesetzreform erwies sich der Paragraph über Steuerübertretung (StG 29:4) in dem Entwurf als eine solche äußerst konfliktgeladene Vorschrift, wenn auch die Züge der Effektivierungskriminalisierung in der Form, wie sie vom Reichstag angenommen wurde, abgeschwächt worden sind.

Die Regierung begründete diese Vorschrift mit dem Bestreben, die vorschriftsmäßige Entrichtung der vom Steuerpflichtigen zu zahlenden Steuern und Gebühren zu sichern. Die Mehrheit des Gesetzausschusses des Reichstags wiederum sah es als faktisches Ziel des Entwurfs, mit Hilfe der strafrechtlichen Verantwortung den für die Steuern entschädigungspflichtigen Personenkreis zu erweitern (insbesondere in der Weise, daß die strafrechtliche Verantwortung und die Schadenshaftung sich auf die Organe und Vertreter von steuerpflichtigen Körperschaften bezog). Diese Mehrheit war der Ansicht, daß der Inhalt der Vorschrift aufgrund eines Interessenvergleichs zu entscheiden sei, wobei die Sicherung der Stellung des Steuerempfängers und der Rechtsschutz des Individuums gegeneinander stehen.

In ihrer schließlich angenommenen Form erweitert die Vorschrift über Steuerübertretung auf der einen Seite die Strafbarkeit auf die Nichtleistung der Umsatzsteuer, schränkt aber auf der anderen Seite den Bereich der Kriminalisierung ein, indem sie voraussetzt, daß der Täter in Bereicherungsabsicht gehandelt hat, wodurch aus Zahlungsunfähigkeit erfolgende und andere geringfügige Nichterfüllungen ausgeschlossen werden. Die Folge dieser Gesetzesänderung dürfte sein, daß die Vorschrift bedeutend seltener als zuvor auf Übertretungen bei der Vorauserhebung von Steuern angewandt wird. - Zur Wahrnehmung der fiskalischen Interessen ist es möglich, die Steuer- und sonstige Schadenshaftung der Organe und Vertreter von steuerpflichtigen Körperschaften zu erweitern durch Veränderung der steuer- oder entschädigungsrechtlichen Verantwortung.

d) Das Bewußtsein um die Grenzen des Strafrechtes und zugleich um dessen besondere Züge hat des weiteren das Bestreben impliziert, das strafrechtliche Gesetzlichkeitsprinzip und die Symbolfunktion des Strafrechts durch gewisse, mit der Schreibweise und Struktur des Gesetzes verbundene Lösungen zu stärken (siehe unten IV.2).

e) Die Aspekte, die für die Linie der Strafgesetzreform sprechen, schließen indes Kritik nicht aus. Für besonders problematisch halte ich die von der Reform implizierte Erweiterung des Gesamtbereichs des strafbaren Verhaltens. Der Gedanke, daß das Strafrecht das letzte Mittel, die ultima ratio, sein soll, hat sich in der Praxis als unerreichbares Ideal erwiesen. Obwohl bei der Ausarbeitung der ersten Phase der Reform die Vorschriften bestimmter Rechtsbereiche - insbesondere des Steuerrechts - systematisch durchgegangen wurden und Strafvorschriften aus ihnen gestrichen oder deren Geltungsbereiche eingeengt wurden, ist die Zahl der Dekriminalisierungen kleiner als die der Erweiterungen der Strafbarkeit. Auch der Gedanke, daß für geringfügige Gesetzesbrüche ein mitteleuropäischen Mustern gemäßes allgemeines Ord- 
nungswidrigkeitensystem geschaffen werden könnte, scheint sich nicht durchzusetzen. $^{15}$

\section{3. Über die Auswirkungen der Veränderung des Strafrechts auf die allgemeinen Lehren des Straf- und Strafprozeßrechts}

a) Die dynamische Entwicklung des Strafrechts und die Veränderung seiner Rolle müssen meiner Meinung nach auf die Ausgestaltung der allgemeinen Lehren dieses Rechtsbereichs - der Voraussetzungen der strafrechtlichen Verantwortung - eine Auswirkung haben. Ein entsprechender Änderungsdruck besteht auch beim Strafprozeßrecht. Die Hauptbegründung meiner Einschätzung ist die, daß die Struktur der neuen Straftatbestände aus den oben angesprochenen Gründen oft von den Strukturen abweicht, wie sie für die herkömmlichen Straftaten typisch sind. Der Umstand, daß in einigen der von den neuen Strafvorschriften bezeichneten Bereichen ein besonderer, in erster Linie administrativen Zielen dienender Kontrollapparat besteht, hat einen Einfluß auf die Stellung des strafrechtlichen Systems und damit u.a. auf die Prinzipien, denen gemäß Strafanzeige gestellt und Anklage erhoben wird.

Ein Problem ist, daß die umfangreichen Reformen des Straf- und Strafprozeßrechts zu sehr verschiedenen Zeiten verwirklicht werden. Es besteht somit die Gefahr, daß die Prinzipien des Strafprozeßrechts (z.B. die die Beweiswürdigung betreffenden) in der Strafgesetzreform nicht die gebührende Aufmerksamkeit finden. Das Strafprozeßrecht ist zur Verwirklichung des Strafrechts da. Ungeachtet dieses Ausgangspunktes ist bei der Schaffung des Strafrechts dessen Anwendbarkeit in der Praxis zu berücksichtigen.

b) Die Strafgesetzreform müßte also dazu führen, daß die traditionellen allgemeinen Lehren des Rechtsbereichs auf die Probe gestellt werden. Die hinsichtlich der Reform zentralen, die Voraussetzungen der strafrechtlichen Verantwortung bestimmenden Begriffe und Rechtsprinzipien sind einer gründlichen juristischen Analyse zu unterziehen. Zum Beispiel gibt die Gefährdungshaftung, die vielen Kriminalisierungen eigen ist, Veranlassung zu einer Neubewertung der Begriffe der Gefahr und des Risikos sowie zu einer Bestimmung ihres Inhalts in einer von den neuen Strafvorschriften geforderten Weise. Eine solche kritische Prüfung kann auch die Überprüfung der noch in

15 Vgl. dazu Koskinen: RIDP 1988 (Anm.12), S. 176-177. 
der Ausarbeitungsphase befindlichen Entwürfe des Strafgesetzprojekts für angebracht erscheinen lassen. ${ }^{16}$

c) Mit der Strafgesetzreform wird sich wohl auch die Tendenz verstärken, das seit alters her als sehr homogen empfundene strafrechtliche System zu differenzieren. Allerdings unterschied unser Strafgesetz schon in seiner ursprünglichen Form in gewissen Beziehungen die sog. polizeilichen Delikte von den übrigen Delikten, und mehrere vereinfachte Verfahrensweisen des Strafprozesses sind im Laufe der Jahrzehnte eingeführt worden. Gegen eine umfangreiche Differenzierung können starke Argumente ins Feld geführt werden, zum Beispiel die zentralen Werte der Gleichheit und Rechtssicherheit in der Strafrechtspflege; auch setzen die Finnland und seine Rechtsprechungsorgane bindenden Menschenrechtsnormen der Differenzierung Grenzen, die oft absoluter Natur sind.

Von den Objekten der Differenzierung des strafrechtlichen Systems sind die (kriminalisierten) geringfügigen Gesetzesverstöße das am deutlichsten umrissene Beispiel. Obwohl diese z.B. bezüglich des Schuldprinzips in unseren Gesetzen keine andere Stellung einnehmen als die anderen Delikte, führen allein schon die ihre Behandlung betreffenden vereinfachten Verfahrensweisen u.a. dazu, daß der Schuldzurechnung oder dem Nachweis des Vorsatzes nicht die gleiche Aufmerksamkeit gewidmet wird, wie es bei schwereren Straftaten der Fall ist. Die Reform der Vorschriften über das Absehen von Strafverfolgung wird diese Entwicklungstendenz verstärken.

In den Begründungen der zuletzt genannten Reform wird u.a. konstatiert, daß, da die Anklage auf „wahrscheinlichen Gründen“ zu basieren hat, beim Absehen von Strafverfolgung, welches den Charakter einer Sanktion hat, der Beweis zumindest ebenso stark sein muß wie bei der Anklageerhebung. Es wird dabei also kein sog. voller Beweis verlangt. Aus dem Blickwinkel der Menschenrechtsnormen ist es wesentlich, daß in derartigen Fällen - entsprechend wie beim summarischen Strafprozeß - dem Angeklagten die Möglichkeit bleibt, die Schuldfrage vor ein Gericht zur Behandlung zu bekommen. Siehe Gesetz über die Inkraftsetzung des Strafgesetzes, §§ $15 \mathrm{~b}$ und $15 \mathrm{c}$ (im Gesetz 301/90).

Als zweites Beispiel eignen sich die im Bereich der juristischen Person begangenen Delikte. Die Prinzipien, nach denen die individuelle strafrechtliche Verantwortung auf diese Delikte bezogen wird, haben sich in erster Linie

16 Ein gutes Beispiel von solchen kritischen Analysen ist der Artikel von Frände, in diesem Band, Criminal Law Theory in Transition - Strafrechtstheorie im Umbruch, S. 349-366. 
aufgrund der Gerichtspraxis herausgebildet, ohne daß es möglich gewesen war, die für herkömmliche Delikte entwickelten Teilnahme- oder anderen Verantwortungslehren als solche anzuwenden. Eine besonders deutliche Differenzierung der strafrechtlichen Verantwortung wird die vom Strafgesetzprojekt vorgeschlagene Einführung der strafrechtlichen Verantwortung von Körperschaften bedeuten, da diese Form der Verantwortung u.a. das Verzicht auf das Prinzip der individuellen Verschuldenshaftung implizieren wird.

\section{IV. Über die Kriminalisierungsprinzipien der Strafgesetzreform und die die Struktur des Strafgesetzes betreffenden Lösungen}

\section{1. Über die Kriminalisierungsprinzipien}

a) Die Absicht dieses Abschnittes (IV) ist es, zusammenfassend zu klären, wie die oben im Abschnitt II beschriebenen Ausgangspunkte der Strafgesetzreform in den die Kriminalisierungsprinzipien (und die Struktur des Strafgesetzes) betreffenden Lösungen ihren Ausdruck gefunden haben. Meine Anmerkungen bleiben auf recht allgemeiner Ebene, und erst aufgrund einer systematischen Analyse der betreffenden Strafvorschriften kann eine detaillierte Einschätzung getroffen werden.

b) Die Kriminalisierungsprinzipien werden recht knapp in der Regierungsvorlage zur ersten Phase der Reform behandelt. In dem Abschnitt, der sich mit der gesellschaftlichen Bedeutung und besonders mit den Zielen der Vorlage befaßt, wird u.a. folgendes ausgesagt: (s. Regierungsvorlage Nr. 66/1988 S. 9; s. auch S. 10 und 12).

Mit Hilfe der in der Vorlage enthaltenen Strafregulierungen soll strafrechtlicher Schutz in erster Linie gegen solches Mißverhalten gegeben werden, welches die Eigentums- und Besitzrechte, die öffentliche Wirtschaft und die störungsfreie Funktion des Wirtschaftslebens sowie den Güteraustausch zwischen privaten Bürgern oder kooperativen Wirtschaftseinheiten schädigt, gefährdet oder stört. Die Entwicklung der Produktion und des Wirtschaftslebens, die Verkomplizierung der Verkehrsbeziehungen, die technischen Erneuerungen sowie die Zunahme der Mittelverwendung und der Regulierungsaufgaben des Staates haben dazu geführt, daß die Vorschriften des Strafgesetzes besonders bezüglich dieser Teile merklich veraltet sind..

Der Gesetzausschuß des Reichstags hielt es für richtig, daß die Reformarbeit mit den Vorschriften über die Eigentums-, Geschäftsverkehrs- und Wirtschaftsdelikte begonnen wurde (Bericht des Gesetzausschusses Nr. 6/1990 S. 3):

Die geltenden Gesetze sind besonders bei einigen Eigentumsdelikten unnötig detailliert und spiegeln deutlich gesellschaftliche Verhältnisse wider, die von den 
heutigen abweichen. Bei den Wirtschaftsdelikten ist die Gesetzgebung deutlich hinter der gesellschaftlichen Entwicklung zurückgeblieben und ist nicht mehr imstande, ohne Veränderungen die von dieser neuen Form der Kriminalität gestellten Erfordernisse zu erfüllen.

c) $\mathrm{Da} ß$ die Überprüfung der Vorschriften über die Wirtschaftsdelikte und zum Teil auch der Vorschriften über die Delikte des Geschäftsverkehrs an den Anfang der Strafgesetzreform gesetzt wurde, ist im Zusammenhang damit zu sehen, daß seit Beginn der 70er Jahre die Wirtschaftskriminalität in hohem $\mathrm{Maße}$ das Aufsehen der Öffentlichkeit auf sich gezogen hat. Infolge der damaligen Diskussion begann man allmählich das Ausmaß dieser Kriminalität und die Notwendigkeit zu begreifen, ihre Bekämpfung in verschiedener Weise zu effektivieren. Die Arbeitsgruppe zur Klärung der Wirtschaftskriminalität, die in den Jahren 1982-83 tätig war, hielt die Wirtschaftskriminalität für nachteiliger als die herkömmlichen Vermögensdelikte und veranschlagte die direkten Verluste für unser Land auf mehrere Milliarden Finnmark pro Jahr. Aufgrund der Statistiken, die die Arbeitsgruppe von der Polizei erhalten hatte, waren die Steuer- und Konkursdelikte sowie die mit diesen regelmäßig verbundenen Buchführungsdelikte die wichtigsten Wirtschaftsdelikte.

Eine die Vorschriften über die Vermögensdelikte betreffende bedeutende Teilreform wurde im Jahre 1972 verwirklicht (498/72). Eines der wichtigsten Reformziele war damals, den Schwerpunkt der Strafregulierung vom Diebstahl und den damit verknüpften Taten auf Delikte zu verlagern, die allgemein mit dem Verkehr von Gütern und Vermögensgegenständen zusammenhängen, wie Unterschlagung, Untreue, Betrug und Wucher. Die erste Phase der Strafgesetzreform kann als Abschluß der damals im Jahre 1972 begonnenen Gesamtreform der die Vermögensdelikte betreffenden Vorschriften gelten.

Der Anteil der Delikte der Entwendung und des unbefugten Gebrauchs an der Kriminalität, von der der offizielle Kontrollapparat Kenntnis erhält, ist indes nach wie vor bedeutsam. So bildeten im Jahre 1989 diese Delikte über 40 Prozent der Taten gegen das Strafgesetz, die von der Polizei aufgenommen wurden. Auf der anderen Seite ist der relative Anteil der Unterschlagungs-, Betrugs- und Steuerbetrugsdelikte an den von der Polizei registrierten Straftaten im Wachsen begriffen.

d) Alles in allem ist es also das Ziel gewesen, die Strafvorschriften der gesellschaftlichen Entwicklung anzupassen, die sich in der wirtschaftlichen Tätigkeit und den Vermögensverhältnissen zwischen Privaten vollzogen hat. Diese Entwicklung hat auch u.a. auf die allgemeinen Lehren des Vermögensrechts einen Änderungsdruck ausgeübt.

Die in der ersten Phase der Strafgesetzreform verwirklichten, die wirtschaftliche Tätigkeit betreffenden Strafregulierungen erweitern den Kreis der Rechtsgüter in die Richtung der kollektiven und staatlichen Interessen (siehe 
oben III.2). Mit Hilfe der reformierten Vorschriften über die Steuer- und Subventionsdelikte (StG Kapitel 29) sollen die Mittelbeschaffung von öffentlichen Gemeinschaften und der sachgemäße Einsatz der Mittel gesichert werden. Die Vorschriften über die Bewirtschaftungsdelikte (StG Kapitel 46) haben den Zweck, die Befolgung der materiellen Bewirtschaftungsgesetze zu effektivieren und somit die mit ihnen angestrebten, in erster Linie wirtschaftspolitischen Ziele zu fördern. Mit den Vorschriften über die Gewerbedelikte (StG Kapitel 30) wiederum zielt man in erster Linie auf Gewährleistung einer sachgemäßen Gewerbetätigkeit; die einschlägigen Delikte laufen zumindest auf lange Sicht den Interessen des Wirtschaftslebens zuwider, wenn auch im Einzelfall nur ein einzelner Verbraucher oder ein konkurrierendes Unternehmen der unmittelbar Verletzte sein kann.

In den neuen die Vermögensverhältnisse betreffenden Strafregulierungen fällt vielleicht die Erweiterung des Bereichs der Tatobjekte am deutlichsten ins Auge. Gemäß den ursprünglichen Diebstahls- und Unterschlagungsvorschriften bezog sich die Entwendung auf Geld oder eine Ware, während in den neuen Vorschriften des Kapitels 28 des Strafgesetzes bewegliche Güter, elektrische Energie, Wärmeenergie, bei Unterschlagung auch Vermögenswerte (wie das als Kontostand sich ausdrückende Erwerbsrecht) Tatobjekte sein können. Besitz- und Sicherungsrechte auf das Eigentum werden in dem genannten Kapitel 28 des Strafgesetzes in einem weiteren Umfang geschützt.

Über die die Zahlungsmittel betreffenden Delikte sind wegen ihrer besonderen Charakteristika in einem eigenen Kapitel (StG Kapitel 37) Vorschriften erlassen worden. Die zum Schutz des Erwerbsrechts des Gläubigers gegenüber dem Schuldner gegebenen rechtlichen Mittel verstärken sich, wenn die die Interessen des Gläubigers verletzenden oder gefährdenden Handlungen umfassender als bisher kriminalisiert sind (StG Kapitel 39). Mit der Entwicklung der Datentechnik sind Daten und Informationen zu solch einem immateriellen Gut geworden, dessen Schutzbedarf in mehreren Strafvorschriften berücksichtigt worden ist. Dasselbe gilt allgemeiner auch für die EDV-Mißbräuche, d.h. für die sogenannten Computerdelikte.

Der Gesetzausschuß des Reichstags akzeptierte den bei der Reformierung der Vorschriften über die Computerdelikte angenommenen Grundsatz, daß in das Strafgesetz kein gesondertes Kapitel über diese Delikte aufgenommen wird, sondern die herkömmlichen Straftatbestände so ergänzt werden, daß die EDV-Delikte Berücksichtigung finden. Siehe besonders StrG 28:7-9, 30:4, 33:6.1, 35:1.2 und 36:1.2. Der Ausschuß drang auf eilige Verabschiedung der restlichen Vorschriften über die Computerdelikte und setzte voraus, daß bei ihrer Ausarbeitung die die Computerdelikte betreffenden Empfehlungen des Europarats berücksichtigt werden. Siehe Bericht des Gesetzausschusses Nr. 6/1990 S. 5. 
Der Entwurf zur zweiten Phase der Strafgesetzreform (1989) zusammen mit der verwirklichten ersten Phase entspricht den besagten Empfehlungen des Europarats recht gut. $\mathrm{Zu}$ diesen Empfehlungen siehe Final Activity Report: Computer-Related Crime. Council of Europe. CDPC (89) 9.

e) Bei der Erwägung des Bedarfs der Kriminalisierung einer Verhaltensform durfte man sich nicht damit begnügen, die Nachteiligkeit dieses Tattyps nur aufgrund dessen zu erörtern, welche Interessen dadurch verletzt oder gefährdet werden. Auch die Art der Verletzung bzw. Gefährdung des Intereses ist bei der Einschätzung von Belang auch wenn es dann häufig um die Erwägung der Vorwerfbarkeit des Tattyps geht.

So hat man zum Beispiel den Gedanken, daß mit einer eng an ein materielles Gesetz zu koppelnden Strafvorschrift an erster Stelle die Verwirklichung der Ziele des fraglichen Gesetzblocks zu sichern sei, in dem Kapitel über die Bewirtschaftungsdelikte in der Weise realisieren wollen, daß der Bruch einer Bewirtschaftungsbestimmung vorliegen muß und da $\beta$ ein geringfügiger Bruch einer Verfahrensbestimmung nicht als Bewirtschaftungsdelikt gilt. Als zweites Beispiel kann die Meinungsverschiedenheit angeführt werden die in der Reichstagsverhandlung bei der Einschätzung der Nachteiligkeit und Vorwerfbarkeit von Steuerübertretung (StG 29:4) auftrat; das Resultat der Verhandlung war, da $\beta$ die Art der Tat enger definiert wurde, als es vorgeschlagen worden war (siehe oben III.2.c.).

f) Ein besonders bedeutendes Kriminalisierungsprinzip in der ersten Phase der Strafgesetzreform ist, daß vorausgesetzt wurde, daß die unter Strafe gestellten Taten nur als vorsätzlich begangene Taten strafbar sind - mit nur einigen wenigen Ausnahmen (zu diesen siehe StG 30:10, 32:4-5 und 39:4-5). Für diese in der Hauptsache der früheren Rechtslage entsprechende Leitentscheidung sind u.a. die folgenden Begründungen vorzubringen: Die Vorwerfbarkeit einer vorsätzlichen Tat ist im Durchschnitt größer als die einer aus Fahrlässigkeit begangenen. Die Vermögensdelikte sind im allgemeinen nur bei Vorsatz strafbar gewesen. Wenn keine schwerwiegenden kriminalpolitischen Gegengründe gegeben sind, ist der Bereich der Strafbarkeit möglichst eng umgrenzt zu halten.

Gemäß den für die zweite Phase der Strafgesetzreform zur Regulierung vorgesehenen Vorschriften über die Gefährdungsdelikte (wie die Umwelt- und gemeingefährlichen Delikte) wäre auch aus Fahrlässigkeit oder grober Fahrlässigkeit erfolgendes Handeln in vielen Fällen strafbar. Bei den in der ersten Phase der Reform enthaltenen Delikten dürfte die Forderung nach Vorsatz besondere Beweisschwierigkeiten mit sich bringen, vor allem wenn es sich um solche Delikte handelt, die im Bereich der juristischen Person begangen 
worden sind und auf die also die Prinzipien der strafrechtlichen Organ- und Vertreterhaftung angewendet werden.

g) Zusammenfassend sei konstatiert, daß der Bereich des strafbaren Verhaltens zwar erweitert wird, aber in einer behutsamen Weise. So ist man zum Beispiel bei der Beschreibung des Hauptinhalts der Regierungsvorlage der Ansicht, daß die die Eigentums- und Geschäftsverkehrsdelikte betreffenden Regulierungen in ihrem Umfang und ihren Wirkungen überwiegend unverändert bleiben. Die in der Reform enthaltenen Änderungen der Straftatbestände erklären sich zu einem erheblichen Teil durch die die Schreibweise der Tatbestände betreffenden Lösungen und den hinter ihnen stehenden Begründungen (siehe unten IV.3.c).

\section{2. Über Strafdrohungen und Strafrahmen sowie über die speziellen Tatbestände}

a) Die Überprüfung der Strafrahmen in den Strafvorschriften und die Herstellung einer Ausgewogenheit zwischen diesen ist den Begründungen der Strafgesetzreform zufolge eng mit der Überprüfung des Gehalts der Strafgesetzgebung, d.h. mit den soeben (IV.1) behandelten Kriminalisierungsprinzipien, verbunden. Auf die Festsetzung der Strafdrohungen und Strafrahmen haben indes auch noch andere Umstände als die Bestimmung des Strafwerts (der Nachteiligkeit und Vorwerfbarkeit) der Deliktstypen einen Einfluß.

Die Festsetzung der Strafdrohung wird an einigen Stellen in den Begründungen ausdrücklich mit dem Bestreben verbunden, die Nachteiligkeit und Vorwerfbarkeit des jeweiligen Deliktstyps neu $\mathrm{zu}$ bewerten und somit entsprechend auf die Praxis der Bestimmung der Strafe einzuwirken. In der Regierungsvorlage wird die Ansicht geäußert, daß die über die Vermögensdelikte verhängten Strafen im Durchschnitt unbegründet streng seien im Vergleich zu den Strafen, mit denen bestimmte Straftaten gegen das Leben und die Gesundheit geahndet werden. Die deutliche Botschaft an die Rechtsanwender lautet hinsichtlich der Vermögensdelikte, daß die Strafpraxis zu mildern sei. Ein konkretes Zeichen dafür ist, daß die Höchststrafe bei der Grundform der Diebstahlsdelikte (StG 28:1) von zwei Jahren Gefängnis auf ein Jahr sechs Monate Gefängnis herabgesetzt wurde. Wegen des engen Zusammenhangs der Straftaten wurde diese Änderung auch auf die Grundform der Unterschlagungs- (StG 28:4) und Hehlereidelikte (StG 32:1) ausgedehnt. ${ }^{17}$

17 Siche Regierungsvorlage Nr. 66/1988, bes. S. $17-18$ und 33, sowie Bericht des Gesetzausschusses Nr. 6/1990, S. 6. 
Da man in der Reform außerdem bestrebt war, solche Strafrahmen, die sich in der Praxis als unnötig weit erwiesen hatten, einzuengen - ohne zugleich zumindest unmittelbar auf die Strafpraxis einwirken zu wollen -, betonte der Gesetzausschuß des Reichstages, daß es wichtig sei, die Ziele für die Änderung der Strafrahmen deutlich herauszustellen. Um ein genaues Bild zu erhalten, ist also die Betrachtung je nach Deliktstyp zu differenzieren. Die Frage des Strafmaßes ist auch vor dem Hintergrund der Ziele der Reformierung des strafrechtlichen Sanktionensystems zu betrachten (siehe unten V.2). Ich begnüge mich im folgenden mit einigen Anmerkungen allgemeiner Natur.

Man darf annehmen, daß mit den Änderungen, die an den Mindeststrafen vorgenommen wurden, im allgemeinen bezweckt wurde, einen Einfluß auf die Strafpraxis auszuüben. In der vorliegenden Reform ist ein typisches Beispiel für die Herabsetzung der Mindest- und zugleich auch der Höchststrafe die unbefugte Ingebrauchnahme eines Kraftfahrzeugs, die nun aufgrund der Vorschriften über den unbefugten Gebrauch (StG 28:7-9) zu beurteilen ist. Ein weiteres Beispiel bieten die Grundtatbestände der neuen Fälschungsdelikte (StG Kapitel 33). Aus den Begründungen dieser Gesetzesänderungen geht das Bestreben hervor, die Strafpraxis zu mildern.

Durch Anhebung der Höchststrafe hat man in der Reform im allgemeinen entsprechenderweise zumindest aufzeigen wollen, daß die Vorwerfbarkeit des betreffenden Deliktstyps relativ zugenommen hat. Die Wirkung der Änderung auf die Strafpraxis ist in Relation zu anderen Delikten zu beurteilen, deren Strafrahmen möglicherweise auch geändert worden sind. So war die Regierung zum Beispiel der Ansicht, daß die Strafregulierung der im Bereich der Wirtschaft aufgetretenen Kriminalität häufig unbegründet mild gewesen sei. Der Gesetzausschuß wiederum hielt es vom Standpunkt des Wandels der gesellschaftlichen Verhältnisse für verständlich, daß der Strafrahmen der Grundform der Sachbeschädigung (StG 35:1) ebenso wie die Strafrahmen für die im Wirtschaftsleben im Zusammenhang mit Betriebsgeheimnissen und Bestechung auftretenden Delikte (StG 30:4-8) strenger gestaltet werden. ${ }^{18}$ Die Bedeutung dieser Strafrahmenänderungen sollte also vor allem in Relation dazu erwogen werden, was oben über das für Vermögensdelikte als angemessen erachtete Strafmaß gesagt wurde.

Die in den Strafrahmen angegebene Ordnung der Strafarten wird jetzt konsequent in der Weise beschrieben, daß an erster Stelle die mildeste Strafart

18 Siehe Regierungsvorlage Nr. 66/1988, S. 13 und 75, sowie Bericht des Gesetzausschusses Nr. 6/1990, S. 6. 
genannt wird, also Geldstrafe vor Freiheitsstrafe. Mit dieser Reihenfolge will man indes keinen steuernden Einfluß auf die Strafpraxis ausüben.

Insgesamt gesehen sind die im Zusammenhang mit den Teilreformen vorgenommenen Änderungen an den Strafrahmen mit Bedacht und in Anbetracht dessen zu beurteilen, daß die Strafrahmen und das Strafmaß in dem neuen Strafgesetz in ihrer Gesamtheit in der letzten Phase der Gesamtreform des Strafgesetzes überprüft werden sollen.

b) Die Abstufung der Schwere der Straftaten und die Typenstrafrahmen sind zum einen vor dem Hintergrund der oben (II.2) erwähnten Symbolfunktion des Strafgesetzes und der hierdurch anzustrebenden mittelbaren generalpräventiven Wirkung des Strafgesetzes zu verstehen. Aufgrund der legislativen Lösungen ist es möglich, sich deutlicher als zuvor der im Schweregrad verschiedener Straftaten vorhandenen Unterschiede bewußt zu werden. Auf der anderen Seite strebt man mit diesen Lösungen an, die Rechtssicherheit (siehe oben II.3) zu fördern, d.h. man übt einen vereinheitlichenden Einfluß auf die Strafpraxis aus und verbessert dadurch die Vorhersehbarkeit.

In der ersten Phase der Strafgesetzreform sind hauptsächlich sechs Strafrahmen angewandt worden (Geldstrafe; Geldstrafe - 6 Monate Gefängnis; Geldstrafe - 1 Jahr Gefängnis; Geldstrafe - 2 Jahre Gefängnis; 4 Monate - 4 Jahre Gefängnis und 2-10 Jahre Gefängnis), während vor der Reform im Strafgesetz mehr als 70 verschiedene Strafrahmen in Gebrauch gewesen waren. Der Gesetzausschuß des Reichstags billigte den Gedanken einer erheblichen Reduzierung der Strafrahmen und verlangte, daß in den späteren Phasen der Reform große Zurückhaltung in der Anwendung von neuen, außerordentlichen Strafrahmen geübt wird. ${ }^{19}$

Die Bedeutung der Schwereabstufung als Indikator für den Schweregrad der Deliktstypen wird dadurch verringert, daß die Schwereklassen - entgegen dem Vorschlag des Strafrechtskomitees - keine eigenen Namen haben. Allerdings ist die Schwereklassifizierung häufig indirekt in den Bezeichnungen der einzelnen Delikte zu sehen. Bei den der Reform unterzogenen Delikten ist in der Strafvorschrift konsequent (neben dem Straftatbestand und der Strafdrohungsklausel) der Deliktsname genannt worden. Der Gesetzausschuß des Reichstags hielt es indes für bedauerlich, daß in den Deliktsnamen bei den geringfügigen Tatformen der Delikte keine volle Konsequenz erreicht worden ist. Angemerkt sei noch, daß mit der besagten Schwereklassifizierung als

19 Siehe Regierungsvorlage Nr. 66/1988, S. 16-17, sowie Bericht des Gesetzausschusses Nr. 6/1990, S. 4. 
solche keine straf- oder strafprozeßrechtlichen Folgewirkungen gekoppelt worden sind (vgl. oben III.3.c).

c) Bezüglich der speziellen (qualifizierten und privilegierten) Tatbestände, d.h. der schweren und geringfügigen Tatformen eines Delikts vom gleichen Typ, hat man sich die folgenden Prinzipien zu eigen gemacht. Delikte, die von ihrem Schweregrad her unterschiedlich sind, sollten an erster Stelle in einem eigenen Paragraphen einen eigenständigen Tatbestand haben. Bei qualifizierten Tatbeständen werden die Verschärfungsgründe abweichend von der früheren Praxis zur Stärkung des Gesetzlichkeitsprinzips erschöpfend aufgezählt ohne Verweis auf „sonstige Fälle“. Bei privilegierten Tatbeständen brauchen die Milderungsgründe auch weiterhin nicht erschöpfend aufgezählt zu werden. Die Anwendung beider spezieller Tatbestände (in erster Linie in Beziehung zum Grundtatbestand) wird letztendlich von der Gesamtbeurteilung der Straftat entschieden. Sogenannte unbenannte Nebenrahmen sind in der Reform nicht enthalten.

Der Gesetzausschuß des Reichstags hielt es für empfehlenswert, daß bei solchen Straftaten, bei denen die Vorwerfbarkeit stark variieren kann, die verschiedengradigen Ausdrucksformen der Straftat im Gesetz bestimmt werden und damit die Strafpraxis gesteuert wird. Auch ansonsten akzeptierte der Gesetzausschuß die oben erläuterten Prinzipien; indes verlangte er, daß die Regierung die Anwendung der Verschärfungsgründe verfolge und bei Bedarf deren Änderung in Angriff nehme. ${ }^{20}$

\section{3. Über die Gesetzessystematik und die Struktur der Straftatbestände}

a) Eine Aufgabe der Strafgesetzreform ist es, die zentralen Strafvorschriften wieder in einem Gesetz, dem neuen Strafgesetz, zusammenzufassen. Der wichtigste Inhalt dieses Konzentrierungsprinzips ist, daß die Strafvorschriften mit Freiheitsstrafdrohung in das zu reformierende Strafgesetz einbezogen werden. In gleicher Weise wie die Abstufung des Schweregrads der Delikte hat diese gesetzessystematische Entscheidung zum Ziel, effektiver auf die Auffassungen betreffend den Schweregrad der Deliktstypen einzuwirken und dadurch die negativen Einstellungen zu diesen Taten zu verstärken. Zugleich wird angestrebt, die Rechtssicherheit zu fördern, indem die im Strafgesetz zusammenzufassenden Vorschriften gesetzestechnisch entsprechend zufriedenstellender und einheitlicher Prinzipien niedergeschrieben werden. Der Gesetzausschuß des Reichstags hat die Anwendung des genannten Konzentrierungsprinzips akzeptiert, dabei aber betont, daß die Befolgung des Prinzips

20 Bericht des Gesetzausschusses Nr. 6/1990, S. 5. 
kein Selbstzweck sei und daß man nicht an ihm festhalten solle, wenn dies die Klarheit der Gesetze gefährden und zu Mehrdeutigkeiten führen würde. ${ }^{21}$

In der praktischen Gesetzausarbeitung hat es sich in vielen Fällen als äußerst mühselig erwiesen, die mit den materiellen Gesetzen eng verbundenen Tatbestände in der Weise zu formulieren, daß sie möglichst weitgehend den normalen Straftatbeständen entsprechen. Das Endergebnis kann trotz aller Bemühungen unbefriedigend sein (z.B. bei den Bewirtschaftungsdelikten im Kapitel 46 des Strafgesetzes). Die Mühseligkeit, die die Befolgung des Konzentrierungsprinzips mit sich bringt, hat auch dazu geführt, daß die Strafvorschriften der besonderen Gesetze, die eine relativ milde Freiheitsstrafdrohung beinhalten, nur erst teilweise in der vom Prinzip geforderten Weise durchdacht werden konnten (soll die Freiheitsstrafdrohung bewahrt bleiben und die Vorschrift ins Strafgesetz übertragen werden, oder soll die Vorschrift mit der Androhung einer Geldstrafe verknüpft werden, oder soll dekriminalisiert werden?).

b) Schon in der ersten Phase der Strafgesetzreform wird eine konsequentere Kapitelsystematik angestrebt. Diese hat auch die neuen Schwergewichte der Kriminalisierungsprinzipien und Strafdrohungen $\mathrm{zu}$ reflektieren (siehe oben IV.1-2). Die in der nun vorliegenden Teilreform zu regulierenden Straftaten sind in den Gesetzausarbeitungsdokumenten in Eigentums-, Geschäftsverkehrs- und Wirtschaftsdelikte eingeteilt worden.

Eine neuartige, aus den Namen der Kapitel hervorgehende Systematik repräsentieren das Kapitel 29 (Über die Delikte gegen die öffentliche Wirtschaft), das Kapitel 30 (Über die Gewerbedelikte), das Kapitel 37 (Über die Zahlungsmitteldelikte) und das Kapitel 46 (Über die Bewirtschaftungsdelikte und den Schmuggel). Von diesen haben sich sämtliche Strafvorschriften des Kapitels 30 infolge der Einhaltung des Konzentrierungsprinzips herausgebildet, und das gleiche gilt auch für die Bewirtschaftungsdelikte des Kapitels 46. Das Kapitel 37 über die Zahlungsmitteldelikte reguliert neben den herkömmlichen Geldfälschungsdelikten auch den Zahlungsmittelbetrug (StG 37:8) und die damit zusammengehörigen Delikte. Im Hintergrund der neuen Kapitelsystematik steht das zugenommene Interesse, die Sicherheit des Zahlungsverkehrs zu schützen.

Da man die Kapitel in den freigewordenen alten Kapiteln des Strafgesetzes hat unterbringen müssen, ist das Ergebnis unsystematisch und auch ungeordnet. Erst in der letzten Phase der Strafgesetzreform wird man die angestrebte Konsequenz u.a. in der Ordnung der Kapitel untereinander erreichen können.

21 Bericht des Gesetzausschusses Nr. 6/1990, S. 4, im Verhältnis zu der Regierungsvorlage Nr. 66/1988, S. 12-13. 
c) Die Formulierung der Straftatbestände ist gemäß der in den letzten Jahren befolgten Praxis erneuert worden. Es scheint drei zentrale Forderungen zu geben, die man durch Lösungen in der Struktur der Straftatbestände und allgemeiner der neuen Strafgesetzgebung hat erfüllen wollen: die Gesetzesformulierung soll einheitlicher (konsequenter), deutlicher (verständlicher) und exakter sein als zuvor. Besonders klar treten diese Forderungen in dem Bericht des Strafrechtskomitees zutage. ${ }^{22}$ Die Deutlichkeit der Strafvorschriften verbessert ihre sich auf die Bürger richtende Steuerwirkung und ist somit mit dem Ziel der Generalprävention verbunden. Eine möglichst exakte Gesetzesformulierung kommt dem Gesetzlichkeitsprinzip entgegen ${ }^{23}$, und die Forderung nach Exaktheit ebenso wie die nach Einheitlichkeit fördern die Rechtssicherheit (die Vorhersehbarkeit) in der Strafrechtspflege.

Von den aufgezählten Prinzipien können Deutlichkeit und Exaktheit in eine Spannung miteinander geraten. So scheint zum Beispiel die für die Reform kennzeichnende Weise, die Straftatbestände allgemeiner als früher, d.h. synthetischer, abzufassen, für die Verständlichkeit des Textes - oder zumindest seines Hauptinhalts - besser zu sein als eine Schreibweise, die sich rein an Einzelfällen orientiert. Ich denke da zum Beispiel an die neuen Vorschriften über die Delikte des Schuldners (StG Kapitel 39) im Vergleich zu den alten Konkursstrafvorschriften.

In manchen Fällen mag es indes schwierig sein zu beurteilen, ob eine allgemeiner abgefaßte Regulierung - in der außerdem womöglich verschiedene Tatbestände vereinigt worden sind (wie zum Beispiel beim Delikt des Mißbrauchs der Vertrauensstellung; StG 36:5) - die Verständlichkeit des Straftatbestandes verbessert. Dieser Zweifel erscheint umso begründeter, je ungenauer die in der Regelung verwendete Formulierung ist (d.h. je mehr sie dem Ermessen Spielraum überläßt). Dies ist zumindest dann der Fall, wenn Begriffe und Vorschriften allgemeiner Natur nicht mit Beispielen verknüpft werden, die ihren Inhalt erhellen. Es ist jedoch anzumerken, daß die Formulierung der Straftatbestände sich in solchen Fällen durch das Bestreben erklärt, ein bestimmtes materielles Ziel der Kriminalpolitik zu erreichen (siehe oben IV.1-2).

Die Deutlichkeit der Vorschriften kann auch von der Tendenz geschwächt werden, die Tatbestände zu differenzieren, zum Beispiel in der Weise, daß außer über den gewöhnlichen Betrug (StG 36:1-3), auch über damit verwandte Delikte wie den Versicherungsbetrug (StG 36:4) über Subventionsdelikte (StG

22 Siehe Komiteebericht 1976:72, S. 159-160, 168 und 187, Regierungsvorlage Nr. 66/1988, S. 16, sowie Bericht des Gesetzausschusses Nr. 6/1990, S. 4.

23 Siche im allgemeinen Dan Frände: Den straffrättsliga legalitetsprincipen. Ekenäs 1989. 
29:5-8), über Delikte des Vermarktungs- und Wettbewerbsverfahrens (StG 30:1-2) sowie über den Zahlungsmittelbetrug (StG 37:8-11) Vorschriften erlassen werden. Auch bei diesem Beispiel stehen im Hintergrund der Differenzierung gewisse kriminalpolitische Ziele.

Der Gesetzausschuß des Reichstags hielt relativ allgemein abgefaßte Strafvorschriften mit folgender Begründung für akzeptabel: „Das Strafgesetz sollte seine Aufgabe über Jahrzehnte hinweg mit relativ wenigen Veränderungen erfüllen können, auch wenn sich die Lebensbedingungen der Gesellschaft und der Menschen wandeln..." - Die Entwicklung zur wachsenden Differenzierung der Strafvorschriften führt nach der Ansicht des Gesetzausschusses leicht zu Problemen bei der Gesetzesanwendung, so zum Beispiel in der Anwendung der allgemeinen Betrugsvorschriften in Fällen, wo die besonderen Betrugsvorschriften nicht angewendet werden können. $\mathrm{Zu}$ einer solchen Differenzierung der Strafvorschriften sollte man nach Meinung des Ausschusses in Zukunft nur dann greifen, wenn die Entwicklung der gesellschaftlichen Verhältnisse oder der Technik dies eindeutig erfordert. Siehe den Bericht des Gesetzausschusses 6/1990, S. 4.

Im Geiste der vom Gesetzlichkeitsprinzip implizierten Forderung nach Exaktheit sind zum Beispiel die Strafvorschriften vom Blankotyp entweder ganz abgeschafft oder zumindest präzisiert worden. Es war auch offenbar das Ziel, eine solch allgemeine Formulierung, wie sie dem deswegen kritisierten Strafgesetz Schwedens (von 1962) eigen ist, zu vermeiden. Dieses ist durch die Äußerung charakterisiert worden, daß allein durch das Lesen des Gesetzestextes des Strafgesetzes es häufig nicht möglich sei, die Grenzen der Strafbarkeit zu erkennen; oft könne man darin nur lesen, was vielleicht strafbar ist. ${ }^{24}$

\section{$V$. Über das Verhältnis der ersten Phase der Strafgesetzreform zu der Reformierung der allgemeinen Lehren des Strafrechts, des Sanktionensystems und der strafprozessualen Vorschriften}

\section{1. Über die Reformierung der allgemeinen Lehren des Strafrechts ${ }^{25}$}

a) Die Verwirklichung der allgemeinen kriminalpolitischen Ausgangspunkte der Strafgesetzreform wird dadurch verkompliziert, daß die Reform, wenn auch in umfangreichen Teilreformen, so doch stufenweise durchgeführt wird. Aus dem Verzug der Regulierung der allgemeinen Lehren des Strafrechtes erwachsen gewisse Probleme. Zum einen bestimmen auch die Lehren über die strafrechtliche Verantwortung in zentraler Weise die Grenze zwischen strafbarem und nicht strafbarem Verhalten. Zum zweiten ist die Reformierung des Besonderen Teils des neuen Strafgesetzes weitgehend auf der prognostischen

24 Siehe Göran Elwin: Häleribrottet. P. A. Norstedt \& Söners Förlag, Stockholm 1969, Kapitel II.

25 Zum folgen sieh auch im allgemeinen Lahti: ZStW 1991 (Amn. 3). 
Auffassung davon aufzubauen, wie sich die allgemeinen Voraussetzungen der strafrechtlichen Verantwortung später im Gesetz gestalten werden. Man hat dabei schon aus praktischen Gründen vorauszusetzen, daß die Verantwortungslehre in ihrem Gehalt so weit wie möglich beibehalten wird. Zum dritten gibt es keine in der Anfangsphase der Strafgesetzreform als Grundlage für die Ausarbeitung gründlich durchdachte, konsequente Auffassung davon, welchen Gehalt den Grundbegriffen und Rechtsprinzipien der Verantwortungslehre zu geben ist.

Nach Meinung des Gesetzausschusses des Reichstags hätte es die Behandlung der ersten Teilreform erleichtert, wenn man zum Beispiel gewußt hätte, welcher Inhalt den Vorschriften über die Zurechenbarkeit (Vorsatz und Fahrlässigkeit) und die strafrechtliche Verantwortung von Körperschaften gegeben werden soll. Siehe den Bericht des Gesetzausschusses Nr. 6/1990, S. 3.

b) Wenn man in der Teilreform zu einer zum Bereich der allgemeinen Lehren gehörenden Frage Stellung beziehen muß, entstehen aus der Unabgeschlossenheit der Regelung leicht Schwierigkeiten. Als erstes Beispiel hierfür bietet sich das Prinzip des Grades der Zurechenbarkeit an, das aus Versehen nur an einer Stelle im Bericht des Gesetzausschusses in deutlichen Worten ausgedrückt ist:

...Man ging von der als etabliert anzusehenden Auffassung aus, daß in dem Strafgesetz die Strafbarkeit der Tat den Vorsatz voraussetzt, sofern nicht über die Zurechenbarkeit gesondert etwa anderes bestimmt wurde. Fahrlässiges Verhalten ist nur dann strafbar, wenn der Tatbestand ausdrücklich auf aus Fahrlässigkeit erfolgendes Handeln ausgedehnt worden ist. (Siehe den Bericht des Gesetzausschusses S. 3.)

Wie gut man sich dieses Prinzip zu eigen machen wird, da es nur in dem Bericht des Gesetzausschusses niedergeschrieben ist, darüber kann man nur unsichere Vermutungen anstellen. Die Aussage hat unmittelbare Bedeutung nur für die Auslegung der Vorschriften, die in der verwirklichten Teilreform enthalten sind. Nach der herrschenden Interpretation, wie sie auch von dem Lehrbuch Brynolf Honkasalos vertreten wird, hat sich die Strafbarkeit fahrlässigen Verhaltens außer auf eine ausdrückliche Bestimmung im Gesetz auch auf die Konklusion über den Zweck (oder den Zusammenhang) der Vorschrift gründen können, sei es auch, daß in Ermangelung einer ausdrücklichen Bestimmung die Ausgangsannahme für die Forderung des Vorsatzes spricht. Dem Präjudiz des Obersten Gerichtshofes vom 29. August 1990 zufolge (OGH 1990:97) gilt gemäß den allgemeinen Begründungen die herrschende Interpretation für Delikte aller Art, also auch für die polizeilichen Delikte.

Als zweites Beispiel möchte ich die Aussagen in den Vorschriften über Buchführungsdelikte und die Delikte des Schuldners (StG 30:9-10 und 39:7) anführen, welche die strafrechtliche Organ- und Vertreterhaftung bestimmen. Die Weise, in der der Täterkreis beschrieben wird, ist eine unterschiedliche: 
bei den Buchführungsdelikten ist der Täterkreis enger (Buchführungspflichtige, deren Vertreter oder diejenigen, die mit der Buchführung betraut worden sind) und bei den Delikten des Schuldners weiter gezogen (der Schuldner oder die für ihn Tätigen). Es ist schwer, für eine in dieser Weise unterschiedliche Bestimmung haltbare kriminalpolitische Begründungen aufzuzeigen. Aufgrund der Gerichtspraxis läßt sich auch erwarten, daß Auslegungsprobleme entstehen.

Dem Präjudiz OGH 1988:95 zufolge kann sich eines sog. buchhalterischen Konkursdelikts als Täter ein faktischer Leiter ohne formelle Organstellung schuldig machen. Ist eine entsprechende Auslegung möglich, wenn in derselben Situation nun die Vorschrift über Buchführungsdelikte anzuwenden ist? Dem Wortlaut dieser Vorschrift gemäß darf also als Täter nur der Buchführungspflichtige, dessen Vertreter oder derjenige bestraft werden, der mit der Buchführung betraut worden ist - also nicht derjenige, der ansonsten für den Buchführungspflichtigen tätig ist.

c) Da die Revision des Strafgesetzes durch umfangreiche Teilreformen erfolgt, entsteht eine Spannung zwischen der Teilreform bzw. den Teilreformen und den noch nicht erneuerten Teilen. Zum Abbau dieser Spannung ist es angebracht, in den Auslegungen der veränderten und noch unveränderten Teile eine gegenseitige Wechselwirkung und bei den die allgemeinen Lehren betreffenden Fragen eine möglichst große Einheitlichkeit anzustreben (sofern nicht für die Differenzierung der Prinzipien gute Gründe vorliegen; vgl. oben III.3.c). In einer solchen Wechselwirkung ist es bei der Auslegung der Vorschriften einer Teilreform wichtig, die Ausgangspunkte der gesamten Strafgesetzreform sowie ferner die Gesetzgebungsdokumente, in denen diese Ausgangspunkte ihren Ausdruck finden, wie auch die übrigen auf diesen Ausgangspunkten beruhenden Teilreformen zu berücksichtigen.

Der Schwerpunkt der Wechselwirkung liegt also auf den Prinzipien, die in der Reform bzw. den Reformen ihren Ausdruck finden, und diese schlagen sich in der Auslegung der bis dahin noch unveränderten Teile des Strafgesetzes nieder. So ist zum Beispiel anzunehmen, daß die oben erwähnte Begründung des Gesetzausschusses des Reichstags über den Grad der Zurechenbarkeit auch auf die Auslegung der noch unveränderten Teile des Strafgesetzes in der Weise einwirkt, daß es nur noch in immer engeren Grenzen akzeptiert wird, die fahrlässige Schuldzurechnung mit dem Zweck der Strafvorschrift zu begründen, wenn eine die Zurechenbarkeit ausdrückende Gesetzesbestimmung fehlt (siehe auch die oben erwähnte Entscheidung OGH 1990:97). ${ }^{26}$

26 Siehe auch den vorläufigen Vorschlag zu Bestimmungen über die strafrechtliche Verantwortung des neuen Strafgesetzes: $\S 5$ Kap. 2 (Anhang 2 in diesem Band). 
Das soeben Gesagte darf indes nicht bedeuten, daß man den Begründungen irgendeiner Teilreform kritiklos gegenübersteht. Besonders in den zum Bereich der allgemeinen Lehren gehörenden Fragen sind solche Aussagen umso überzeugender, je gründlicher die Ausarbeitung in dem Strafgesetzprojekt ist, auf die sie sich stützen. So wird zum Beispiel über die Gesetzeskonkurrenz in der Regierungsvorlage zur ersten Phase der Strafgesetzreform konstatiert, daß man bestrebt war, die Straftatbestände so abzufassen, daß möglichst wenig Situationen der Gesetzeskonkurrenz entstünden. ${ }^{27}$ Trotz dieser Begründung des Gesetzes und der Konkurrenzklauseln, die in einigen Strafvorschriften der Teilreform enthalten sind, halte ich es am Platze zu betonen, daß bei der Erwägung einzelner Tatbestände die allgemeinen Prinzipien der Gesetzeskonkurrenzlehre gebührend zu berücksichtigen sind.

\section{Zur Reformierung des strafrechtlichen Sanktionensystems ${ }^{28}$}

a) Die von mir eingangs (II.1) erwähnte Forderung, daß die erste Phase der Strafgesetzreform auch in der Beziehung zu den Ausgangspunkten der gesamten Reform und zu den übrigen auf diesen basierenden Teilreformen zu beurteilen ist, ist von besonderer Bedeutung, wenn es darum geht, die Auswirkungen des legislativen Projektes auf das Strafniveau und allgemeiner auf die Sanktionenpraxis zu erwägen. Darauf habe ich bereits oben (IV.2.a) an der Stelle hingewiesen, wo es um die Setzung der Strafdrohungen und Strafrahmen ging.

Mit der Verwirklichung der ersten Phase der Reform ist als deren Teil die Änderung einer Vorschrift des Kapitels 2 des Strafgesetzes verbunden (StG 2:2.2), welche zur Folge hat, daß eine Freiheitsstrafe unter drei Monaten in Tagen zu verhängen ist. Das Schwergewicht der Änderung liegt, ihren Begründungen zufolge, darauf, neue Zumessungsalternativen zustande zu bringen, aber in der Regierungsvorlage kommt auch das kriminalpolitische Ziel stark zum Tragen, die Anwendung der Freiheitsstrafe einzuschränken.

Siehe Regierungsvorlage Nr. 66/1988, S. 23-25, und Bericht des Gesetzausschusses 6/1990, S. 2. Zur Beleuchtung des zuletzt genannten Ziels sei die Regierungsvorlage zitiert (S. 23):

Die kriminologische Forschung hat bewiesen, daß die Generalprävention der Strafe nicht einseitig mit der Länge der Strafe verknüpft werden kann. Schon der Umstand ins Gefängnis zu müssen, hat eine erhebliche Abschreckungswirkung. Desgleichen ist die Auffassung aufzugeben, daß die 'Besserungswirkung' des

27 Siehe Regierungsvorlage Nr. 66/1988, S. 21.

28 Siehe auch im allgemeinen Pellinen, in: Kriminalpolitik und Strafzumessung im Umbruch (Anm. 2). 
Gefängnisses eine gewisse Mindestdauer der Freiheitsstrafe erfordere. Im Gegenteil: Wie man weiß, schwächt die Freiheitsstrafe fast immer die Resozialisierungsmöglichkeiten nach Verbüßung der Strafe. Außerdem kommt die Vollstreckung von Freiheitsstrafen der Gesellschaft teuer. - Es wäre somit zweckmäßig, die Anwendung der Freiheitsstrafe auf das Mindestnotwendige zu beschränken.

Eine bedeutende Erneuerung des Sanktionensystems betrifft die Konfiskationssanktionen. Im Kapitel 46 des Strafgesetzes über die Bewirtschaftungsdelikte sind die Vorschriften betreffend die Konfiszierung des Gegenstand der das Objekt des Deliktes war, d.h. des sog. Corpus delicti, gründlich erneuert worden. Das Ziel war, die Voraussetzungen für die Verhängung einer derartigen Einziehungssanktion in der Weise zu verschärfen, daß die Sanktion mehr die Natur einer Sicherungsmaßnahme bekomme und weniger die einer Strafe. Einige der Prinzipien, die man sich in der Reform zu eigen gemacht hat, scheinen zu indizieren, daß die Konfiszierungsvorschriften einer weitgehenden Revision unterzogen werden.

b) Zu den Erneuerungen, die gleichzeitig mit der ersten Phase der Strafgesetzreform in Kraft getreten sind, gehören die erhebliche Erweiterung des Bereichs des Absehens von strafrechtlicher Verfolgung und Verurteilung und die probeweise Ingebrauchnahme des gemeinnützigen Dienstes als Sanktion (siehe oben I.1). Mit den erneuerten Vorschriften über das Absehen von Verfolgung und Verurteilung werden den Begründungen des Gesetzes zufolge mehrere Ziele verfolgt: die Strafsanktionen sollen angemessener gestaltet werden; andere Formen der offiziellen Kontrolle (in erster Linie im Bereich der Sozialfürsorge) anstelle der Anklageerhebung sollen ermöglicht werden; das Strafsystem soll abgestuft werden, und die Ressourcen des strafrechtlichen Systems sollen zweckmäßiger eingesetzt werden.

Mit der Erweiterung des Bereichs des Absehens von Verfolgung im Vergleich zu dem, was die Regierung vorgeschlagen hatte, hatte sich auch der Gesetzausschuß des Reichstags bei der Behandlung der ersten Phase der Strafgesetzreform befaßt. Bezüglich der Steuerdelikte erhoffte man sich die Klärung dessen, ob die Reue des Steuerpflichtigen es häufiger als früher ermöglichen könne, von einer Bestrafung abzusehen. Dem Kapitel über die Sachbeschädigungsdelikte wurde wiederum eine besondere Vorschrift über das Absehen von Verfolgung und Verurteilung (StG 35:7) beigefügt, in der u.a. zur Einführung des Täter-Opfer-Ausgleichs ermutigt wurde.

Die probeweise Einführung des gemeinnützigen Dienstes ist verbunden mit dem Ziel, die Anwendung der Freiheitsstrafe zu reduzieren, was in der diesbezüglichen Regierungsvorlage als eines der wichtigsten Ziele der Gesamtreform 
des Strafgesetzes genannt wurde. Die neue Sanktionsform würde zudem die Auswahlmöglichkeiten der Gerichte erhöhen, da sie sich auf der Härteskala der Sanktionen zwischen der bedingten und der unbedingten Freiheitsstrafe plaziert. Der zu erprobende gemeinnützige Dienst ist als Alternative zu einer unbedingten Freiheitsstrafe von maximal acht Monaten gedacht.

Zusammen mit der Vorlage des Gesetzesentwurfs über die Erprobung des gemeinnützigen Dienstes nahm der Staatsrat am 24. Mai 1990 eine Erklärung an, der zufolge das Justizministerium entsprechend einer bereits früher vom Reichstag angenommenen Entschließung auch sonstige alternative Strafformen untersuchen soll. Der Erklärung zufolge könnten derartige alternative Sanktionen auch anstelle von bedingten Freiheitsstrafen angewendet werden. Die Entschließung des Reichstags war verbunden mit der Behandlung einer Regierungsvorlage, die zur Änderung des Gesetzes über die bedingte Bestrafung (992/89) führte: Seit Jahresbeginn 1990 darf für ein Delikt, das von einer Person unter 18 Jahren begangen wurde, keine unbedingte Freiheitsstrafe verhängt werden, sofern nicht schwerwiegende Gründe dies erfordern.

Von den übrigen aktuellen Änderungen des Sanktionensystems sei hier noch die Reformierung der Gesetze über das Zusammentreffen mehrerer Straftaten erwähnt (Nrn. 697-710/91; Inkrafttreten 1.4.1992). Von der Differenzierung der Formen der Staftatenkonkurrenz wird man bei der Verhängung einer Strafe für zwei oder mehrere Delikte Abstand nehmen und zu dem sog. Einheitsstrafensystem übergehen, bei dem für die Delikte von Anfang an nur eine gemeinsame Strafe verhängt wird. Im Zusammenhang mit dieser Reform wurde u.a. das Gesetz über die bedingte Bestrafung in der Weise geändert, daß das Gericht von einer bedingten Strafe nur einen Teil zur Vollstreckung bestimmen sowie von den bedingten Strafen und einer sonstigen unbedingten Freiheitsstrafe die Vollstreckung einer gemeinsamen Freiheitsstrafe bestimmen könnte.

c) Das Ziel der obigen Betrachtung war es, herauszustellen, daß zum Teil genau gleichzeitig mit der Verwirklichung der ersten Phase der Strafgesetzreform und zum Teil etwas früher oder später umfangreiche Veränderungen am Sanktionensystem vollzogen wurden. Insgesamt machen diese eine ebenso umfangreiche Erneuerung aus wie die fünfzehn Jahre zuvor, als die Vorschriften über die bedingten Strafen sowie gewisse Vorschriften über die Bestimmung der Geldstrafe geändert wurden und die Vorschriften über den Rückfall durch die Regulierung der Strafzumessung ersetzt wurden. ${ }^{29}$

29 Siehe dazu Lahti: Criminal Sanctions in Finland: A System in Transition. Scandinavian Studies in Law 1977, S. 119-157 (148-151). 
Es sind somit gute Voraussetzungen dafür gegeben, die Praxis der Bestimmung der Sanktionen in der Weise zu ändern, daß die kriminalpolitischen Ausgangspunkte der Gesamtreform des Strafgesetzes und die Teilreformen, die auf diesen beruhen und diese zum Teil auch modifizieren, berücksichtigt werden. Dies ist wichtig, da die das gesamte Sanktionensystem umfassende Reform noch einige Jahre lang ausstehen wird. Wie aus dem Obengesagten hervorgeht, wird sich von den vom Strafrechtskomitee vorgebrachten Zielen des Sanktionensystems vor allem das Bestreben, die Anwendung der unbedingten Freiheitsstrafe einzuschränken, in mehreren Teilreformen verwirklichen. Auf der anderen Seite hat die vom selben Komitee vertretene Forderung nach einem Sanktionensystem, das möglichst eng am Prinzip der Angemessenheit und Gleichheit festhält, den übrigen Aspekten in gewissem Maße nachgeben müssen.

\section{3. Über die strafprozeßrechtlichen Veränderungen}

a) In der die erste Phase der Strafgesetzreform betreffenden Regierungsvorlage wird konstatiert, daß die Reform Wirkungen hervorbringen würde, wie sie mit dem Zwangsmittelgesetz (450/87) verbunden sind. Der Ausgangspunkt war, daß die strafprozeßrechtlichen Normen den Voraussetzungen des Strafrechts angepaßt werden: die die Zwangsmittel betreffenden Gesetze sind also so abzufassen, daß sie zweckmäßigerweise auf die zu untersuchenden Delikte anwendbar sind (siehe auch oben III.3.a). ${ }^{\mathbf{3 0}}$ Auf der anderen Seite sind zusammen mit der Reform - aus schwerwiegenden Gründen der Ermittlung - in einige Vorschriften des Zwangsmittelgesetzes auch solche Delikte einbezogen worden, deren Strafrahmen nach der Normalregel nicht zur Auslösung der Anwendung von Zwangsmitteln ausreichen.

Die beiderseitige Wechselwirkung zwischen dem Straf- und dem Strafprozeßrecht wird in den Begründungen zu dem Gesetz in der Überlegung darüber ersichtlich, ob die Höchststrafe für die Grundtatform des Diebstahls auf ein Jahr oder auf anderthalb Jahre Gefängnis herabzusetzen sei. Daß man sich für die letztere Alternative entschieden hat, darauf hatte die normale Voraussetzung des Zwangsmittelgesetzes betreffend das Festnahme- und Verhaftungsrecht einen Einfluß, nach der die Höchststrafe für das zu untersuchende Delikt mehr als ein Jahr Gefängnis sein muß.

b) Ein zweiter mit der besagten Reform eng zusammenhängender Vorschriftenkomplex ist die Regelung des Anklagerechts. Die kriminalpolitisch relevanteste Frage betrifft den Bereich der Antragsdelikte. Nach Ansicht des

30 Siehe Regierungsvorlage Nr. 66/1988, bes. S. 18 und 21-22. 
Gesetzausschusses des Reichstags sollten vor allem relativ geringfügige Eigentumsdelikte sowie solche Delikte, bei denen eine Gerichtsverhandlung für den Verletzten unbillige Nachteile mit sich bringen würde, Antragsdelikte sein. Geringfügige Delikte sollten möglichst weitgehend den Parteien selbst zur Schlichtung überlassen werden. ${ }^{31}$

Zum Teil in Folge der noch im Reichstag vorgenommenen Änderungen teilen sich die in der Reform behandelten Delikte vom Standpunkt des Anklagerechts in drei Gruppen auf: Die Zahl der sog. reinen Antragsdelikte nahm etwas zu, zum Beispiel geringfügiger Betrug (StG 36:3 und 8.1). Die Zahl solcher Mischtyp-Delikte, die an sich Antragsdelikte sind, aber ausnahmsweise - wenn ein wichtiges öffentliches Interesse es erfordert - der Offizialverfolgung unterstellt werden, nahm erheblich zu; zum Beispiel geringfügiger Diebstahl, geringfügige Unterschlagung und unbefugter Gebrauch (StG 28:3,6-9 und 15.1). Die dritte Gruppe, d.h. die ausschließlich der Offizialverfolgung unterliegenden Delikte, blieb weiterhin die größte Gruppe. Zu bemerken ist, daß grobe Sachbeschädigung (StG 35:2) der Offizialverfolgung unterstellt wurde. In Anbetracht des Obengesagten ist es inkonsequent, daß selbst ein geringfügiger Zahlungsmittelbetrug (StG 37:10) ausnahmslos ein Offizialdelikt darstellt.

Im Gesetzausschuß wurde die Stellung einer speziellen Überwachungsbehörde, des Verbraucherschutzbeauftragen, bei der Behandlung von Vermarktungsoder Wettbewerbsverfahrensdelikten erörtert. Die Tendenz der Reform geht dahin, die Verfolgung der Delikte nicht mehr so stark an die Stellungnahme des Verbraucherschutzbeauftragen zu binden, wenn auch die Wichtigkeit der Kooperation der Behörden und die Erstrangigkeit der vom Verbraucherschutzbeauftragten verordneten Maßnahmen hinsichtlich der Bestrafung nach wie vor anerkannt wird (siehe oben III.2.b). ${ }^{\mathbf{3 2}}$

c) Der Vorschriftenkomplex über das Absehen von strafrechtlicher Verfolgung steht in einem engen Zusammenhang zum Strafprozeßrecht, und die Erweiterung seines Geltungsbereichs hat einen bedeutenden Einfluß auf die kriminalpolitische Rolle des Staatsanwalts und trägt zur Differenzierung des strafrechtlichen Systems bei (siehe oben III.3.c).

Die zur Zeit betriebene Strafgesetzreform hat auch unmittelbare Einflüsse auf das Prozessverfahren ausgeübt: Das Gesetz über die in Sitzungen mit einem Richter zu verhandelten Strafsachen (1026/88) ist erweitert worden und betrifft nun auch solche Delikte, für die keine strengere Strafe als Geldstrafe oder

31 Bericht des Gesetzausschusses Nr. 6/1990, S. 5-6.

32 Bericht des Gesetzausschusses S. 12 und 19-20. 
Gefängnis von maximal einem Jahr und sechs Monaten (1109/90) bestimmt worden ist. Das Gesetz über den Strafbefehl (146/70) gilt nun unter gewissen Voraussetzungen auch für Antragsdelikte (1108/90). 


\section{Die jüngsten Entwicklungen im finnischen Strafrecht*}

\section{Einleitung}

Die dreißigjährige Gesamtrevision des finnischen Strafgesetzbuchs (das aus dem Jahre 1889 stammt) wurde im Jahre 2003 in ihren wesentlichen Teilen abgeschlossen. ${ }^{1}$ Sie wurde auf der Grundlage des Berichts des Strafrechtskomitees (1972-1976) eingeleitet und in den Jahren 1980-1999 von einer besonderen Projektgruppe des Justizministeriums vorbereitet. Anlässlich des Abschlusses der Gesamtreform sollen im Folgenden die neuesten Entwicklungstendenzen im finnischen Strafrecht und in der Strafrechtsdogmatik aufgezeigt und analysiert werden. Hierbei werden einige aktuelle Fragen des Allgemeinen Teils - der Zurechnungslehre - im erneuerten Strafgesetzbuch (StGB) näher behandelt werden.

Die Gesamtreform des finnischen StGB ist durch Teilrevisionen verwirklicht geworden. Ihr Schwerpunkt lag auf den Deliktstatbeständen, d.h. dem Besonderen Teil des Strafrechts. Besonders umfangreich waren die 1991 und 1995 in Kraft getretenen Änderungen des Besonderen Teils und vieler Nebengesetze. ${ }^{2}$ Im Jahre 1995 trat auch eine in prinzipieller Hinsicht wichtige Neuheit in

* Revidierte Fassung des auf dem internationalen Symposium „Estnische Strafrechtsreform und neues Strafrecht im europäischen Vergleich“, 10.-11.10.2002, Tartu (Estland), gehaltenen Vortrags.

1 Über die Reformarbeit siehe näher P. Koskinen, Strafrechtsentwicklung in Finnland: Zielsetzung und Stand, in: A. Eser / K. Cornils (Hrsg.), Neuere Tendenzen der Kriminalpolitik, 1987, S. 83 ff.; R. Lahti, Die Gesamtreform des finnischen Strafgesetzes: Zielsetzung und Stand der Reformarbeit bis 1991 - insbesondere mit Blick auf die erste Phase der Gesamtreform, in: R. Lahti / K. Nuotio (Hrsg.), Criminal Law Theory in Transition - Strafrechtstheorie im Umbruch, Helsinki 1992, S. 27 ff.; Ders., Recodifying the Finnish Criminal Code of 1889, Israel Law Review 1993, vol. 27, 100 ff.; siehe auch Ders., Die finnische Strafrechtstheorie im Umbruch, in: J. Sootak (Hrsg.), Estnische Strafrechtsreform: Quellen und Perspektiven, Tartu 1996, S. 34 ff. - Zur Strafrechtsentwicklung ab den achtziger Jahren siehe auch die Landesberichte Finnland in: A. Eser / B. Huber (Hrsg.), Strafrechtsentwicklung in Europa 2, 1988 ff.; zuletzt: Dan Frände / A. M. Nuutila, Strafrechtsentwicklung in Europa 5, Bd. S 62.1, 1997, S. $359 \mathrm{ff}$.

2 Gesetzessammlung 769-834/1990 und 578-742/1995. 
Kraft: die strafrechtliche Verantwortlichkeit von juristischen Personen wurde eingeführt. ${ }^{3}$ Wichtige Reformen des strafrechtlichen Sanktionensystems begannen schon in den 70er Jahren. In diesen Reformen spiegelte sich eine neue kriminalpolitische Denkweise, der sog. nordische Neoklassizismus, wider. ${ }^{4}$ Als letzte Phase sind nun die Gesetzesänderungen zur Reform der allgemeinen Lehren des Strafrechts (Zurechnungs- und Strafbemessungslehre) am 13. Juni 2003 vom Staatspräsidenten unterzeichnet worden; die neuen Bestimmungen treten zum 1. Januar 2004 in Kraft. ${ }^{5}$ Danach bleiben nur noch Kleinigkeiten zu tun. Es besteht die Absicht, zum Abschluss der Gesamtreform ein förmliches neues StGB zu erlassen. ${ }^{6}$

\section{Zu den Ausgangspunkten der finnischen Strafgesetzreform und deren Wirkungen - Das strafrechtliche Sanktionensystem}

$\mathrm{Zu}$ den kriminalpolitischen Ausgangspunkten der Strafgesetzreform gehören der begründete Glaube an die generalpräventiven Wirkungen (besonders die sog. Integrationsprävention) des Strafrechts und des gesamten strafrechtlichen Kontrollsystems sowie die Betonung der Prinzipien der Gerechtigkeit und Humanität dieses Systems. Diese Ausgangspunkte haben die Reformierung des strafrechtlichen Sanktionensystems und die Kriminalisierungsprinzipien (die Reform des Besonderen Teils des StGB) am stärksten beeinflusst.

3 Gesetzessammlung 743-747/1995.

4 Siehe näher z.B. R. Lahti, Zur Entwicklung der Kriminalpolitik in Finnland, in: Festschrift for Jescheck, 1985, S. 871 ff.; Ders., Towards a Rational and Humane Criminal Policy - Trends in Scandinavian Penal Thinking, Journal of Scandinavian Studies in Criminology and Crime Prevention 2000, vol. 1, 141 ff.; I. Anttila, Ad ius criminale humanius. Essays in Criminology, Criminal Justice and Criminal Policy, Helsinki 2001, passim; Eser / Cornils (Hrsg.), (Anm. 1), passim.

5 Gesetzessammlung 515-540/2003.

6 In diesem Zusammenhang sei das Internationale Forschungskolloquium „Finnisches Strafgesetz 100 Jahre“ erwähnt, das 1990 an der Universität Helsinki veranstaltet wurde. Ein Ziel des Kolloquiums war es, die vorläufigen Entwürfe zu den Bestimmungen über den Allgemeinen Teil des StGB zu erörtern. Das gesamte Material des Kolloquiums wurde in drei Bänden $(1990,1992)$ publiziert. Einige Änderungen, die man vor den endgültigen Formulierungen vornahm, wurden schon in den kritischen Kommentaren des Kolloquiums befürwortet. Siehe dazu Lahti / Nuotio (Hrsg.), (Anm. 1); R. Lahti / K. Nuotio (eds.), Towards a Total Reform of Finnish Criminal Law, Helsinki 1990; $R$. Lahti / K. Nuotio / P. Minkkinen (Hrsg.), Criminal Policy and Sentencing in Transition - Kriminalpolitik und Strafzumessung im Umbruch, Helsinki 1992. - Eine inoffizielle englische Übersetzung des Strafgesetzbuchs ist durch das Justizministerium erhältlich (Adresse: https://.finlex.fi/fi/laki/kaannokset/1889/en18890039_20150766.pdf). 
Die erwähnten Ausgangspunkte waren schon für den „Neoklassizismus“ typisch, dessen Blütezeit in die zweite Hälfte der 1970er Jahre fiel. Konkrete Reformvorschläge richteten sich dabei am stärksten auf die Reduzierung der Häftlingszahlen; man wollte sowohl die durchschnittliche Länge der Freiheitsstrafen verkürzen (insbesondere für die wegen Vermögensdelikten Verurteilten) als auch Alternativen zur Freiheitsstrafe entwickeln (wie die Reformen der bedingten Verurteilung und der Geldstrafe). Finnland unterschied sich damals von den übrigen nordischen Ländern dadurch, dass es hier mit über 100 Häftlingen pro 100.000 Einwohnern proportional gesehen deutlich mehr Strafgefangene als anderswo gab. Seit Mitte der 1970er Jahre bis 1999 wurde diese Zahl fortwährend herabgesetzt und liegt gegenwärtig bei ungefähr 70 Strafgefangenen - ähnlich wie in den anderen nordischen Ländern. ${ }^{7}$

Seit Beginn der 1990er Jahre zeigen die Änderungen des strafrechtlichen Sanktionensystems eine gemäßigte Erweiterung des individualisierenden Ermessens von Gericht oder Staatsanwaltschaft. So wurde z.B. der Bereich des Absehens von strafrechtlicher Verfolgung und Verurteilung erheblich erweitert, und die Leistung gemeinnütziger Dienste wurde - zuerst probeweise - als Sanktion in Gebrauch genommen. In dieselbe Richtung zielte die Änderung der Gesetze über das Zusammentreffen mehrerer Straftaten. Hierbei wurde von der Differenzierung der Formen der Straftatenkonkurrenz bei der Verhängung einer Strafe für zwei oder mehrere Delikte Abstand genommen und zu dem sog. „Einheitsstrafensystem“ übergegangen, bei dem für die Delikte von Anfang an nur eine gemeinsame Strafe verhängt wird. Ziel der neuesten Reform vor einigen Jahren war es, eine besondere Jugendstrafe für (zur Tatzeit) 15 - bis 17 jährige Rechtsbrecher probeweise einzuführen. ${ }^{8}$

7 Siehe näher z.B. P Törnudd, Fifteen Years of Decreasing Prisoner Rates in Finland. National Research Institute of Legal Policy, Helsinki 1993; R. Lahti, Neoklassizismus und danach, in: Festschrift für Günther Kaiser, 1998, S. 873 ff.; T. Lappi-Seppälä, Proportionality and other Values in the Finnish Sentencing System, in: Flores juris et legum festskrift till Nils Jareborg, Uppsala 2002, S. 401 ff.; Ders., Das Proportionalitätsprinzip in der finnischen Strafzumessungspraxis, in: W. Frisch / A. v. Hirsch / H.-J. Albrecht (Hrsg.), Tatproportionalität. Buchenbach-Symposium 1999, 2003, S. 261 ff.

$8 \mathrm{Zu}$ dieser Entwicklung siehe näher z.B. T. Lappi-Seppälä, Alternative Penal Sanctions, in: A. Suviranta (ed.), Finnish National Reports to the Fourteenth Congress of the International Academy of Comparative Law, Helsinki 1994, S. 197 ff.; Ders., in: Flores juris et legum (Anm. 7). 


\section{III. Über die Kriminalisierungsprinzipien und die Grenzen des Strafrechts: kriminalpolitische Zweckmäßigkeit versus rechtsstaatliche Prinzipien}

Im Zentrum der Gesamtreform des StGB stehen die Kriminalisierungen, also die besonderen Tatbestände des Strafrechts und damit die Frage der umfassenden und einheitlichen Beurteilung dessen, was zu bestrafen ist und mit wie strengen Strafen. Das Strafrechtskomitee (1976) benutzte für die Erwägung der Kriminalisierungen ein besonderes Denkmodell. Neben der Evaluierung der Nachteile und Vorwerfbarkeit (Strafwürdigkeit) der betreffenden Verhaltensformen ist mit Hilfe von systematischen Vorteilsvergleichen abzuwägen, ob Bedarf besteht, auf das Strafrecht zurückzugreifen (Strafbedürftigkeit).

Trotz der letztgenannten Forderung, nach der das Strafrecht eine ultima ratio sein sollte, ist es das vorrangige Ziel der finnischen Reformarbeit gewesen, die Strafvorschriften der gesellschaftlichen Entwicklung anzupassen, d.h. das Strafrecht dynamisch weiter zu entwickeln. Kennzeichnende Beispiele hierfür sind die Erweiterung der vom Strafrecht geschützten Rechtsgüter in Richtung auf die kollektiven und staatlichen Interessen besonders durch Strafbestimmungen, welche die wirtschaftliche Tätigkeit betreffen (Wirtschafts- und Umweltkriminalität), sowie die Ausdehnung der strafrechtlichen Gefährdungshaftung, insbesondere durch zunehmende Kriminalisierung der sog. abstrakten Gefährdung von Rechtsgütern.

In der strafrechtstheoretischen Diskussion ist diese Entwicklung kritisiert worden. Beispielsweise sprechen der Strafrechtslehrer und Verfassungsrichter Winfried Hassemer von wesentlichen Nachteilen des symbolischen Strafrechts ${ }^{9}$ und der Schwede Nils Jareborg von den Nachteilen der offensiven Anwendung des Strafrechts. ${ }^{10}$ Die Grenzen des Strafrechts sollten dieser Kritik zufolge ernsthaft anerkannt werden.

In der finnischen Debatte wurden als verteidigende Argumente für die offizielle Kriminalpolitik u a. folgende Gesichtspunkte vorgebracht: Erstens seien der erweiterte strafrechtliche Schutz der gemeinschaftlichen Interessen und die Ausdehnung der strafrechtlichen Gefährdungshaftung recht moderat - zumin-

9 Siehe W. Hassemer, Symbolisches Strafrecht und Rechtsgüterschutz, NStZ 1989, 553 ff.; Ders., Kennzeichen und Krisen des modernen Strafrechts, in: Lahti / Nuotio (Hrsg.), (Anm. 1), S. $113 \mathrm{ff}$.

10 N. Jareborg, What kind of criminal law do we want? in: A. Snare (ed.), Beware of Punishment, Oslo 1995, S. 17 ff. 
dest im Vergleich zu denkbaren extremen Alternativen. ${ }^{\mathbf{1 1}}$ Zweitens habe man das Strafrecht niemals nur als symbolische Gesetzgebung gedacht, obgleich die Symbolfunktion wichtig sei. Man müsse die den neuen Strafbestimmungen entsprechende materielle Gesetzgebung ergänzen sowie gleichzeitig die Prävention, Kontrolle und Ermittlung der neu geregelten Delikte verbessern.

Drittens seien die Rechtsschutz- und Menschenrechtsgarantien für Individuen im Hinblick auf das strafrechtliche Kontrollsystem (das materielle Recht sowie das Verfahren) am weitesten entwickelt. Die Abgrenzung der zulässigen Zwangsmaßnahmen in anderen Rechtsgebieten sei viel schwieriger und unklarer.

Viertens sei die Bedeutung der grundlegenden rechtsstaatlichen Prinzipien des Strafrechts, d.h. des Gesetzlichkeitsprinzips und des Schuldprinzips, durch die gesamte finnische Reformarbeit verstärkt worden. Zudem sei bei der Änderung des finnischen Grundgesetzes $(1995,1999)$ das strafrechtliche Gesetzlichkeitsprinzip den neu geregelten Grundrechten hinzugefügt worden.

Aus der Sicht des Gesetzlichkeitsprinzips ist auch die Anforderung bemerkenswert, dass der Gesetzestext so einheitlich (konsequent), verständlich und exakt wie möglich sein sollte. Der Ermessensspielraum der Gerichte bei der Anwendung der Strafbestimmungen ist dadurch begrenzt worden, dass es nach der Gesamtreform eine geringere Zahl von Strafrahmen und im Allgemeinen enger umgrenzte Strafrahmen gibt als zuvor. Ebenso werden die Strafschärfungsgründe bei qualifizierten Tatbeständen jetzt erschöpfend aufgezählt.

Schwieriger zu werten ist, in welcher Hinsicht die Akzentuierung des Schuldprinzips wahrnehmbar ist, bringt doch die Einführung der strafrechtlichen Verantwortung von juristischen Personen eine gewisse Schwächung des traditionellen individuellen Schuldprinzips mit sich (siehe unten IV).

Einen Indikator für die Verstärkung des Schuldprinzips in der Gesamtreform kann man darin sehen, dass für die Zurechenbarkeit eine Regel eingeführt wurde, der zufolge die im StGB bezeichneten Taten nur im Falle des Vorsatzes strafbar sind, sofern nicht expressis verbis etwas anderes bestimmt ist. Z.B. sind seit der ersten Phase der Strafgesetzreform (1990), die vor allem die Vermögens- und Wirtschaftsdelikte betraf, die unter Strafe gestellten Taten mit einigen wenigen Ausnahmen - nur als vorsätzlich begangene Taten strafbar. Dagegen ist bei vielen der in der zweiten Phase (1995) geregelten Gefährdungsdelikte - wie die Umwelt- und gemeingefährlichen Delikte - auch (grobe) Fahrlässigkeit strafbar.

11 Siehe auch K. Nuotio, Kausalität und Gefährdung - theoretische und gesetzgebungstechnische Fragen, in: Sootak (Hrsg.), (Anm. 1), S. 44 ff. 
Ein anderes Zeichen für die Betonung des Schuldprinzips - und auch des Gesetzlichkeitsprinzips - ist die neue Regelung, in der die Begriffe des Vorsatzes und der Fahrlässigkeit sowie die Irrtumsfälle und Entschuldigungsgründe im Allgemeinen Teil des StGB definiert worden sind. ${ }^{\mathbf{1 2}}$ Die Formulierung von $\S 2$ (Verbotsirrtum), $\S 4$ Abs. 2 (Notwehrexzess), § 5 Abs. 2 (entschuldigender Notstand) und $\S 6$ Abs. 3 (Exzess in der Anwendung von Gewaltmitteln) im 4. Kapitel macht klar, dass diese Strafausschließungsgründe Entschuldigungsgründe sind. Die Differenzierung zwischen den Rechtfertigungs- und Entschuldigungsgründen spiegelt somit die Unterscheidung von Rechtswidrigkeit und Schuld im angenommenen Verbrechensbegriff wider. Im Gegensatz zum Vorentwurf wurden die Bestimmungen über ein programmatisches Schuldprinzip und über einen allgemeinen Exkulpationsgrund der Unzumutbarkeit (,Zwingende Gründe“) in der Regierungsvorlage fallengelassen. $^{13}$

\section{IV. Über die Regelung der strafrechtlichen Verantwortung juristischer Personen ${ }^{14}$}

Die grundlegenden Vorschriften über die strafrechtliche Verantwortung juristischer Personen finden sich im 9. Kapitel des reformierten StGB (743/1995). Zunächst einmal ist mit dem Verantwortungsobjekt eine Körperschaft, Stiftung oder sonstige juristische Person gemeint.

Als Sanktion für die Straftat kommt nur eine gemeinschaftliche Geldstrafe in Frage. Juristische Personen zur strafrechtlichen Verantwortung zu ziehen ist nur dann möglich, wenn dies im StGB bei dem jeweiligen Deliktstyp gesondert vorgesehen ist. Solche Deliktstypen sind typischerweise Wirtschaftsdelikte wie Gewerbedelikte, Subventionsdelikte, Geldwäschedelikte und Umweltdelikte.

Als zweite Grundvoraussetzung für die gemeinschaftliche Verantwortung gilt, dass eine Straftat im Rahmen der Tätigkeit der juristischen Person begangen wurde. Diese Verantwortungsform entfällt jedoch, wenn das Delikt bei der Ausübung öffentlicher Gewalt begangen wurde. Das Delikt gilt als im Rahmen der Tätigkeit der juristischen Person begangen, wenn der Täter im Auftrag

12 Siehe Kap. $3 \S \S 6-7$ und Kap. $4 \S \S 1-3$, 4 Abs. 2, § 5 Abs. 2, § 6 Abs. 3.

13 Die erwähnten Lösungen entsprechen den Vorschlägen von C. Roxin, in: Lahti / Nuotio (Hrsg.), (Anm. 1).

14 Siehe dazu M. Riihijärvi, The Criminal Liability of Enterprises, in: Suviranta (ed.), (Anm. 8), S. 159 ff.; D. Frände, Kommentar, in: H. J. Hirsch (Hrsg.), Krise des Strafrechts und der Kriminalwissenschaften? 2001, S. 228 ff. 
oder zu Gunsten der juristischen Person gehandelt hat, wenn er der Leitung der juristischen Person angehört oder zu dieser in einem Angestellten- oder Dienstverhältnis steht oder wenn er aufgrund eines Auftrags gehandelt hat, den er von einem Vertreter der juristischen Person erhalten hat. Es ist jedoch nicht unbedingt notwendig, dass ein solcher individueller Täter ermittelt oder bestraft wird. Die strafrechtliche Verantwortung des Individuums für im Auftrag oder zu Gunsten der juristischen Person begangener Delikte (d.h. die Organ- oder Vertreterhaftung) bleibt parallel zur Verantwortung der juristischen Person bestehen.

Zum Dritten setzt die gemeinschaftliche Verantwortung eine gemeinschaftliche Schuld voraus. Eine zu einem gesetzmäßigen Organ oder zur sonstigen Leitung der juristischen Person gehörende Person muss an der Straftat beteiligt sein oder die Tat zugelassen haben, außer wenn denn im Rahmen der Tätigkeit der juristischen Person nicht die notwendige Sorgfalt und Vorsicht zur Verhütung der Straftat gewahrt wurde.

Die Zurechnungsstruktur dieser neuen Bestrafungsform ist nicht ganz klar. In erster Linie denkt man, dass die juristische Person aufgrund der Tat eines individuellen (in Ausnahmefällen auch anonymen) Täters bestraft wird, aber andererseits ist in der Regelung eine gewisse kollektive, „gemeinschaftliche“ Schuld oder Zurechenbarkeit erkennbar.

Zum Vierten liegt die Strafverfolgung sowie die Bestrafung der juristischen Person im weiten Ermessen der Strafverfolgungsbehörden und Gerichte. Diese Regelung führte dazu, dass während der ersten sieben Jahre ihrer Geltung nur ungefähr zehn Fälle in den unteren Gerichten behandelt worden sind. Die strafrechtliche Verantwortung stellt also vorwiegend eine symbolische gesetzliche Regelung dar. Mit einer neuen Gesetzesänderung (61/2003), die den Ermessensspielraum für die Bestrafung vermindert, wird nunmehr angestrebt, die Zahl der Strafverfolgungen zu steigern.

\section{$V$. Die allgemeinen Lehren in der Strafrechtserneuerung}

Die allgemeinen Lehren des Strafrechts - wie die Zurechnungslehre, d.h. die Lehre der allgemeinen Voraussetzungen der strafrechtlichen Verantwortung als Strafbemessungslehre - werden im neuen Allgemeinen Teil (2003) des StGB detaillierter geregelt als im ursprünglichen StGB. ${ }^{15}$ Dadurch entspricht die gesetzgeberische Lösung dem, was Keiichi Yamanaka als ein ,positivisti-

15 Siehe schon den Überblick von T. Lappi-Seppälä, The Doctrine of Criminal Liability and the Draft Criminal Code of Finland, in: Lahti / Nuotio (Hrsg.), (Anm.1), S. 214 ff. 
sches Regelungs-Modell“" bezeichnet. ${ }^{16}$ Als Gründe werden die dem Legalitätsprinzip zugrunde liegenden Werte, die Förderung der Vorhersehbarkeit und der Rechtssicherheit hervorgehoben.

$\mathrm{Ob}$ diese gesetzliche Regelung mehr zum Strafbarkeitsausdehnungsmodell oder zum Strafbarkeitsreduzierungsmodell neigt, ist nicht leicht zu entscheiden. Im Allgemeinen strebt man nach den Vorarbeiten zu der Regelung nicht in die eine oder die andere Richtung, obgleich mehrere neue Bestimmungen so ausgelegt werden können. Zum ersten Modell würden dann die neuen Bestimmungen über die Strafbarkeit der Unterlassung (Kap. 3 § 3), die mittelbare Täterschaft (Kap. 5 § 4) und die Organ- oder Vertreterhaftung („Handeln für einen anderen“, Kap. 5 § 8) gerechnet. In die andere Richtung wird die Anwendung der folgenden neuen Bestimmungen wirken: des Legalitätsprinzips (Kap. $3 \S 1$, in dem jetzt ein verstärktes Bestimmtheitsgebot ausgedrückt ist), des Prinzips der Zurechenbarkeit (Kap. $3 \S 5$ Abs. 2, wonach eine im StGB bezeichnete Tat nur im Falle des Vorsatzes bestraft wird, sofern nicht etwas anderes bestimmt ist) sowie der Regelung des Verbotsirrtums und des Irrtums über einen strafausschließenden Umstand (Kap. 4 § 2-3).

Welche Forderungen wurden an die Begriffs- und Systembildung des neuen Strafrechts gestellt? ${ }^{17}$ Zuerst ist die Bestrebung zu erwähnen, sich mit den neuen Bestimmungen nicht einer bestimmten theoretischen Schule zu verpflichten. An dieser Forderung festzuhalten, war jedoch nicht möglich, wenn man z.B. an die angenommenen Legaldefinitionen des Vorsatzes oder des Verbotsirrtums denkt.

Die größten wissenschaftlichen Meinungsverschiedenheiten während der Vorbereitungsarbeit betrafen die Definition des niedrigsten Grades des Vorsatzes (Kap. 3 § 6). Sollte man der Wahrscheinlichkeitstheorie folgen - wie in der Regierungsvorlage Nr. 44/2002 - oder zusätzlich einer Version der modernen Willenstheorien - wie noch im Vorentwurf? Die Rechtspraxis des Obersten Gerichtshofs scheint zumindest bei Tötungsfällen zur Anwendung der Wahrscheinlichkeitstheorie zu neigen, offensichtlich weil diese Theorie (u.a. vom beweisrechtlichen Standpunkt aus) pragmatischer als die anderen empfunden wird. In der Praxis ist das Bild jedoch nicht einheitlich, wenn man auch andere

16 Siehe K Yamanaka, Dogmatische Grunderfordernisse eines Allgemeinen Teils aus japanischer Sicht, in: Hirsch (Hrsg.), (Anm. 14), S. 181.

17 Siehe schon $R$. Lahti, Neues in der finnischen Strafrechtswissenschaft und in den allgemeinen Lehren des finnischen Strafrechts, ZStW 103 (1991), S. 529. 
Straftatbestände berücksichtigt, und die Doktrin ist in dieser Frage diffus. ${ }^{\mathbf{1 8}}$ Die endgültige Lösung des Parlaments war, diese Grenzziehung etwas offener für verschiedene Interpretationen zu lassen als die Regierungsvorlage, weil die Legaldefinition den Vorsatz nur im Hinblick auf den tatbestandsmäßigen Erfolg bestimmt; der Vorsatz im Hinblick auf die Tatumstände muss zunächst auf der Grundlage der Bestimmung über den Tatbestandsirrtum (Kap. $4 \S 1$ ) bestimmt werden.

Interessant aus strafrechtsideologischer Sicht ist bei der Argumentation des Strafrechtskomitees, wie in dessen Bericht (1976) die straftheoretischen und kriminalpolitischen Verbindungen der allgemeinen Lehren betont werden. Beispielsweise werden die Grundprinzipien des Strafrechts - das Gesetzlichkeits- und Schuldprinzip - vorrangig mit der Rechtssicherheit oder mit dieser eng verbundenen Werten, aber auch mit Zweckmäßigkeitsargumenten bezüglich der Generalprävention (im Sinne der Integrationsprävention) begründet.

Man kann fragen, ob sich in dieser Argumentation die Annahme eines funktionalistischen Rechtsdenkens - im Gegensatz zum ,,alteuropäischen“ Prinzipiendenken - ausdrückt. ${ }^{19}$ Ich möchte die Bedeutung dieser Gegenüberstellung mindern und stattdessen eine Verbindung zwischen dem wohlfahrtsstaatlichen und dem rechtsstaatlichen Strafrecht aufbauen und meinen früheren Standpunkt wiederholen:

Alle Voraussetzungen der strafrechtlichen Verantwortlichkeit sind in der Weise aufzubauen, dass gewährleistet ist, dass die individuelle Zurechnung nicht zu ungerecht empfundenen Resultaten führt, dass für die Zurechnung auch präventive Gesichtspunkte eine Rolle spielen und dass bei der strafrechtlichen Zurechnung Raum für Entscheidungen verbleibt, die sich an Billigkeit und Humanität orientieren (die Achtung der Menschenrechte inbegriffen). ${ }^{\mathbf{2 0}}$

Bei der Vorbereitungsarbeit war man sich deutlich des Zusammenhangs zwischen der Struktur und Funktion des strafrechtlichen Systems und der Kriminalpolitik / Moral bewusst. Andererseits sind die Bestimmungen des Allgemeinen Teils meistens in traditioneller Weise an rechtsstaatliche Prinzipien gebunden. Die Modelle der Neuformulierungen stammen zunächst aus

18 Siehe zur Diskussion u.a. Lappi-Seppälä (Anm. 15), S. 229 ff.; J. Matikkala, Über den bedingten Vorsatz, in: Lahti / Nuotio (Hrsg.), (Anm. 1), S. 415 ff.; A.-M. Nuutila, Report, in: Lahti / Nuotio / Minkkinen (Hrsg.), (Anm. 6), S. 245.

19 Vgl. insbesondere B. Schünemann, Kritische Anmerkungen zur geistigen Situation der deutschen Strafrechtswissenschaft, GA 1995, 201 ff., sowie G. Jakobs und K. Lüderssen, Das Strafrecht zwischen Funktionalismus und ,alteuropäischem“ Prinzipiendenken, ZStW 107 (1995), S. 843 ff., 877 ff.

20 Lahti (Anm. 17), S. 539. 
den deutschsprachigen Ländern (vor allem aus Deutschland) und den anderen nordischen Ländern (vor allem Schweden). Die wichtigsten Modifizierungen dieser relativ traditionellen Regelung, welche eingefügt wurden, um den modernen Kriminalitätsformen $\mathrm{zu}$ begegnen, betreffen die strafrechtliche Verantwortung von juristischen Personen und die Organ- oder Vertreterhaftung.

\section{Anforderungen an die Strafrechtslehre}

Die Strafrechtsreform stellt die traditionellen allgemeinen Lehren auf die Probe. Darum ist es wichtig, die dogmatischen Grunderfordernisse (Begriffe, Rechtsprinzipien und Theorien) einer gründlichen juristischen Analyse zu unterziehen. So gibt etwa die Gefährdungshaftung, die vielen Kriminalisierungen eigen ist, Veranlassung zu einer Neubewertung der Begriffe der Gefahr und des Risikos sowie zu einer Bestimmung ihres Inhalts in einer von den neuen Strafvorschriften geforderten Weise. ${ }^{21}$

Als zweites Beispiel eignen sich die im Bereich juristischer Personen begangenen Delikte. Die neuen Bestimmungen über die Organ- oder Vertreterhaftung sowie die Einführung der strafrechtlichen Verantwortung juristischer Personen erzeugen Bedarf zur Entwicklung einer entsprechenden Doktrin.

Drittens stellen die neuen Vorschriften über die Wirtschaftsdelikte sowie die Arbeits- und Umweltdelikte neue Herausforderungen an die strafrechtswissenschaftliche Systematisierungs- und Auslegungsarbeit.

In den letzten zehn Jahren hat sich eine starke Entwicklung in der finnischen Strafrechtsdogmatik vollzogen. Seit Mitte der 1990er Jahre sind zwei strafrechtstheoretisch wichtige Dissertationen ${ }^{22}$ und neue Lehrbücher über die allgemeinen Lehren des Strafrechts erschienen. ${ }^{23}$ In diesen Werken ist die neueste Entwicklung der modernen deutschen und nordischen Strafrechtsdogmatik in weitem Umfang berücksichtigt worden. Besonders wichtig war der Einfluss des deutschen Strafrechtlers Claus Roxin und des schwedischen Strafrechtlers Nils Jareborg. Die Titel der zwei genannten Doktorarbeiten zeigen, dass der Schwerpunkt der neuen Strafrechtstheorie in der Entwicklung

21 Siehe näher Nuotio, in: Sootak (Hrsg.), (Anm. 1).

22 Siehe A.-M. Nuutila, Rikosoikeudellinen huolimattomuus (Fahrlässigkeit als Verhaltensform und als Schuldform), Helsinki 1996; K. Nuotio, Teko, vaara, seuraus (Handlung, Gefahr, Erfolg), Helsinki 1998.

23 D. Frände, Allmän straffrätt. En introduktion, Helsingfors 1994 (2. Aufl. 2001); A.-M. Nuutila, Rikoslain yleinen osa, Helsinki 1997; O. Heinonen u.a., Rikosoikeus, Helsinki 1999 (2. Aufl. 2002). 
der Rechtsdogmatik von Fahrlässigkeits- und Gefährdungsdelikten liegt. In beiden Werken wird die Spannung zwischen den wohlfahrtsstaatlichen und den liberalen rechtsstaatlichen Rechtsentwicklungen und -ideologien analysiert.

\section{Zur Internationalisierung und Europäisierung des Strafrechts; Schlussbemerkungen}

Die Tendenz zur wachsenden Internationalisierung und Europäisierung des Strafrechts wurde in der Gesamtreform des finnischen StGB nicht klar reflektiert, obgleich gewisse Teilrevisionen aufgrund dieser Verpflichtungen erfolgten. Der einzige Hinweis auf diese internationalen Verpflichtungen, den man in der Regierungsvorlage zur Reform der allgemeinen Lehren des Strafrechts findet, betrifft den Befehl des Vorgesetzten (Kap. 45 § 26b).

Es ist offensichtlich, dass in einer zukunftsorientierten Reformarbeit die verstärkte Bestrebung zur Harmonisierung des europäischen Strafrechts nicht mehr außer Acht gelassen werden kann. ${ }^{24}$ Gewisse ,,alteuropäische“ Prinzipien - wie das Gesetzlichkeitsprinzip, das Schuldprinzip und das Verhältnismäßigkeitsprinzip - werden sich als Grundlage des modernen rechtsstaatlichen Strafrechts allerdings erhalten. ${ }^{25}$ Joachim Vogel sieht in der Strafrechtsentwicklung mit Recht solche Erscheinungen wie Rechtspluralismus und Interlegalität und spricht sich für Methodenoffenheit und den Vorrang des Problemdenkens vor dem Systemdenken in der europäischen Kriminalpolitik und Strafrechtsdogmatik aus. ${ }^{\mathbf{2 6}}$

Gerade um wissenschaftliche Diskussionen über die gesamteuropäischen kriminalpolitischen und strafrechtlichen Prinzipien zu fördern, sind internationale Forschungsveranstaltungen äußerst wichtig. Die strafrechtsvergleichenden Studien und überhaupt die Rolle der Kriminalwissenschaften werden immer wichtiger, um gesetzgeberische Lösungen für die Harmonisierungsmaßnahmen des europäischen Strafrechts $\mathrm{zu}$ finden, die weithin als legitim angesehen werden.

24 Siehe näher z.B. R. Lahti, Towards an International and European Criminal Policy? In: M. Tupamäki (ed.), Liber Amicorum Bengt Broms, Helsinki 1999, S. 222 ff.; J. Vogel, Europäische Kriminalpolitik - europäische Strafrechtsdogmatik, GA 2002, 517 ff.

25 Siehe z.B. M. Delmas-Marty (Hrsg.), Corpus Juris der strafrechtlichen Regelungen zum Schutz der finanziellen Interessen der Europäischen Union, 1998 (Ausgangspunkte; S. 30); M. Delmas-Marty /J. A. E. Vervaele (eds.), The Implementation of the Corpus Juris in the Member States, vol. 1, Antwerpen 2000.

$26 \operatorname{Vogel}$ (Anm. 24), S. 522. 



\section{Das strafrechtliche Sanktionensystem in der Gesamtreform des Strafrechts. Erfahrungen mit den finnischen Strafgesetzreformen 1972-2007}

\section{Einführung}

Das strafrechtliche Sanktionensystem stellt neben der Straftatlehre ein zweites Hauptgebiet der Allgemeinen Lehren des Strafrechts dar. Die Gesamtreform des finnischen Strafrechts wurde im Jahre 1972 eingeleitet, als ein Strafrechtskomitee ${ }^{1}$ eingesetzt wurde. In der Endphase der Reform wurde das wichtige Gesetzespaket über die Allgemeinen Lehren des Strafrechtes im Jahre 2003 angenommen, und zum 1. Januar 2004 trat es in Kraft. Bei dieser Gesamtreform wurde das Hauptaugenmerk auf den Besonderen Teil des Strafrechtes gerichtet, d.h. auf die Beurteilung der Strafbarkeit (,wofür wird bestraft und wie streng?"). Das strafrechtliche Sanktionensystem ist in Teilreformen seit den 70er Jahren reformiert worden, und zwar ohne umfangreiche Gesetzespakete. Bei der Reform des Jahres 2003 (GBl. 515/2003) ist bezüglich des Sanktionensystems von Bedeutung, dass über die Verhängung von Strafen und die Strafzumessung einheitliche Rechtsvorschriften erlassen und dass die diesbezüglichen Vorschriften in ein Kapitel des Strafgesetzbuches (StGB Kapitel 6) gestellt wurden. ${ }^{2}$

In diesem Artikel möchte ich einen Blick auf die Linie der Reformierung des strafrechtlichen Sanktionensystems und auf einzelne Gesetzesänderungen in den letzten 35 Jahren werfen. Ich beurteile dabei die Auswirkungen der Reformen des Sanktionensystems und bringe kritische Gesichtspunkte zur Überprüfung der Kriminal- und Sanktionspolitik sowie zur Weiterentwicklung

1 Komiteebericht 1976:72

2 Siehe jetzt: Das Finnische Strafgesetz (nach dem Stand vom 1.10.2005). Übersetzung und Einführung von K. Cornils, D. Frände und J. Matikkala, Max-Planck-Institut für ausländisches und internationales Strafrecht 2006. Zum Hintergrund siehe vor allem R. Lahti \& K. Nuotio (Hrsg.), Criminal Law Theory in Transition - Strafrechtstheorie im Umbruch, Helsinki 1992, passim. 
des Systems vor. ${ }^{3}$ Zugleich ist es mein Ziel, der gemeineuropäischen Diskussion über diesen Themenbereich Anstöße zu geben.

\section{Die strafrechtsideologischen Ausgangspunkte: das humane neoklassizistische Strafrecht}

Bei den Plänen zur Reformierung des Sanktionensystems hat der Bericht des Strafrechtskomitees weitgehend die Gedankengänge widergespiegelt, die sich bereits auf die vorangegangenen Teilreformen ausgewirkt hatten. Inkeri Anttila und Patrik Törnudd haben bei der Herausbildung des neuen Strafrechtsdenkens eine zentrale Rolle gespielt. ${ }^{4}$ Anttila hatte schon vor dem Erscheinen des besagten Berichts in ihren Schriften eine kritische Einstellung zur Behandlungsideologie bezogen und sich für alternative Mittel der Kriminalpolitik ausgesprochen. Des Weiteren hat sie das von ihr vertretene neue kriminalpolitische Denken zum einen als eine Rückkehr zum neoklassizistischen Strafrecht bezeichnet, bei dem die Aufgabe der Strafe als Vorwurf und die Verhängung von übermäßig strengen Strafen vermieden wird, und zum anderen als ein Kosten-Nutzen-Bewusstsein bei der Ausrichtung der Tadelressourcen der Gesellschaft. Derartige Ziele und Werte sind zentral für eine Kriminalpolitik, die als rational und human charakterisiert worden ist; Rationalität bedeutet in diesem Zusammenhang Bewusstsein über Wirkungen, Werte und Alternativen.

Die erste bedeutende Maßnahme, die aus dem neuen Strafrechtsdenken erwuchs, war im Jahre 1971 die Reformierung der Gesetzgebung über die Isolierung der Gefangenen in einer Zwangsanstalt (GB1. 303/1971). Im darauf folgenden Jahr wurden die Vorschriften über die Eigentumsdelikte (GB1. 498/1972) erneuert, wobei u.a. angestrebt wurde, den Strafrahmen für

3 Ich führe in diesem Artikel die Entwicklung des Themas fort, das ich unter der Überschrift „Neoklassizismus und danach. Zur neuesten Entwicklung der finnischen Kriminalpolitik“ behandelt habe. In: Festschrift für Günther Kaiser, Duncker \& Humblot 1998, S. 873-883. Siehe auch R. Lahti, Criminal Sanctions in Finland, Scandinavian Studies in Law, Vol. 21 (1977), S. 119-157; R. Lahti, Über die neueste Strafrechtsentwicklung in Finnland, Juridica international VIII, 2003, S. 62-67; R. Lahti, Zur Kriminal- und Strafrechtspolitik des 21. Jahrhunderts, in: Festschrift für Albin Eser, C.H. Beck 2005, S. 1393-1408; T. Lappi-Seppälä, Penal Policy and Prisoner Rates in Scandinavia, in: Festschrift in Honour of Raimo Lahti, University of Helsinki 2007, S. 265-306; K. Nuotio, The Rationale of the Nordic Penal Policy compared with the European Approach, in: Festschrift in Honour of Raimo Lahti, S. 157-174.

4 Siehe von ihren wichtigsten Artikeln die Schriftensammlungen P. Törnudd, Facts, Values and Visions, National Research Institute of Legal Policy 1996, und I. Anttila, Ad ius criminale humanius, Finnish Lawyers' Association 2001. Siehe auch I. Anttila, Neue Tendenzen der Kriminalpolitik in Skandinavien, ZStW 95 (1983), S. 739-748. 
Diebstahl und schweren Diebstahl herabzusetzen sowie die Verhängung von unbedingten Freiheitsstrafen zu reduzieren. Zur selben Zeit war ein so genanntes Kriminalfürsorgekomitee ${ }^{5}$ tätig, dessen prinzipielle Erwägungen über die strafrechtlichen Sanktionen einen maßgeblichen Einfluss auf die spätere Entwicklung ausgeübt haben. In dem Bericht dieses Komitees empfiehlt man, die Zwangs- bzw. Kontrollfunktionen von denen der Entlassenenfürsorge zu trennen, man vergleicht systematisch die Vorteile der Freiheitsstrafen mit denen der Kriminalsanktionen ohne Freiheitsentziehung und spricht sich schließlich dafür aus, den Anwendungsbereich der letztgenannten Sanktionen zu erweitern.

Die wesentliche Phase im Wandel des Sanktionensystems trat in der Mitte der siebziger Jahre ein. Die Vorschriften betreffend die bedingte Bestrafung und einige Vorschriften betreffend die Verhängung von Geldstrafen wurden geändert (GBl. 135/1976 und 650/1976), und die Bestimmungen betreffend Rückfalltäter wurden durch Strafzumessungsvorschriften ersetzt (StGB Kap. 6, GBl. 466/1976). Die zwei erstgenannten Gesetzesänderungen wurden mit einer Erneuerung der Vorschriften betreffend die Trunkenheit am Steuer (StGB Kap. 23, GBl. 960/1976) verknüpft, da man der Ansicht war, auf diese Weise hinsichtlich der Generalprävention effektivere strafrechtliche Mittel zur Bekämpfung dieser in der Praxis gewöhnlichen Straftaten zu schaffen.

Ein kennzeichnender Zug der erläuterten Gesetzesreformen war es, auf Kosten der Spezialprävention, d.h. der Individualisierung der Strafen, die generalpräventive Wirkung des strafrechtlichen Systems zu betonen. Als einschränkendes Prinzip für die Anwendung der bedingten Strafe wurde außerdem die Aufrechterhaltung der allgemeinen Gesetzestreue bestimmt. Was die Wirkungsweisen der Generalprävention angeht, so wurde das Augenmerk auf mehrere gerichtet: vor allem auf das Risiko, gefasst zu werden, auf die Kenntnis der Normen sowie auf die Funktion der Strafe als Ausdruck der Missbilligung. Man war bestrebt, den allgemeinen Strafrahmen herabzusetzen und auch sonst das Sanktionensystem zu humanisieren, wenn auch einzelne Maßnahmen durchgeführt wurden, durch die die Strafen strenger gestaltet wurden (die Erhöhung des Tagessatzes bei Geldstrafen, die Einführung einer begleitenden Geldstrafe zur Effektivierung bedingter Strafen und die Bestimmung der Gründe für härtere Strafen). Neben der Generalprävention wurde auch der Gedanke der Gerechtigkeit der Strafe betont: Die Anwendung des Strafrechtes sollte voraussagbar und gleich sein, und Unbilligkeiten

5 Komiteebericht 1972: A 1. 
sollten vermieden werden. Diese Grundsätze gehen deutlich aus dem Kapitel 6 des Strafgesetzbuchs über die Strafzumessung hervor. ${ }^{6}$

Diese Prinzipien eines „humanen, neoklassizistischen Strafrechtes“ wurden vom Strafrechtskomitee auch als Richtlinien für die zukünftige Reformierung des Sanktionensystems bestätigt. ${ }^{7}$ Zunächst einmal wird in dem Bericht des Komitees die Kriminalpolitik eng mit der sonstigen Gesellschaftspolitik verbunden und die Begrenztheit des strafrechtlichen Systems im Vergleich zu den sonstigen Mitteln der Vorbeugung und Kontrolle betont, wenn es darum geht, unerwünschte Erscheinungen zu bekämpfen und auf das Verhalten von Individuen einzuwirken. Die Bedeutung der Generalprävention des Sanktionensystems wird zwar betont, aber ihre einseitige Verknüpfung mit der Strenge der Strafe wird abgelehnt. Der Einschätzung des Komitees zufolge hat die Strenge der Strafen nur eine relativ geringe Auswirkung auf die Gesamtkriminalität. Das strafrechtliche Sanktionensystem sollte einfach und deutlich umrissen sein, auch wenn man sich Alternativen zur Freiheitsstrafe wünschte.

Die Anforderungen, die an die Strafen und allgemein an die aufgrund von Straftaten zu verhängenden Sanktionen zu stellen sind, waren laut dem Strafrechtskomitee die folgenden: Die Sanktionen dürften nicht grausam sein und weder das Gleichheits- noch das Proportionalitätsprinzip verletzen; sie dürften sich nur gegen den Straftäter richten; dem Straftäter dürften keine unnötigen Leiden zugefügt werden; die Strafen dürfen nicht zu unkontrollierbaren Kumulierungen führen, und das Sanktionensystem müsse wirtschaftlich sein. Die Strafen, die über das Individuum verhängt werden können, seien die Freiheitsstrafe (auch unter Beibehaltung der bedingten Strafe) und die Geldstrafe sowie als neue Straftypen die Führungsaufsicht und die Strafverwarnung. Außerdem wurde gefordert, die strafrechtliche Verantwortlichkeit von juristischen Personen einzuführen, und die Straftypen, die auf diese Anwendung finden könnten, wären die Körperschaftsgeldstrafe und die Strafverwarnung.

In erster Linie ist es den oben erläuterten Veränderungen in der Strafgesetzgebung - der rationalen und humanen Kriminalpolitik - zuzuschreiben, dass die Anwendung der Freiheitsstrafe in dem Zeitraum von 1976 bis 1999 abnahm. In Folge dieser Entwicklung, die 1976 begann, ist die durchschnittliche Zahl der Gefangenen in Finnland von 5.600 (d.h. von 188 je 100000 Einwohner)

6 Siehe näher T. Lappi-Seppälä, Das Proportionalitätsprinzip in der finnischen Strafzumessungspraxis, in: W. Frisch \& A. von Hirsch \& H.-J. Albrecht (Hrsg.), Tatproportionalität, C. F. Müller 2003, S. 261-287.

7 Siehe zum folgenden Komiteebericht 1976:72, besonders das Kapitel V. 
fast gleichmäßig innerhalb von zwanzig Jahren auf 3.500 (d.h. auf etwa 60-65 je 100000 Einwohner) gesunken. Ebenso hat die Zahl der auf unbedingte Freiheitsstrafe lautenden Urteile abgenommen und entsprach dem Stand in den übrigen nordischen Ländern Diese Entwicklung hat sich vollzogen, ohne dass die vom Strafrechtskomitee gewünschten neuen Alternativen zur Freiheitsstrafe in Gebrauch genommen worden wären bzw. ohne dass diese eine wesentliche Auswirkung auf die Zahl der Gefangenen gehabt hätten. ${ }^{8}$ - Vor der Spezifizierung der Auswirkung der Veränderung in der Zahl der Gefangenen und der sonstigen Auswirkungen der Reformen sind diejenigen Gesetzesänderungen zu betrachten, die als Teil der Gesamtreform der Strafgesetzgebung durchgeführt worden sind. Danach ist die jüngste Entwicklung zu beurteilen, bei der die kriminalpolitischen Einstellungen sich verschärft haben und die Anwendung von Freiheitsstrafen erneut zugenommen hat.

\section{Die Gesamtreform des Strafrechts und die Änderungen des Sanktionensystems: Weiterführung einer pragmatisch- rationalen Kriminalpolitik}

Die mit der Gesamtreform der Strafgesetzgebung zusammenhängenden Änderungen des Sanktionensystems haben sich als pragmatisch-rationale Realisierung des im vorigen Abschnitt erläuterten Strafrechtsdenkens erwiesen, ohne dass diese Ausgangspunkte neu durchdacht worden wären. Die ersten Änderungen des Sanktionensystems, die von der im Jahre 1980 eingesetzten Projektorganisation, dem sog. Strafrechtsprojekt, ausgearbeitet worden waren, betrafen die Entwicklung von Alternativen zur Freiheitsstrafe. Zeitgleich mit der ersten Phase des Projekts (GB1. 769-834/1990), die sich auf den Besonderen Teil des Strafrechts konzentrierte, traten auch die erneuerten Vorschriften über das Absehen von Strafe und Strafverfolgung (GBl. 300303/1990) und das Gesetz über die Erprobung der gemeinnützigen Arbeit (GBl. 1105/1990) in Kraft.

Die erstgenannten Vorschriften hatten mehrere Ziele: die Berücksichtigung des Wertes der Billigkeit (,equity“) der Straffolgen; die Ermöglichung von sonstigen Formen und Maßnahmen der offiziellen Kontrolle (in erster Linie der Sozialfürsorge) anstelle der Anklageerhebung; die Abstufung des Sanktionensystems sowie die zweckmäßige Ausrichtung der Ressourcen des strafrechtlichen Systems (,,minima non curat praetor“). In den Vorarbeiten zu den Vorschriften wird erwähnt, dass von Verfolgung abgesehen werden könne,

8 Siehe näher über die Entwicklung und deren Erklärung T. Lappi-Seppälä, in: Festschrift in Honour of Raimo Lahti (Fn. 3), S. 265-298. 
wenn sich der Täter darum bemüht hat, die Wirkungen seiner Straftat abzuwehren, und dass in einem solchen Fall der Täter-Opfer-Ausgleich angewendet werden könne. Das Strafrechtsprojekt hat hierzu an sich eine positive Stellung bezogen, auch wenn man meinte, dass dieses Mittel nicht als eine bedeutende Alternative zur Freiheitsstrafe anzusehen sei. Eine auf Freiwilligkeit der Parteien basierende Täter-Opfer-Ausgleichstätigkeit wurde im Rahmen eines Forschungsprojekts im Jahre 1983 in der Stadt Vantaa begonnen. ${ }^{9}$ Ein einheitliches Gesetz über den Täter-Opfer-Ausgleich bei Strafsachen sowie über die Schlichtung bei bestimmten Zivilsachen - mit weitem Anwendungsbereich - wurde erst im Jahre 2005 erlassen (GBl. 1015/2005).

Die versuchsweise Ingebrauchnahme der gemeinnützigen Arbeit („,community service") wurde mit praktischen Aspekten begründet, mit anderen Worten: damit würde man ein zentrales Ziel der Gesamtreform des Strafrechtes fördern: die Reduzierung der Anwendung der Freiheitsstrafe. Die neue Sanktionsart würde außerdem die Möglichkeit des zu dieser Sanktion verurteilten Straftäters verbessern, sich wieder in die Gesellschaft zu integrieren, und seine eigene Verantwortung betonen. Zudem hätten die Gerichte eine größere Auswahlmöglichkeit, wenn eine Sanktionsform zur Verfügung stünde, die sich hinsichtlich ihrer Strenge zwischen der bedingten und der unbedingten Freiheitsstrafe platzieren würde. Die gemeinnützige Arbeit, die vom Delinquenten während seiner Freizeit unentgeltlich abzuleisten ist, wurde als Ersatz für eine höchstens achtmonatige unbedingte Freiheitsstrafe bestimmt. ${ }^{10}$ Mit einem 1996 erlassenen Gesetz wurde die gemeinnützige Arbeit als eine strafrechtliche Sanktionsart etabliert (GBl. 1055/1996), und dabei wurden auch die Voraussetzungen für die Verhängung dieser Sanktion präzisiert (siehe die Paragraphen 3-4 des Gesetzes). Außer der Anforderung bezüglich der Höchstdauer der Strafe gelten als formelle Voraussetzungen die Einwilligung der zu verurteilenden Person zum gemeinnützigen Dienst und ihre Eignung hierfür. Eine materielle einschränkende Voraussetzung besteht in dem Ermessen des Gerichtes darüber, ob unbedingte Freiheitsstrafen, frühere Verurteilungen $\mathrm{zu}$ gemeinnütziger Arbeit oder sonstige schwerwiegende Gründe die Anwendung dieser Sanktion verhindern.

9 Siehe J. Iivari, The Process of Mediation in Finland, in: H. Messmer \& H.-U. Otto (eds.), Restorative Justice on Trial, Kluwer 1992, S. 137-147; T. Lappi-Seppälä, Finland, in: A. Eser \& S. Walther (Hrsg.), Wiedergutmachung im Kriminalrecht - Reparation in Criminal Law, Max-Planck-Institut für ausländisches und internationales Strafrecht, Band 1, 1996, S. 317-420.

10 Siehe J.-P. Takala, Responses in Finland to Community Sanctions, in: M. Davies \& J.P. Takala \& J. Tyrer, Penological Esperanto and Sentencing Parochialism, Dartmouth 1996, S. $110 \mathrm{ff}$. 
Im Jahre 1992 trat die Reform der Gesetzgebung über das Zusammentreffen mehrerer Straftaten (GBl. 697-710/1991) in Kraft, deren Ausarbeitung in die frühen siebziger Jahre zurückgeht. Mit der Reform ging man zum so genannten Einheitsstrafensystem über, dessen Grundgedanke darin besteht, dass für mehrere Straftaten eine gemeinsame Strafe verhängt wird. Zugleich wurde der Ermessensspielraum der Gerichte bei der Entscheidung darüber, ob bedingte Strafen zu vollstrecken sind, wesentlich vergrößert mit dem Ziel, die Kumulierung von Strafen zu unangemessen langen Freiheitsstrafen zu vermeiden. Die Regelung der so genannten Nachkonkurrenz ${ }^{11}$ im Kapitel 7 des Strafgesetzbuches wurde im Jahre 1997 reformiert (GBl. 751/1997; siehe auch GBl. $515 / 2003$ und $1195 / 2004)$.

Die Gesetzesänderungen, die im Rahmen der Strafrechtsreform im Besonderen Teil verwirklicht wurden - wie in der ersten und zweiten Phase der Reform (GB1. 769-834/1990 ja 578-747/1995) - haben sich auch auf das Sanktionensystem ausgewirkt. Vor allem die Festsetzung der Strafandrohungen und Strafrahmen sowie die Abstufung der Straftaten nach ihrer Schwere und die Art und Weise der Bestimmung von speziellen Tatbeständen bei Taten desselben Grundtyps (schwere und geringfügige Tatformen) sind in dieser Hinsicht von Bedeutung. $\mathrm{Zu}$ einer Herabsetzung des Strafrahmens haben vor allem die Gesetzesänderungen beigetragen, die dies ausdrücklich zum Ziel gehabt haben, wobei gerade die Mindeststrafen herabgesetzt wurden und die Anwendung von strengeren Strafvorschriften aufgrund erschöpfender Aufzählungen der qualifizierenden Umstände ausgeschlossen wurde.

Das Ermessen darüber, Sanktionen zu verhängen, ist in zunehmendem Maße auch anderen Rechtspflegeorganen als den Gerichten übertragen worden. Neben der Erweiterung des Bereichs des Absehens von Strafverfolgung und Strafanzeige ist in dem neuen Gesetz über das Strafbefehlsverfahren (GBl. 692/1993) dem Staatsanwalt bei der Sanktionierung von Kleindelikten rechtsprechende Gewalt eingeräumt worden. Ein spürbares administratives Bußgeld - die Buße für Wettbewerbsverstöße - ist gemäß dem Vorbild des Wettbewerbsrechts der Europäischen Gemeinschaft in einem Gesetz über die Wettbewerbseinschränkungen (GBl. 480/1992) in Gebrauch genommen worden. Im Zusammenhang mit der zweiten Phase der Gesamtreform des Strafrechtes ist auch die strafrechtliche Verantwortlichkeit der juristischen Person (StGB Kap. 9, GBl. 743/1995) eingeführt worden, und als Strafe wird die so genannte Körperschaftsstrafe verhängt.

11 Es geht um die Frage, wie man eine früher verhängte Strafe berücksichtigt. 
Mit diversen Gesetzesänderungen wurde die Jugendstrafe in Gebrauch genommen, und zwar zunächst versuchsweise (GBl. 1058/1996) und später permanent (GBl. 1196/2004). ${ }^{12}$ Desgleichen sind die Rechtsvorschriften betreffend die folgenden strafrechtlichen Sanktionen erneuert worden: die Geldstrafe, die Ersatzfreiheitsstrafe und die Geldbuße (GB1. 550/1999), die bedingte Freiheitsstrafe (GBl. 520/2001) und die Einziehung als Rechtsfolge (GB1. 875/2001). Die Beendigung des Strafrechtsprojekts im Jahre 1999 bedeutete, dass mehrere Reformen des Sanktionensystems nicht mehr zu einer endgültigen Form ausgearbeitet werden konnten. Noch auf der letzten Versammlung der Leitungsgruppe des Strafrechtsprojektes am 31. März 1999 wurde über grundlegende Fragen der Reformierung des Sanktionensystems diskutiert.

In dem Memorandum, das ich für diese letzte Versammlung verfasst hatte, war ich der Ansicht, dass, da das neoklassizistische Strafrechtsdenken schon vor allem durch die Einführung der Sanktionen der gemeinnützigen Arbeit und der Jugendstrafe modifiziert worden war, es nun nötig gewesen wäre, die allgemeineren Auswirkungen des Wandels in diesem Denken auf die Beziehung zwischen den Sanktionstypen untereinander und auf die Ausformulierung des sachlichen Inhalts ihrer Anwendungsvoraussetzungen zu evaluieren. Eine solche Neubeurteilung war jedoch im Rahmen der Arbeit des Strafrechtsprojekts nicht mehr möglich. So wurde die weitere Ausarbeitung der Reformen betreffend die Freiheitsstrafe und ihre Vollstreckung sowie die bedingte Entlassung, die Jugendkriminalrechtspflege ebenso wie die vertragsmäßige Behandlung als Strafe speziellen Organen anvertraut, und die diese betreffenden legislativen Vorschläge sind samt den dazu fertig gestellten Berichten beim Justizministerium zur Erwägung eingereicht worden. ${ }^{13}$ Der neueste Vorschlag betrifft die elektronische Überwachung, die als Alternative für eine höchstens viermonatige unbedingte Freiheitsstrafe in Betracht käme. ${ }^{14}$

12 Zur Beurteilung dieses Straftyps und der gesamten Jugendkriminalrechtspflege siehe T. Harrikari, The juvenile justice system in Finland, in: V. Patanè (ed.), European Juvenile Justice Systems, Milano 2007, S. 95-116; M. Marttunen, Juvenile Criminal Justice, Summary of Publication no. 236 of the National Research Institute of Legal Policy 2008, S. 451-464. Zur früheren Situation siehe R. Lahti, Freiheitsstrafe und Jugendgefängnis in Finnland, in: F. Dünkel \& K. Meyer (Hrsg.), Jugendstrafe und Jugendstrafvollzug, Teilband 1, Max-Planck-Institut für ausländisches und internationales Strafrecht 1985, S. 425-461.

13 Siehe Bericht des Freiheitsstrafe-Komitees 2001:6; Bericht der so genannten Vertragsbehandlungs-Kommission 2002:3; Bericht der Jugendkriminalrechtspflege-Kommission 2003:2.

14 Siehe Arbeitsgruppenbericht des Justizministeriums 2007:17. 
Am 1. Oktobere 2006 trat ein umfangreiches Gesetzreformpaket betreffend die Freiheitsstrafe und ihre Vollstreckung sowie die bedingte Entlassung in Kraft (GBl. 767-782/2005). Dabei behielt man unter anderem die frühere Regulierung der bedingten Entlassung von zu zeitlicher Freiheitsstrafe Verurteilten (von 14 Tagen bis zu 12 Jahren oder bei der Kumulierung von Strafen bis zu 15 Jahren) bei: die regelmäßige bedingte Entlassung erfolgt nach Verbüßung von zwei Dritteln der Freiheitsstrafe oder bei Ersttätern unter dem Aspekt der Gefangenenfürsorge nach Verbüßung der Hälfte der Freiheitsstrafe. Bei Verurteilten, die zum Zeitpunkt der Begehung der Straftat unter 21 Jahre alt gewesen sind, betragen die entsprechenden Zeiten die Hälfte und ein Drittel. Neu an der Reform der Vorschriften über die Freiheitsstrafen war zudem, dass eine entsprechende Entlassungsprozedur auch für Langzeitgefangene festgesetzt wurde, so für zu lebenslanger Freiheitsstrafe Verurteilte, die mindestens zwölf Jahre ihrer Strafe verbüßt haben, und für Gefangene, die dazu verurteilt worden sind, die gesamte Strafe zu verbüßen, also nach der früheren Terminologie für in einer Zwangsanstalt zu Isolierende, wenn mindestens fünf Sechstel der Strafe verbüßt sind. Der allgemeine Zug der Reform bestand darin, die Stellung und die Rechte der Gefangenen in einer Weise zu verbessern, wie die Reform der finnischen Grundrechte es voraussetzte.

Bei der die allgemeinen Lehren des Strafrechts betreffenden Reform (GBl. 515/2003) war es das Ziel gewesen, diejenigen Prinzipien und Kriterien, die sich auf die Dauer und die Art der Strafe auswirken, in dem Strafgesetzbuch zu einer logische Gesamtheit zusammenzustellen, mit der man bessere Voraussetzungen für eine Vereinheitlichung der Strafpraxis hätte. Bezüglich der Änderungen, die an den Vorschriften über die Bestimmung der Strafe vorzunehmen wären, war man der Ansicht, dass deren kriminalpolitische Bedeutung gering sei. Man hatte nicht die Absicht, auf das allgemeine Strafniveau oder auf die Beziehungen der für verschiedene Straftaten zu verhängenden Strafen untereinander einzuwirken. ${ }^{15}$ Aus dieser Zielsetzung geht die recht begrenzte Aufgabe hervor, die der letzten Phase der Reform auferlegt worden war.

\section{Beurteilung der Entwicklungslinien und Reformen des Sanktionensystems nach der Verschärfung der kriminalpolitischen Einstellungen seit 2000}

Oben, am Ende des Abschnitts 2, hatte ich erwähnt, dass die Reform des Sanktionensystems sich dahingehend ausgewirkt hat, dass die Zahl der Ge-

15 Siehe Regierungsvorlage 44/2002, Allgemeine Begründungen, Abschnitt 3.1. 
fangenen in Finnland gesunken ist. Diese Wirkung ist vor dem Hintergrund der allgemeinen Ziele und Werte der seinerzeit angenommenen Kriminal- und Sanktionspolitik zu beurteilen: Wie gut ist es gelungen, die Nachteile, die sich aus der Kriminalität und ihrer Kontrolle ergeben, zu minimieren und gerecht zu verteilen, und wie hat man dadurch eine rationale und humane Kriminalpolitik fördern können? ${ }^{16}$ Ein zentrales Kriterium für die Beschlussfassung ist die Wirkung der Abnahme der Gefangenenzahl auf die Entwicklung der Kriminalität, da man mit dem Strafsystem letztendlich die Verhütung von Straftaten (vor allem die Generalprävention) sowie die Verbesserung der Sicherheit für die Gesellschaft und ihre Mitglieder anstrebt. Wenn man die Gefangenenzahlen in den nordischen Ländern und die Zahl der Straftaten, die der Polizei zur Kenntnis gekommen sind, in den Jahren 1950-2005 miteinander vergleicht, so ist die Entwicklung der letztgenannten Zahl in den verschiedenen Ländern weitgehend ähnlich verlaufen, und zwar trotz unterschiedlicher Kurven in der Zahl der Gefangenen. Zusammen mit den übrigen kriminologischen Erkenntnissen spricht diese Beobachtung gegen die Auffassung, dass eine Senkung der Gefangenenzahl entsprechend zu einem Anwachsen der Kriminalität führen würde. ${ }^{17}$

Die Schwankungen in der Gefangenenzahl Finnlands sollte man also nicht als eine von der übrigen Entwicklung losgelöste Erscheinung betrachten, und die Entwicklung der Kriminalpolitik, die gegen Ende der 60er Jahre begann und bis in die 90er Jahre hinein anhielt, darf man nicht als ein strafrechtsideologisches Aktionsprogramm sehen, das nur von einer bestimmten Gruppe von Sachverständigen vorangetrieben wurde. Tapio Lappi-Seppälä, der diese Frage eingehender untersucht hat, hat den engen Zusammenhang der Kriminalpolitik mit der allgemeinen gesellschaftlichen und gesellschaftspolitischen Entwicklung betont, zum Beispiel die Verknüpfung des humanen neoklassizistischen Strafrechtsdenkens zur Zeit seiner Entstehung mit dem Modell des nordischen Wohlfahrtsstaates, das damals in Finnland stärkere Unterstützung gewann. ${ }^{18}$

$16 \mathrm{Zu}$ den genannten Zielen der Kriminalpolitik sowie den Anforderungen an das strafrechtliche System siehe R. Lahti, Zur Entwicklung der Kriminalpolitik in Finnland, in: Festschrift für Hans-Heinrich Jescheck, Duncker \& Humblot 1985, S. 871892 (884-885).

17 Siehe besonders T. Lappi-Seppälä, in: Festschrift in Honour Raimo Lahti (Fn. 3), S. 273-274.

18 Siehe T. Lappi-Seppälä, in: Festschrift in Honour of Raimo Lahti (Fn. 3), insbesondere S. 294-298, wo er die Wechselwirkungen zwischen den sozialen, politischen, ökonomischen und kulturellen Faktoren sowie die Erklärungskraft dieser Faktoren erörtert. 
Nach 1999 hat die Anwendung der Freiheitsstrafe wieder zugenommen, so dass man von der niedrigsten Zahl (durchschnittlich unter 3000 Gefangene) wieder auf eine Zahl von beinahe 4000 Gefangenen im Jahre 2005 (das heißt auf 70-75 Gefangene je 100.000 Einwohner) gekommen ist. Die Erklärung hierfür liegt erstrangig in der Verschärfung der kriminalpolitischen Einstellungen, und zwar u.a. unter dem Einfluss der Medien und einiger kriminalpolitischer Entscheidungsträger sowie durch einzelne Gesetzesänderungen und die Verschärfung der Strafpraxis, die diesem Trend nachzukommen versuchten. Die Veränderungen, die sich in der Kriminalität vollzogen haben, stellen keine hinreichende Erklärung dar; die Gründe sind vielmehr in der Aufweichung der Strukturen des Wohlfahrtsstaates und der Verhärtung der gesellschaftlichen Werte zu suchen. In den jüngsten Planungsdokumenten des Justizministeriums wird hingegen wieder die Wichtigkeit einer rationalen und humanen Kriminalpolitik als eines für den Wohlfahrtsstaat eigenen Charakteristikums betont.

\section{Zur Neubewertung der strafrechtlichen Sanktionenpolitik}

In welchem Maße besteht bei den Ansätzen der aus den siebziger Jahren stammenden Strafrechtsideologie ein Bedarf an neuer Beurteilung, und wie hat die Gesamtreform des Strafrechts diesem Bedarf entsprochen? Meine Kritik richtet sich darauf, dass man in der Endphase der Gesamtreform der Strafgesetzgebung als Fundament zur Entwicklung des Sanktionensystems kein ausreichend logisch und einheitlich konstruiertes Gedankengebäude gehabt hat, nachdem man in Finnland neuartige, individuell zu verhängende Sanktionsarten (gemeinnützige Arbeit, Täter-Opfer-Ausgleich, Jugendstrafe, elektronische Kontrolle, Vertragsbehandlung) eingeführt hat bzw. dabei ist, diese einzuführen. Eine vielleicht noch größere Auswirkung hat der Umstand gehabt, dass gegen Ende der 90er Jahre einzelne Maßnahmen zur Verschärfung des Strafsystems punktuell und sozusagen „schleichend“ verwirklicht wurden.

Die Ziele und Werte, von denen das Sanktionensystem gesteuert wird, sowie die konkreten Interessen und Prinzipien sollte man in regelmäßigen Abständen gründlich evaluieren, vor allem da die europäische und internationale Entwicklung dabei ist, den Bedarf einer derartigen Neubewertung zu beschleunigen. Ein auf einer solchen Neubewertung beruhendes, vom theoretischen und praktischen Standpunkt her begründetes logisches Gedankengebäude bzw. System kann dazu beitragen, die Gesetzgebungs- und Rechtsprechungsentscheidungen $\mathrm{zu}$ rationalisieren und $\mathrm{zu}$ vereinheitlichen und 
wahrscheinlich auch den Umstand zu fördern, das die Strafrechtspflege als gerecht und annehmbar (legitim) empfunden wird.

Man sollte die im Kapitel 6 des Strafgesetzbuchs (515/2003) bezeichneten, bei der Verhängung einer Strafe anzuwenden Grundsätze neu überdenken, und zwar deswegen, weil die Bemessung der Strafe und die Wahl der Strafart darin einheitlicher geregelt sind und weil die bei der Erwägung zu berücksichtigenden Prinzipien weiter gefasst worden sind (vgl. besonders StGB Kap. 6 $\S 3$ Abs. 3 sowie die $\S \S 6-7)$. Wie sollten die bei der Verhängung einer Strafe zu berücksichtigenden Gerechtigkeitsprinzipien (Proportionalität, Gleichheit und Vorhersehbarkeit) und die Aspekte der Billigkeit mit den Aspekten der Zweckmäßigkeit und Prävention vereinbart werden, die auf dieses Ermessen gleichfalls unabdingbar einwirken? Welchen Einfluss auf das Ermessen haben der Charakter des Strafrechtes als ultima ratio sowie die Anforderung, die auf den Prinzipien der (prospektiven) Verhältnismäßigkeit ${ }^{19}$ und der Humanität basieren, dass stets die mildestmögliche Sanktionsalternative zu wählen sei? In dem neueren kriminologischen und kriminalpolitischen Denken finden die Theorien des Kommunitarismus und Republikanismus Unterstützung, in denen die Gemeinschaftlichkeit und die Bedeutung der Wiedergutmachung im Kriminalrecht und die Restitution statt der Retribution hervorgehoben werden. ${ }^{20}$ Andererseits bestehen weltweit Tendenzen zu erhöhter Retribution (,punitiveness“) ${ }^{21}$ Wie sollten diese theoretische Diskussionen in der kriminalpolitischen Beschlussfassung berücksichtigt und die gegenseitigen Ziele und Werte ausbalanciert werden?

Außer der Klärung dieser Fragen benötigen wir zur Förderung der Einheitlichkeit der Strafpraxis mehr detaillierte Forschungsresultate und vielleicht auch von den Richtern selbst formulierten Richtlinien für Strafbemessung. Die Begründungen der Strafurteile bei den Fragen der Verhängung von Strafen sind konsequent weiterzuentwickeln, unter anderem damit solche Urteile „kommunikativ“ wirken, überzeugend sind und als berechtigt empfunden werden. ${ }^{22}$

19 Über die Trennung der retrospektiven (strafrechtlichen) Proportionalität und der prospektiven (administrativen) Proportionalität siehe P. Asp, Two Notions of Proportionality, in: Festschrift in Honour of Raimo Lahti (Fn. 3), S. 207-219.

20 Zur reichen Literatur siehe u.a. J. Dignan, Understanding victims and restorative justice, Open University Press 2005.

21 Siehe besonders J. Pratt et al. (eds.), The New Punitiveness, Willan Publishing 2005.

22 R.A. Duff hat eine den besagten Aspekt betonende kommunikative Straftheorie entwickelt: Punishment, Communication and Community, Oxford University Press 2000, passim. 


\section{Die Herausforderungen, die von der Internationalisierung und der Europäisierung des Strafrechts gestellt werden}

Es ist auch am Platze, die beschriebene Entwicklung auch vor dem Hintergrund der internationalen und gemeineuropäischen Trends zu beurteilen. Man muss in der Lage sein, in anderen Ländern getroffene strafrechtsphilosophische und kriminalpolitische Entscheidungen kritisch $\mathrm{zu}$ evaluieren und aus ihnen die Denkweisen zu eruieren, die zu dem jeweiligen Gesellschaftsmodell und zur jeweiligen Rechtskultur unter den gewandelten Verhältnissen am besten passen. ${ }^{23}$

Eine besondere Herausforderung besteht darin, auf die kriminalpolitische Entwicklung, die sich in der Europäischen Union (EU) und in anderen internationalen Organisationen (insbesondere in den Vereinten Nationen) vollzieht, zu reagieren und auf diese Einfluss zu nehmen. Unter anderem die folgenden Fragen haben es verdient, in Finnland und in anderen Mitgliedstaaten der EU erwogen zu werden. In welcher Weise hat man die Europäisierung und Internationalisierung der Kriminal- und Sanktionspolitik bei einer solchen Beurteilung zu berücksichtigen ${ }^{24}$

Wir benötigen in der europäischen straftheoretischen und kriminalpolitischen Diskussion neue Gedankenanstöße hinsichtlich dessen, dass die mit der Staatssouveränität eng verbundene Strafrechtspflege zum Teil den Bereich der direkten Entscheidungszuständigkeit der Nationalstaaten verlassen hat und dass dieser Prozess weitergeht. Von besonderer Bedeutung ist hierbei, dass die EU auf diesem Gebiet ein Akteur geworden ist, der eine immer wichtigere Rolle spielt. Eine zentrale Wirkungsrichtung ist dabei die stufenweise Angleichung des Strafrechts - bei den Straftatbeständen ebenso wie bei den Strafdrohungen. ${ }^{25}$ Auf diese Entwicklung haben vor allem die im Gefolge des Vertrags von Amsterdam (1999) in Gebrauch gekommenen Rahmenbeschlüsse bei der Beschlussfassung von polizeilicher und justitieller Zusammenarbeit

23 Vgl. im Allgemeinen insbesondere M. Delmas-Marty, Towards a Truly Common Law, Cambridge University Press 2002, passim; W. Frisch, Einheit und Vielfalt des Strafrechts in Europa, in: Festschrift in Honour of Raimo Lahti (Fn. 3), S. 7-23.

24 Siehe u.a. R. Lahti, Towards a Rationale and Humane Criminal Policy, Journal of Scandinavian Studies in Criminology and Crime Prevention, Vol. 1 (2000), S. 141155 (148-153); K. Nuotio, in: Festschrift in Honour of Raimo Lahti (Fn. 3), S. 167174; H. Satzger, Das Strafrecht als Gegenstand europäischer Gesetzgebungstätigkeit, KritV 1/2008, S. 17-38.

25 Siehe zum folgenden näher u.a. E. J. Husabø \& A. Strandbakken (eds.), Harmonization of Criminal Law in Europe, Intersentia 2005, passim; H. Satzger, KritV 1/2008, S. 17-38. 
in Strafsachen der dritten Säule eingewirkt, welche allgemein den Bereich der Strafbarkeit erweitert und ein repressiveres Strafrechtsdenken als die Reformen des einheimischen Strafrechts repräsentiert haben. Am deutlichsten kommt dieser Zug in den europarechtlichen und internationalen legislativen Verpflichtungen betreffend die Terrorismusbekämpfung zum Ausdruck, bei denen die Rechte des Individuums weitgehend im Schatten des Strebens nach staatlicher Sicherheit bleiben. ${ }^{26}$

Der Vertrag von Lissabon ${ }^{27}$ wird die Zuständigkeit der EU vermehren, wobei die sich herausbildenden Prinzipien eines europäischen Sanktionsrechts in immer größerem Umfang sich auf die nationalen strafrechtlichen Sanktionssysteme auswirken dürften. ${ }^{28}$ Bei dem Vertrag von Lissabon spielt das sich weiter verstärkende Prinzip der gegenseitigen Anerkennung auch bei der Angleichung der strafrechtlichen Sanktionen gleichfalls eine bedeutende Rolle. Für Finnland ist es problematisch, dass diejenigen punitiven administrativen Sanktionen, die u.a. im Wettbewerbs- und Wertpapiermarktrecht wegen der Vorbildwirkung der EU in Gebrauch gekommen sind, bei der Gesamtreform des Strafrechts keine Beachtung gefunden haben. Die Stellung dieser administrativen Sanktionen und die Prinzipien ihrer Verhängung sind nun als wichtiger Teil des Sanktionsrechts der EU zu evaluieren. Als zweites Beispiel sei der in Finnland vor kurzem ausgearbeitete Gesetzesentwurf erwähnt, bei dem die Voraussetzungen dafür festgelegt werden, denen entsprechend eine aufgrund einer Straftat in einem anderen EU-Mitgliedstaat verhängte Behandlungssanktion bei einem nicht zu einer Strafe Verurteilen in Finnland vollstreckt wird; das nationale Strafrecht Finnlands kennt eine solche Straffolge nicht. ${ }^{29}$

In entsprechender Weise ist die Gründung eines permanenten internationalen Strafgerichtshofes in Folge ausreichender Ratifizierungen des 2002 in Kraft getretenen Rom-Statuts von 1998 ein Schritt in die Richtung einer supranationalen, weltweit wirksamen Strafrechtspflege. Finnland hat durch eine neulich vorgenommene Änderung des Strafgesetzes (GBl. 212/2008) seine Rechtsvorschriften betreffend Kriegsverbrechen und Verbrechen gegen die Menschlichkeit so modifiziert, dass sie den entsprechenden Vorschriften des Rom-Statuts besser entsprechen. Die internationalen ad hoc-Strafgerichtshöfe haben in

26 Siehe u.a. E. J. Husabø, The Implementation of New Rules on Terrorism through the Pillars of the European Union, in: Harmonization of Criminal Law in Europe, S. 53-78.

27 13.12.2007, Amtsblatt der EU Nr. C 306 vom 17.12.2007.

28 Siehe näher u.a. Satzger, KritV 1/2008, S. 24-27; S. Peers, EU Justice and Home Affairs Law, 2nd ed., Oxford University Press 2006, Abschnitte 8-9.

29 Siehe Arbeitsgruppenbericht des Justizministeriums 2007:13. 
ihrer Praxis Begriffe und Prinzipien der strafrechtlichen Verantwortung und Strafbemessung entwickelt, die sich für ihren Teil auf die nationale Strafrechtsprechung auswirken. ${ }^{\mathbf{3 0}}$

Auf europäischer Ebene hat die kriminalpolitische Tätigkeit nicht auf einer ausreichend einheitlichen und konsequenten Sicht beruht, und bei der europäischen politischen Theoriebildung hat die Strafrechtspflege bislang nicht die ihr gebührende Aufmerksamkeit erhalten. ${ }^{31}$ Auf dem Niveau der nordischen Staaten und auf nationalem Niveau muss man zum ersten die Auswirkungen der besagten Tendenz eruieren. Zunächst ist es begründet zu erwägen, in welchem Maß man das (traditionell einheitliche) Strafrecht sektoral - europäisches Strafrecht, internationales Strafrecht - differenzieren kann, ohne dass die Grundwerte einer rationalen und humanen Kriminalpolitik für den Teil gefährdet werden, wo es nach wie vor um das nach nationaler Beschlussfassung zu bestimmende Strafrecht geht. ${ }^{32}$ Der Wandel des kriminalpolitischen Klimas, der sich in Finnland in den letzten Jahren vollzogen hat, deutet darauf hin, dass legislative Instrumente mit repressivem Akzent eine Auswirkung über die ihnen zukommenden Sektoren hinaus haben und diese Auswirkung minimalisiert werden sollte.

Zum zweiten ist es auch eine begründete Frage, wie man eine bessere Berücksichtigung der den nordischen Wohlfahrtsgesellschaften eigenen kriminalpolitischen Ziele und Werte in der der EU und in den übrigen supranationalen Beschlussfassungsorganen gewährleisten kann. Die Stärkung der kriminalwissenschaftlichen, komparativen Forschung und der auf ihr basierenden Ausarbeitung der Rechtsvorschriften stellt hier offenkundig ein wichtiges Mittel dar. Wir können von einander lernen, wie zum Beispiel zwischen finnischen und estnischen Strafrechtlern ${ }^{33}$.

30 Siehe u.a. R. Lahti, Harmonization of the General Principles of International Criminal Law, in: International Criminal Law: Quo Vadis? Association internationale de droit penal, Érès 2004, S. 345-351. Siehe näher besonders $A$. Cassese, International Criminal Law, $2^{\text {nd }}$ ed., Oxford University Press 2008; W. A. Schabas, The UN International Criminal Tribunals, Cambridge University Press 2006; G. Werle, Principles of International Criminal Law, Asser Press 2005.

31 Siehe dazu u.a. B. Schünemann (Hrsg.), Ein Gesamtkonzept für die europäische Strafrechtspflege, Carl Heymanns Verlag 2006, passim; K. Nuotio, in: Festschrift in Honour of Raimo Lahti (Fn. 3), S. 167-174.

32 Vgl. die Differenzierung des Wirtschaftsstrafrechts: $R$. Lahti, Das Wirtschaftsstrafrecht in der Gesamtreform des Strafrechts, in: Festschrift für Klaus Tiedemann, Carl Heymanns Verlag 2008, S. 61-77.

33 Der Jubilar Jaan Sootak hat in der finnisch-estnischen Wechselwirkung von Strafrechtlern eine wichtige Rolle gehabt. 



\section{Das Wirtschaftsstrafrecht in der Gesamtreform des Strafrechtes. Erfahrungen mit den finnischen Strafgesetzesreformen 1972-2003}

\section{Einführung}

In Finnland wurde in den Jahren 1972-2003 eine Gesamtreform des Strafrechtes verwirklicht, bei der das Wirtschaftsstrafrecht einen zentralen Teil gebildet hat. Von der Gesamtreform steht die Überprüfung einiger Vorschriften des Besonderen Teils des Strafgesetzes sowie die gesamte Kapitelsystematik des Besonderen Teils noch aus, aber ansonsten konnte die Rekodifizierung des aus dem Jahre 1889 stammenden Strafgesetzes im Jahre 2003 zu einem faktischen Abschluss gebracht werden. ${ }^{1}$ Die Wirtschaftsstrafvorschriften wurden in den Jahren 1990, 1995 und 2003 in drei Gesetzgebungspaketen reformiert. Die wichtigsten den Allgemeinen Teil des Strafrechts betreffenden Vorschriften wurden 2003 novelliert. Ein Ziel der Gesamtreform des Strafrechtes bestand nach dem sogenannten Konzentrationsprinzip darin, alle Strafvorschriften in das Strafgesetz einzubeziehen, deren Strafrahmen die Androhung der Freiheitsstrafe enthält. Zum Teil aus diesem Grund wurde ein bedeutender Teil der außerhalb des Strafgesetzes in Nebengesetzen befindlichen Strafvorschriften neu formuliert und in das Strafgesetz gestellt.

Ich betrachte in meinem Artikel ebenso die Ziele und Mittel der Gesamtreform des finnischen Strafrechtes wie die der Reformierung des Wirtschaftsstrafrechtes sowie ferner die bei der Reformarbeit aufgetretenen Schwierigkeiten und die Endergebnisse der Reform. ${ }^{2}$ Mein Hauptaugenmerk liegt auf der Evaluierung der Frage, welche besonderen Züge und Probleme mit der strafrechtlichen Regulierung der wirtschaftlichen Tätigkeit sowie mit der Entscheidung ver-

1 Siehe jetzt Das Finnische Strafgesetz (nach dem Stand vom 1.10.2005). Übersetzung und Einführung von Karin Cornils, Dan Frände und Jussi Matikkala. Max-PlanckInstitut für ausländisches und internationales Strafrecht, 2006.

2 Zur finnischen Gesamtreform des Strafrechts siehe Lahti, Zur Kriminal- und Strafrechtspolitik des 21. Jahrhunderts, in: Festschrift für Albin Eser, 2005, S. 1393 ff.; Lahti, ZStW 115 (2003), S. 753 ff.; Lahti / Nuotio (Hrsg.), Criminal Law Theory in Transition - Strafrechtstheorie im Umbruch, Helsinki 1992, passim. 
bunden sind, die zentralen Vorschriften des Wirtschaftsstrafrechts systematisch in das neu kodifizierte Strafrecht einzubeziehen. Ob die Reformarbeit bezüglich des Wirtschaftsstrafrechts gelungen ist, lässt sich vorläufig aufgrund der mit der Anwendung der einschlägigen Regulierung gewonnenen Erfahrungen beurteilen. ${ }^{3}$

Der Jubilar Klaus Tiedemann hat der Reformierung des finnischen Strafrechts und besonders des Wirtschaftsrechts wichtige Impulse gegeben, unter anderem indem er am 15. September 1983 eine Gastvorlesung über das Wirtschaftsstrafrecht und auf dem Internationalen Forschungskolloquium „Finnisches Strafgesetz 100 Jahre“ (24.-27. September.1990) einen Vortrag über das Thema „Zum Verhältnis von Allgemeinem und Besonderem Teil des Strafrechts“ gehalten hat. ${ }^{4}$ Die Resultate des von Tiedemann geleiteten Forschungsprojekts über die „Europa-Delikte“ sind von großer Bedeutung, wenn man daran geht, das Wirtschaftsstrafrecht der europäischen Staaten zu harmonisieren. ${ }^{5}$ Dasselbe gilt für die Ergebnisse des Corpus-Juris-Forschungsprojekts der Europäischen Union, bei dem Klaus Tiedemann zu den Schlüsselpersonen zählt. ${ }^{6}$

\section{Die Reformierung des Wirtschaftsstrafrechts als Teil der Gesamtreform des Strafgesetzes und der Bekämpfung der Wirtschaftskriminalität}

Der Begriff der Wirtschaftskriminalität und die damit verbundenen Erscheinungen haben gegen Ende der siebziger Jahre in der finnischen Öffentlichkeit Aufmerksamkeit erregt, und zwar zum einen wegen einiger spektakulärer Fälle und zum anderen angeregt von der internationalen Diskussion, die damals begann. $^{7}$ Die offizielle, sich auf dieses Thema konzentrierende Forschung

3 Ich habe in den Jahren 1980-1999 als Mitglied der Leitungsgruppe der vom Justizministerium eingesetzten Projektorganisation, die für die Gesamtreform des Strafrechtes zuständig war, und in den Jahren 1980-1984 als Vorsitzender der Arbeitsgruppe für Wirtschaftsstrafrecht fungiert.

4 Diese beiden an der Universität Helsinki gehaltenen Vorträge wurden in Finnland publiziert: siehe Tiedemann, Taloudelliset rikokset [Die Wirtschaftsstraftaten], Lakimies 84 (1986), S. 189 ff.; Tiedemann, in: Criminal Law Theory in Transition, a.a.O. (Fn 2), S. $280 \mathrm{ff}$.

5 Siehe dazu Tiedemann (Hrsg.), Wirtschaftsstrafrecht in der Europäischen Union, Freiburg-Symposium, 2002, passim.

6 Siehe Delmas-Marty et al., Corpus Juris, 1997; Delmas-Marty / Vervaele (eds), The Implementation of the Corpus Juris in the Member States, Vols I-IV, 2000-2001.

7 Siehe näher Lahti / Träskman, Conception et principes du droit pénal economique et des affaires: Finland, Revue Internationale de Droit Pénal 54 (1983), S. 249 ff. 
wurde 1982 eingeleitet, als das finnische Justizministerium eine Arbeitsgruppe zur Klärung der Wirtschaftskriminalität einsetzte. Die Regulierung dieser Art von Kriminalität war indes in den Organen, die die Gesamtreform des Strafrechtes ausarbeiteten, bereits seit 1972 das Objekt von Überlegungen gewesen; im genannten Jahr wurden das Strafrechtskomitee sowie die Ausschüsse für Arbeits-, Steuer- und Umweltdelikte, die die Tätigkeit des Strafrechtskomitees unterstützten, eingesetzt.

Der Bericht der Arbeitsgruppe zur Klärung der Wirtschaftskriminalität und der Anlageteil zu diesem Bericht (1983) lieferten seinerzeit eine grundlegende Erforschung der Erscheinungsformen der Wirtschaftskriminalität in Finnland sowie eine große Zahl an Vorschlägen zur Vorbeugung und Kontrolle dieser Kriminalität. Die Arbeitsgruppe hat zudem den Bereich des Wirtschaftsstrafrechts in einer Weise definiert, die sich bei der späteren Gesetzesausarbeitung und in der behördlichen Praxis als gelungen erwiesen hat: (1) Delikte, die gegen die wirtschaftlichen Gesetze und Vorschriften sowie den öffentlichen Haushalt verstoßen; (2) Delikte, die im Zusammenhang mit wirtschaftlicher und unternehmerischer Tätigkeit begangen werden und einen wirtschaftlichen Nutzen zum Ziel haben.

Die prinzipiellen Ausgangspunkte der Gesamtreform des Strafrechtes wurden im Strafrechtskomitee (1972-1977) kartiert. Die Arbeit dieses Komitees wurde von der 1980 vom Justizministerium eingesetzten Projektorganisation für das neue Strafrecht fortgesetzt. Als dringlichste Ausarbeitungsaufgabe für dieses so genannte Strafgesetzprojekt wurde 1983 die Regulierung betreffend die Delikte gegen den öffentlichen Haushalt und die wirtschaftlichen Gesetze und Vorschriften sowie betreffend die Vermögensdelikte festgesetzt. Zugleich bestätigte das Justizministerium, dass die Gesamtreform des Strafrechtes in umfangreichen Teilreformen zu erfolgen habe. Zu Beginn wurde geschätzt, dass die Reformarbeit 1984 abgeschlossen sei, aber die Arbeit des Strafgesetzprojektes dauerte bis 1999 an und die letzten bedeutenden Teilreformen des Strafrechtes traten erst Anfang 2004 in Kraft.

Die erste Teilphase der die Wirtschafts- und Vermögensdelikte betreffenden Gesamtreform des Strafrechtes wurde nach mehrjähriger Ausarbeitung verwirklicht, und zwar durch die zu Beginn des Jahres 1991 in Kraft getretenen Gesetzesänderungen (769-834/1990). Damals wurden neue Vorschriften betreffend die Delikte gegen den öffentlichen Haushalt, d.h. betreffend die Steuer- und Subventionsdelikte (StGB Kapitel 29), die Gewerbedelikte (StGB Kapitel 30) und in erster Linie die gegen die wirtschaftlichen Gesetze und Vorschriften gerichteten Bewirtschaftungsdelikte (StGB Kapitel 46) erlassen. In der zweiten Teilphase der Gesamtreform des Strafrechtes wurden 1995 
(578-747/1995) Vorschriften über die Arbeits- und Umweltdelikte (StGB Kapitel 47-48) sowie Vorschriften über die Verletzung immaterieller Rechte (StGB Kapitel 49) in das Strafgesetz gestellt, und es wurde die strafrechtliche Verantwortung von juristischen Personen (StGB Kapitel 9) in Gebrauch genommen. Die Vorschriften über die Delikte der Geldwäsche und die Straftaten gegen den Wertpapiermarkt wurden gleichfalls in das Strafgesetz aufgenommen (StGB Kapitel 32, 1304/1993 und 61/2003; StGB Kapitel 51, 475/1999 und 300/2005).

In der Anfangsphase der Reformen zum Wirtschaftsstrafrecht wurden nur einige wenige Vorschläge, die die Arbeitsgruppe zur Klärung der Wirtschaftskriminalität gemacht hatte, verwirklicht, und zwar zum Beispiel die Vorschläge betreffend die Verbesserung der Vorbeugung, Überwachung und Untersuchung der neuen Subventions-, Buchhaltung- und Schuldnerdelikte. Die Bekämpfung der Wirtschaftsdelikte wurde zu sehr mit den Mitteln der Strafrechtspolitik im Vergleich zu den übrigen kriminalpolitischen Mitteln verwirklicht. Die Effektivierung der Bekämpfung der Wirtschaftskriminalität und der so genannten grauen Wirtschaft wurde jedoch um die Mitte der neunziger Jahre zum Objekt der politischen Aufmerksamkeit. In der kriminologischen Forschung sind die Hintergrundfaktoren hierfür spezifiziert und ist die Ansicht vorgebracht worden, dass die wirtschaftliche Rezession und die Bankenkrise zu Beginn der neunziger Jahre das Fundament für den Wandel geschaffen hätten. ${ }^{8}$

In der Zehnjahresperiode 1996-2005 traten drei auf Entscheidungen der Regierung beruhende Programme zur Bekämpfung der Wirtschaftskriminalität und der grauen Wirtschaft in Kraft (1996, 1998 und 2001). Mit den zwei ersten von ihnen zielte man vor allem darauf ab, den Missbrauch der öffentlichen Einkommens- und Ausgabenfinanzierung zu bekämpfen sowie einen gesunden Wettbewerb im Wirtschaftsleben zu fördern und die Voraussetzungen für die sachgemäße Funktion der Wirtschaft zu verbessern. Das zentrale Ziel des dritten Programms ebenso wie des jüngsten, d.h. des vierten Programms (2006-2009) besteht in der Etablierung der vorbeugenden Maßnahmen als ein Teil der Basistätigkeit der Verwaltungsbehörden. Diese Tätigkeitsprogramme und andere Tätigkeitsstrategien, die die Grenzen der Verwaltungsgebiete überschreiten, haben sich als notwendige Mittel erwiesen, auf die Wirtschaftskriminalität und die graue Wirtschaft mit umfassenden kriminalpolitischen Maßnahmen Einfluss zu nehmen. Nur dadurch ist es möglich, die aus jenen

8 Siehe Alvesalo / Tombs, The Emergence of a „War“ on Economic Crime: The Case of Finland, Business and Politics 3 (2001), S. 239 ff.; Alvesalo, The Dynamics of Economic Crime Control, Espoo 2003, S. 42 ff. 
Erscheinungen herstammenden gemeinschaftlichen Schäden - die auf Jahresniveau in Höhe von mehr als 5 Milliarden Euro geschätzt werden - zu reduzieren.

\section{III. Über die Ziele, Wirkungen und Grenzen des Wirtschaftsstrafrechts ${ }^{9}$}

Die Ziele des reformierten Wirtschaftsstrafrechtes sind vor dem Hintergrund der allgemeinen Ziele der Gesamtreform des Strafrechtes zu sehen. Die wichtigste Aufgabe, die der Reformarbeit des Strafrechtskomitees gestellt worden war, hat darin bestanden, Überlegungen darüber anzustellen, was strafbar sein sollte und wie streng für die einzelnen Delikte zu bestrafen sei. Für die Bestimmung der Strafbarkeit der Taten und der festzusetzenden Strafdrohungen wurde ein Modell vorgebracht, nach dem zuerst die Nachteiligkeit und Vorwerfbarkeit der Tattypen zu beurteilen und dann die Vor- und Nachteile einer eventuellen Kriminalisierung im Vergleich zu den übrigen Regulierungsalternativen abzuwägen sei. Das Komitee betonte die das strafrechtliche System kennzeichnende Wirkung: die mittelbare Wirkung und die symbolische Bedeutung der Strafdrohungen. Mit den Strafvorschriften wird aufgezeigt, welches die für die Gesellschaft zentralen Ver- und Gebote seien. Durch die Existenz der Strafdrohungen und ihre Anwendung in der Praxis wird die autoritative Missbilligung der Gesellschaft ausgedrückt und somit Einfluss auf die Herausbildung der Rechts- und Moralvorstellungen der Bürger genommen. ${ }^{\mathbf{1 0}}$

Die Vorarbeiten zur Strafrechtsreform spiegeln den begründeten Glauben an die generalpräventive Wirkung des strafrechtlichen Systems sowie an die Wichtigkeit der Prinzipien Gerechtigkeit und Humanität für die Legitimität des Strafrechtssystems wieder. Die Reduzierung der Kriminalität und ihrer Nachteile setzt eine vielseitige und wirkungsvolle Kriminalitätsbekämpfung und ein effektives strafrechtliches Kontrollsystem voraus. Von dem strafrechtlichen Kontrollsystem wird Glaubwürdigkeit und Akzeptanz erwartet, mit anderen Worten: man muss an die Funktionsfähigkeit des Systems glauben und auf seine Richtigkeit und Billigkeit vertrauen können. Der Schweregrad der Strafdrohungen bzw. der einzelnen Strafen bildet jedoch nur einen Teil der Umstände, die einen Einfluss auf die Funktionsfähigkeit des gesamten Systems haben. Es ist somit offenkundig, dass man allein dadurch, dass man die Wirt-

9 Vgl. im Allgemeinen u.a. Tiedemann, Wirtschaftsstrafrecht, Einführung und Allgemeiner Teil, 2004, Einführung und $\S 1$; Achenbach, Zur aktuellen Lage des Wirtschaftsstrafrechts in Deutschland, GA 2004, S. 559 ff.

10 Siehe Komiteebericht 1976:72, Kapitel II-IV. 
schaftsstrafvorschriften aktualisiert und deren Strafdrohungen in ein gerechtes Verhältnis zu den Strafdrohungen der konventionellen Vermögensdelikte stellt, die angestrebte Wirksamkeit der Wirtschaftskriminalitätsprävention und -kontrolle nicht erreicht. Die Wirksamkeit des strafrechtlichen Systems ist maßgeblich von dem gesamten Strafprozess, d.h. von den Tätigkeitsvoraussetzungen der verschiedenen Behörden (der Aufsichts-, Polizei- und Anklagebehörden sowie der Gerichte) abhängig, die dafür zuständig sind, die Täter zur strafrechtlichen Verantwortung zu ziehen.

Die mit Strafdrohungen bewehrten Strafvorschriften spielen bei der Bekämpfung und Kontrolle der Wirtschaftskriminalität dennoch eine eigene wichtige Rolle, wie das Strafrechtskomitee die Sachlage ausgedrückt hat. Allerdings hat man bei der Ausarbeitung der Strafrechtsreformen in Finnland, wie auch in anderen Ländern, eine lebhafte kritische Diskussion darüber geführt, ob das strafrechtliche System zur Vorbeugung und Kontrolle des Missbrauchs wirtschaftlicher Tätigkeit oder zur Förderung der Arbeitssicherheit und des Umweltschutzes geeignet sei oder ob dem Strafrecht nur eine rein symbolische Bedeutung zukomme. ${ }^{11}$ Ich möchte im Folgenden diese die Grenzen des Strafrechts betreffende Diskussion und ihre Auswirkungen auf die finnische Strafrechtsreform vor allem von den Anforderungen her erläutern, die an die Setzung von Kriminalisierungsprinzipien und des Legalitätsprinzips gestellt werden.

\section{Das Wirtschaftsstrafrecht, die Kriminalisierungsprinzipien und das Legalitätsprinzip}

Bei der Ausarbeitung der Gesamtreform des Strafrechtes war man bestrebt, bei den Entscheidungen bezüglich der Kriminalisierungen ergänzend zu der herkömmlichen, von den Rechtsgütern ausgehenden Strafregulierung die so genannte Lebensbereichsanalyse anzuwenden. Diese Analyse hat sich darauf ausgewirkt, wie sich die Beurteilung der Nachteiligkeit der Tattypen und dadurch der Bereich der zu schützenden Rechtsgüter erweitert haben. Mit den novellierten Vorschriften über die Steuer-, Subventions- und Bewirtschaftungsdelikte will man an erster Stelle die Funktionsfähigkeit der Volkswirtschaft schützen, und mit den Vorschriften über die Gewerbedelikte will man vor allem die Tätigkeitsvoraussetzungen des Wirtschaftslebens sichern. Die bei

11 Siehe u.a. die kritischen Beiträge im Forschungskolloquium „Finnisches Strafgesetz 100 Jahre", in: Lahti / Nuotio (Hrsg.), Criminal Law Theory in Transition, a.a.O. (Fn 2), insb. Kap. II, und Hassemer, Kennzeichen und Krisen des modernen Strafrechts, S. 113 ff.; sowie Achenbach, GA 2004, S. 562 ff. 
gewerblicher und unternehmerischer Tätigkeit und damit vergleichbarer wirtschaftlicher Tätigkeit begangenen strafbaren Taten erschöpfen sich jedoch nicht in den genannten Delikttypen, sondern diese Taten erfüllen häufig die Tatbestände der Vermögensdelikte (wie die Tatbestände der Betrugs- oder Untreuedelikte im Kapitel 36 des StGB oder die Tatbestände der Schuldnerdelikte im Kapitel 39 des StGB). Die Regulierung von Arbeits-, Umwelt- und Geldwäschedelikten sowie der Straftaten gegen den Wertpapiermarkt im Strafrecht hat den Bereich der zu schützenden Rechtsgüter noch zusätzlich erweitert.

Hinter der Regulierung der Geldwäschedelikte und der Straftaten gegen den Wertpapiermarkt haben international- oder europarechtliche Kriminalisierungspflichten gestanden, und das Recht der Europäischen Union hat später eine Auswirkung auch auf andere Vorschriften des Strafgesetzes gehabt, unter anderem auf die Vorschriften über die Subventions- und Steuerdelikte (StGB Kapitel 29, 814/1998). Für die Strafrechtsreform griff man mittels Rechtsvergleich auf Vorbilder aus Ländern zurück, in denen ähnliche Verhältnisse herrschen wie in Finnland; vor allem kamen die Vorbilder aus Schweden und aus Deutschland. In diesen Ländern waren zur selben Zeit Gesetzesänderungen im Bereich des Wirtschaftsstrafrechts im Gange. Zum Beispiel für die novellierten Vorschriften über die Subventionsdelikte haben die entsprechenden deutschen Strafvorschriften (dStGB § 264) das Vorbild abgegeben. Alles in allem hat sich auf dem Gebiet der wirtschaftlichen Tätigkeit der Bereich der strafrechtlichen Regulierung erweitert, und das Strafmaß der strafbaren Tattypen ist im Durchschnitt strenger geworden.

Als man in den 80er Jahren und zu Beginn der 90er Jahre die Wirtschaftsstrafvorschriften ausarbeitete, hatte man kaum die Möglichkeit, eine wirkliche Nutzen-Nachteil-Abwägung der Kriminalisierungen anzustellen. Im Nachhinein betrachtet lag eine Fehleinschätzung darin, dass man bereits in der Anfangsphase des Strafgesetzprojekts sich die Haltung zu Eigen machte, zu dem kriminalstrafrechtlichen System keine alternativen administrativen Sanktionssysteme - insbesondere ein verwaltungsstrafrechtliches System (wie das deutsche Ordnungswidrigkeitengesetz) - systematisch zu entwickeln. So sind zum Beispiel später bei Wettbewerbsbeschränkungen, bei Missbrauch von EUSubventionen und zuletzt für die Delikte gegen den Wertpapiermarkt BußgeldSanktionen im Rahmen der Gesamtreform des Strafrechtes als Alternativen zu Kriminalstrafen nicht in Erwägung gezogen worden. ${ }^{12}$

12 Es sei hier erwähnt, dass der Jubilar Klaus Tiedemann bei der Vorbereitung der finnischen Kartellgesetzgebung ein Gutachten an die ausarbeitende Kommission abge- 
Von den Kriminalisierungsprinzipien konnte Unterstützung für eine solche Erwägung des Gesetzgebers gewonnen werden, dass wenn zum Beispiel ein grundlegender, durch Vorschriften betreffend die Gewerbedelikte geschützter Vorteil in der Sicherung der Tätigkeitsvoraussetzungen des Wirtschaftslebens liegt, die strafrechtliche Regulierung als solche die individuelle Freiheit ebenso wie die Gewerbefreiheit nicht unnötigerweise einschränken darf. Aus der „ultima ratio“-Begrenzung der Kriminalisierungen und dem Verhältnismäßigkeitsprinzip ist Zurückhaltung bei der Erwägung der Grenzen der Strafbarkeit abzuleiten. So ist zum Beispiel der Umstand, dass in den Wirtschafts- und Vermögensvorschriften in der Regel nur solche Taten als strafbar bestimmt worden sind, die vorsätzlich begangen werden, vor diesem Hintergrund zu verstehen. In entsprechender Weise sind nicht für alle Tattypen von Wirtschaftsdelikten Tatbestände betreffend schwere Tatformen bestimmt worden.

Das Bestimmtheitsgebot des strafrechtlichen Legalitätsprinzips und dessen Hintergrundwerte veranlassen wiederum dazu, sich zurückhaltend gegenüber solchen Ausformulierungen von Tatbeständen zu verhalten, bei denen die wirtschaftlichen Missbräuche recht vage definiert sind; herkömmlicherweise hat man von der fragmentarischen Natur des Strafrechtes gesprochen. Ebenso wurde zum Beispiel eine solche Erweiterung der Strafverantwortung abgelehnt, die ausdrücklich die Tätigkeit von im Hintergrund wirkenden Akteuren (z.B. von Geldgebern) bei illegalen wirtschaftlichen Handlungen kriminalisiert hätte. ${ }^{13}$

Bei jedem Formulieren von Strafgesetzen muss man also das im strafrechtlichen Legalitätsprinzip enthaltene Bestimmtheitsgebot sowie die die Anwendung des Strafrechtes begrenzenden Kriminalisierungsprinzipien berücksichtigen, die heutzutage - nach der Grundrechtsreform Finnlands (1995) - an erster Stelle aus den allgemeinen Prinzipien der Einschränkung der Grundrechte abgeleitet werden. Es besteht eine Spannung zwischen Bestrebungen, die in verschiedene Richtungen wirken: Zum einen musste man wegen des aus dem Legalitätsprinzip folgenden Bestimmtheitsgebots die Straftatbestände möglichst genau umrissen niederschreiben und wegen der Kriminalisierungsprinzipien bei Erweiterungen der Strafbarkeit Vorsicht walten lassen, zum anderen musste man die Wirtschaftsstrafvorschriften aktualisieren, und die Vorschriften mussten die in ihren Wirkungskreisen und in den Tatweisen sich vollziehenden interpretativen Wandlungen in einem höheren Maße ermöglichen, als

geben hat. Siehe auch Tiedemann, Strafrecht in der Marktwirtschaft, in: Festschrift für Walter Stree und Johannes Wessels, 1993, S. 527 ff. (533).

13 Vgl. jedoch seit 2003 StGB Kap. $5 \S 8$ (Handeln für eine juristische Person; siehe unten VI) und StGB Kap. $32 \S 8$ (Verabredung von schwerer Geldwäsche). 
dies bei der Anwendung der Vorschriften über die konventionellen Vermögensdelikte vonnöten ist. ${ }^{14}$

Ein zentraler Wert-Ausgangspunkt bei der Gesamtreform des finnischen Strafrechtes war zudem der Grundsatz der sozialen Gerechtigkeit: Neben den konventionellen Delikttypen musste man auch Missbräuche der öffentlichen und wirtschaftlichen Gewalt kriminalisieren. Das soziale Strafrecht berücksichtigt auf der einen Seite die Tatsache, dass hinter konventionellen Straftaten häufig solche persönlichen Verhältnisse stehen, die die Vorwerfbarkeit der Straftaten mildern, und auf der anderen Seite den Umstand, dass Strafdrohungen auch gegen von ihren Ressourcen her starke Ausüber von Missbräuchen eingesetzt werden.

Die zu missbilligenden Verletzungen von Rechtsgütern und die Tattypen lassen sich in den Grundtatbeständen von solchen konventionellen Vermögensdelikten wie Diebstahl oder Sachbeschädigung relativ leicht in ziemlich exakt umrissener Weise und unter Verwendung von Begriffen, die sich von ihrer Bedeutung her eingebürgert haben, niederschreiben. Bei der Kriminalisierung der Tatweisen von typischen Wirtschaftsdelikten muss man dagegen in den Tatbeständen in hohem Maße auf solche Begriffe zurückgreifen, die einem einen Spielraum für normative Abwägung lassen, und die Strafvorschriften in einer allgemeineren Weise als normal niederschreiben. Diese Begriffe sind häufig eng an die die Wirkungsfelder der Taten regulierende materielle Gesetzgebung und auch an den wirtschaftswissenschaftlichen Begriffsapparat gebunden, obwohl die mit Freiheitsstrafdrohung bewehrten Strafvorschriften in der Hauptsache im Strafgesetz zusammengefasst sind. Das Gesagte gilt auch dann, wenn man bestrebt gewesen ist, die Tatbestände von Wirtschaftsdelikten in eigenständiger Weise und unter Vermeidung der herkömmlichen Blankettstraftechnik niederzuschreiben (siehe zum Beispiel das Kapitel 30 des StGB über die Gewerbedelikte und das Kapitel 51 über die Straftaten gegen den Wertpapiermarkt). An die Blankettstraftechnik hat der Verfassungsausschuss des finnischen Parlaments aus dem Legalitätsprinzip abgeleitete Qualitätsanforderungen für solche relativ gewöhnlichen Situationen gestellt, bei denen man im Wirtschaftsstrafrecht nach wie vor auf diese Technik zurückgreifen muss (wie bei den Umweltdelikten gemäß StGB Kapitel 48 und den Arbeitsdelikten gemäß Kapitel 49).

14 Vgl. Tiedemann, Wirtschaftstrafrecht (a.a.O, Fn 9), Rn 63; Achenbach, GA 2004, S. 562 ff.; Tiedemann, Wirtschaftsstrafrecht und Wirtschaftskriminalität 1, Allgemeiner Teil, 1976. 
Zu dem Ermessen des Ausdehnungsbereichs der Tatbestände von Wirtschaftsstraftaten gehört typischerweise die diffizile Grenzziehung zwischen verbotener und zulässiger Risikoverursachung oder Vorgangsweise in der wirtschaftlichen Tätigkeit, zum Beispiel wenn ein Schuldner in unbegründeter Weise seine Verbindlichkeiten vermehrt und damit seine Zahlungsunfähigkeit verschlimmert (siehe StGB Kap. $39 \S 1$ ). Die Verwaltungsakzessorität von Umweltdelikten (StGB Kapitel 48), mit anderen Worten der Umstand, dass die strafbare Tätigkeit ohne die im Gesetz vorgeschriebene Genehmigung oder gegen die Bedingungen der Genehmigung geschieht, zeigt als solche die Relativität von verbotener und zulässiger Risikoverursachung auf. In den Tatbeständen von Wirtschaftsdelikten ist die Strafbarkeit häufig auf verschiedene Formen der Gefährdungshaftung erweitert worden (zum Beispiel in den Umweltdelikten in StGB Kapitel 48 und den Arbeitsdelikten in Kapitel 49). Alle genannten Umstände tragen zum Auftreten von schwierigen Auslegungsproblemen bei.

\section{Die allgemeinen Lehren des Wirtschaftsstrafrechts ${ }^{15}$}

Die oben dargestellte Integration der Wirtschaftsstrafvorschriften in das Strafgesetz hat die Komplexität des Strafrechtes vermehrt und zu einer gewissen Differenzierung desselben geführt. Bei der Reformierung des Wirtschaftsstrafrechtes und sodann besonders bei der Ausformulierung der Straftatbestände gibt es in Hinsicht auf die Kriminalisierungsprinzipien und das Legalitätsprinzip besondere Züge. Man hat das einen Wohlfahrtsstaat kennzeichnende Strafrecht mit den Forderungen, die an das Formulieren von Strafgesetzen in einem Rechtsstaat zu stellen sind, in Einklang bringen müssen, und zwar in der Weise, dass das Wirtschaftstrafrecht darin nicht nur ein symbolisches Recht darstellt.

Gemäß dem allgemeinen Ansatz der Gesamtreform des Strafrechtes ist man bestrebt gewesen, auch bei der Ausarbeitung der Wirtschaftsstrafvorschriften die Kapitel- und sonstige Gesetzessystematik, den Aufbau der Straftatbestände und die Strafdrohungen so zu formulieren, dass die Wirtschafts- und Vermögensstrafvorschriften ein untereinander möglichst konsequentes (kohärentes) Ganzes bilden und auf einer Linie mit den allgemeinen Zielen der Gesamtreform des Strafrechtes liegen. Es ist jedoch zu bemerken, dass die früher bereits angenommenen legislativen Lösungen und die Rechtslage, die sich durch diese herausgebildet hat, die Motivation zu Veränderungen an der Gesetzessystematik gedämpft haben. So hat man zum Beispiel bei der Systematik der Schuld-

15 Vgl. im Allgemeinen Tiedemann, Wirtschaftsstrafrecht (a.a.O, Fn 9), passim. 
nerdelikte die Einteilung der Tattypen (StGB Kap. $39 \S \S 1-2)$ aufgrund dessen beibehalten, ob eine wirkliche oder scheinbare Verschlechterung der Vermögensstellung des Schuldners vorliegt, was sich später in der Praxis als problematisch erwiesen hat. Des Weiteren kann eine im Licht der Kriminalisierungsprinzipien strittige Vorschrift in einem Kapitel- oder Vorschriftenzusammenhang stehen, in den sie schlecht hineinpasst. Ein Beispiel hierfür ist das Steuervergehen (StGB Kap. 29 § 4: Unterlassung der Verpflichtung, gewisse Steuern rechtzeitig zu bezahlen), das zwar eher eine Ordnungswidrigkeit als eine kriminelle Straftat darstellt, aber in einem Zusammenhang mit solchen Steuer- und Subventionsdelikten steht, die von ihrem Strafwert her schwerwiegender sind.

Eine bedeutende gesetzgeberische und strafrechtstheoretische Frage betrifft das Verhältnis zwischen dem Allgemeinen und dem Besonderen Teil des rekodifizierten Strafgesetzes. Wie löst man den daraus hervorgehenden Widerspruch, dass einerseits die Vorschriften und Prinzipien des Allgemeinen Teils in möglichst konsequenter und einheitlicher Weise auf alle Bereiche des Besonderen Teils anwendbar sein sollten, wo es doch andererseits im Wirtschaftsstrafrecht und auch in anderen Bereichen des Besonderen Teils des Strafgesetzes eigene Züge gibt, die sich mit der Forderung nach völlig einheitlicher Anwendung des Allgemeinen Teils nur schwer in Einklang bringen lassen?

Die Differenzierung des Strafrechts wird auch von einigen besonderen Zügen in der europäischen und internationalen Strafrechtsentwicklung gefördert. Die Entwicklung, die sich in der Europäischen Union vollzieht, ist dazu angetan, die Strafrechtssysteme der Mitgliedsländer einander anzunähern, vor allem bestimmte Spezialgebiete von ihnen - wie zum Beispiel die Straftatbestände, die die wirtschaftlichen Interessen der Europäischen Gemeinschaften schützen, sowie die Tatbestände bezüglich gewisser Formen der organisierten Kriminalität. Als besonders bedeutend bei der Harmonisierung des Strafrechtes haben sich die der ersten Säule der EU unterstellten Richtlinien und die der dritten Säule unterstellten legislativen Maßnahmen erwiesen - der so genannte Gemeinschaftsbetrugsvertrag (1995) und vor allem die Rahmenbeschlüsse -, die zur Bekämpfung bestimmter, mit wirtschaftlicher Tätigkeit verbundener Missbrauchstypen eine wirksame Sanktionierung erfordert haben. ${ }^{\mathbf{1 6}}$

16 Siehe näher u.a. Tiedemann, Wirtschaftsstrafrecht (a.a.O, Fn 9), § 2.IV und $\S 5$; Schünemann (Hrsg.), Ein Gesamtkonzept für die europäische Strafrechtspflege, 2006, passim. 
Die Annäherung, die sich aus der Gesetzgebung der EU ergibt, betrifft insbesondere das Wirtschaftsrecht. Diese Auswirkung hat sich besonders auf die Regulierung der Geldwäschedelikte und der Straftaten gegen den Wertpapiermarkt erstreckt, aber zum Beispiel auch auf die Regulierung der Subventionsund Steuerdelikte. Die Ursprünge der Kriminalisierung der Geldwäsche gehen noch weiter zurück als bis auf die EU, und zwar bis auf die Vereinigten Staaten. Das Recht der EU hat auch auf das Strafrecht immer häufiger eine interpretatorische Auswirkung, wenn die zur Vollstreckung einer Richtlinie oder eines Rahmenbeschlusses erlassene nationale Gesetzgebung im Einklang mit dem EU-Recht anzuwenden ist. Als Einschränkung gilt indes auch hier, dass unter Berücksichtigung der Prinzipien der Gesetzesbindung und Rechtssicherheit das Strafrecht nicht zum Schaden des Angeklagten in erweiternder Weise ausgelegt werden darf. ${ }^{17}$

Die oben dargestellten Entwicklungszüge tragen dazu bei, das von den Allgemeinen Lehren repräsentierte Systemdenken abzuschwächen und deren Allgemeinheitsniveau zu senken. Das Strafrechtssystem in einer nationalen Rechtsordnung - wie zum Beispiel in der finnischen - ist nicht völlig einheitlich, sondern in ihm kommt es im Zuge neuer rechtlicher Erscheinungen und ihrer Regulierung zu einer gewissen Differenzierung. Es ist daher begründet, von einem Anwachsen des rechtlichen Pluralismus und von dem Bedarf zu sprechen, zur Beherrschung der immer vielfältiger werdenden parallelen Rechtsregulierungen und rechtlichen Tätigkeitsfelder ein dynamisches Systemdenken zu entwickeln. Gerade das Wirtschaftsstrafrecht, das stärker als andere Rechtsbereiche unter dem Einfluss des EU-Recht steht, eignet sich als typisches Beispiel für eine solche Differenzierungstendenz. ${ }^{18}$

Aus der Differenzierung des Wirtschaftstrafrechts folgt nicht unbedingt, dass man für es zahlreiche vom übrigen Strafrecht abweichende Allgemeine Lehren (Prinzipien oder Begriffe) aufgestellt hätte oder aufzustellen hätte. Vielmehr geht es um die Flexibilität des Rechtssystems, die von derartigen allgemein anzuwendenden Lehren sowie von diesen und den Rechtsvorschriften ermög-

17 Siehe zur Praxis des EG-Gerichtshofs über die Schwierigkeiten bei der Auslegung einer Richtlinie der Gemeinschaft vor allem die zusammengefassten Rechtssachen C-74/95 und C-129/95 Strafverfahren gegen Unbekannt, Punkt 25. Zu den Auslegungsschwierigkeiten des Rahmenbeschlusses gemäß Abteilung VI des EU-Vertrags siehe entsprechend C-105/03 Strafverfahren gegen Maria Pupino, Urteil vom 16.6.2005, Punkte 43-45 (die allgemeinen Rechtsprinzipien, insbesondere die Prinzipien der Rechtssicherheit und des Rückwirkungsverbots, schränken die Auslegungswirkung ein).

18 Siehe zum rechtlichen Pluralismus Delmas-Marty, Towards a Truly Common Law: Europe as a Laboratory for Legal Pluralism, 2002, passim. 
licht wird, sowie um die Anpassungsfähigkeit des Rechtssystems gegenüber dynamischen Auslegungen der Wirtschaftsstrafvorschriften. Meines Erachtens geht Klaus Tiedemanns Aussage ,der Allgemeiner Teil hat den Besonderheiten des Besonderen Teils Rechnung zu tragen - nicht umgekehrt ${ }^{\text {‘19 }}$ in dieselbe Richtung wie meine eigene Auffassung.

Man muss sich natürlich auch der Probleme einer solchen Differenzierung bewusst sein, vor allem der Gefahr, dass man die Voraussetzungen der Verantwortung für Wirtschaftsdelikte und die Verwirklichung dieser Verantwortung allgemein strenger anzuwenden beginnt als in den anderen Teilbereichen des Strafrechts. Das strafrechtliche Legalitätsprinzip und das Prinzip des gerechten Gerichtsverfahrens samt seinen den Grund- und Menschenrechten entsprechenden praktischen Anwendungen setzen hier in jedem Fall Grenzen. Zum einen darf man den Leitgedanken der Gesamtreform des Strafrechtes nicht aus den Augen verlieren, dem zufolge das Strafrecht und die Strafrechtsprechung so $\mathrm{zu}$ vereinheitlichen und konsequenter $\mathrm{zu}$ gestalten sind, dass sie den Werten und Zielen einer rationalen und humanen Kriminal- und Strafrechtspolitik entsprechen - vor allem den Kriminalisierungsprinzipien sowie den Grund- und Menschenrechten. Zum anderen muss man dabei den Bedarf an Modifizierung der konventionellen Allgemeinen Lehren des Strafrechtes erkennen und verstehen, dass sich diese Lehren nicht in allen ihren Teilen auf die Behandlung von Wirtschaftsdelikten anwenden lassen, obgleich das zentrale Anliegen unserer Strafrechtsreform gerade die Reformierung des Wirtschaftsstrafrechtes ist. Indem man einzelne Straftatbestände überprüft, kann man den Druck zu grundlosen Modifizierungen der Allgemeinen Lehren verringern.

\section{Beispiele für die Differenzierung des Wirtschaftsstrafrechtes}

Eine die Differenzierung des Wirtschaftsstrafrechts betreffende Frage ist zunächst einmal die, in welchem Umfang es in der Rechtsquellen- und Gesetzesauslegungslehre dieses Rechtsbereichs besondere Züge gibt. Nach allgemeiner Auffassung ist im Strafrecht neben der grammatikalischen Auslegung auch die Bedeutung der teleologischen und der damit eng verbundenen systematischen Auslegung besonders zu berücksichtigen. ${ }^{20}$ Im Zuge des Erstarkens

19 Tiedemann, Wirtschaftsstrafrecht (a.a.O, Fn 9), Rn 98. Siehe auch Tiedemann, in: Lahti / Nuotio (Hrsg.), Criminal Law Theory in Transition (a.a.O, Fn 2), S. 284: „Natürlich hat die Anwendung der Regeln des Allgemeinen Teils auf die Tatbestände des Besonderen Teils den Besonderheiten dieser Tatbestände Rechnung zu tragen.“

20 Vgl. zuletzt Hassemer, Juristische Methodenlehre und richterliche Pragmatik, in: Festschrift für Heike Jung, 2007, S. 231 ff. 
des Menschen- und Grundrechtsdenkens muss man auch den Hintergrundwerten vor allem des Legalitätsprinzips Aufmerksamkeit widmen, da diese häufig ein Gegengewicht zu den kriminalpolitischen Nutzaspekten bilden, die hinter der teleologischen Auslegung stehen. In Situationen der Erwägung dessen, ob ein Gesetz anzuwenden sei oder nicht, sind besondere Anforderungen an die Detailliertheit der Begründungen und die Offenheit des Urteils zu stellen, und die Rangordnung der Auslegungsargumente - die grammatikalische Auslegung ausgenommen - kann nicht allgemein festgelegt werden. Die Überzeugungskraft der in verschiedene Richtungen weisenden Begründungen ist unter anderem je nach dem Vorschriften- und Tätigkeitsumfeld zu beurteilen sowie danach, wie weit man sich von dem Kernbereich der Anwendung der jeweiligen Vorschrift und dem zentralen Schutzzweck derselben entfernt.

Bei der Auslegung des Wirtschaftsstrafrechtes kommt den letztgenannten Umständen ein besonderes Schwergewicht zu (siehe auch oben IV). ${ }^{21}$ Man benötigt des Weiteren auch theoretisch-methodologische Entwicklungsprozesse, um die ausreichende Konvergenz der in Frage kommenden Normen und der Fakten beurteilen zu können, indem man in sachgemäßer Weise die Prinzipien berücksichtigt, von denen sowohl die strafrechtliche Auslegung als auch die konkrete Anwendung des Gesetzes im Strafverfahren geleitet werden.

Die Differenzierung der Allgemeinen Lehren des Strafrechtes ist seit alters her dadurch in Erscheinung getreten, dass die Strukturen eines fahrlässigen Delikts und eines Unterlassungsdelikts in anderer Weise gegliedert werden als die Struktur des Basistyps des Delikts, das heißt der vorsätzlichen, durch aktives Handeln begangenen Straftat. Bei der Reformierung der Allgemeinen Lehren des Strafrechts sind diese Delikttypen unter anderem in den neuen einschlägigen Vorschriften (StGB Kapitel $3 \S \S 3$ und 7) zu sehen. Die Vorschriften lassen sehr viel Ermessensspielraum für die Weiterentwicklung der sie betreffenden Lehren in der Wechselwirkung zwischen Rechtswissenschaft und Rechtsprechung.

Des Weiteren ist anzumerken, dass mit der individuellen und gemeinschaftlichen Strafbarkeit von im Rahmen der Tätigkeit einer juristischen Person begangenen Straftaten besondere Züge verbunden sind, die sich weder mit den konventionellen Teilnahmevorschriften noch mit der Lehre über die Unterlassungsverantwortlichkeit handhaben lassen. Die Ingebrauchnahme der echten Kriminalstrafbarkeit der juristischen Person hat die Annahme einer neuen Verantwortungsform bei diesen so genannten Unternehmensdelikten bedeutet

21 Vgl. Tiedemann, Wirtschaftsstrafrecht (a.a.O, Fn 9), Rn 111-129. 
(siehe StGB Kapitel 9; 743/1995). ${ }^{22}$ In die Kapitel über die Arbeits- und Umweltdelikte wurden besondere, die Zuweisung der individuellen Verantwortung betreffende Vorschriften (StGB Kap. $47 \S 7$ und Kap. 48 §) aufgenommen. Bei der Reform der Allgemeinen Lehren des Strafrechtes (2003) wurde in den Zusammenhang mit den Vorschriften über die Teilnahme eine Vorschrift über das Handeln für eine juristische Person (StGB 5:8) aufgenommen.

Das Problem dieser neuen Vorschrift, die auf dem Vorbild des deutschen Strafrechtes (dStGB $\S 14$ ) basiert, besteht indes darin, dass sie die Prinzipien der Zuweisung der Verantwortung bzw. die Maßstäbe völlig undefiniert lässt, auch wenn man aus der neuen Vorschrift über die Strafbarkeit der Unterlassung und die Teilnahmevorschriften einen ergänzenden Auslegungshinweis erhält. Durch den Erlass des $\S 8$ im Kapitel 5 des StGB ist auf jeden Fall anerkannt worden, dass die mit unternehmerischer Tätigkeit verbundenen (wirtschaftlichen) Straftaten solche mit der Konstruierung der Verantwortung zusammenhängenden besonderen Züge aufweisen, die die Aufnahme einer Vorschrift in den Allgemeinen Teil des Strafrechtes begründen. Diese Vorschrift klärt auf jeden Fall die Bestimmung des Täterkreises und verstärkt die eingebürgerte Rechtspraxis, bei der der faktische Geschäftsführer mit der Leitungsperson in der Organstellung gleichgesetzt wird (siehe OGH 2000:74 sowie 2001:80 und 85-86).

Außer auf die Bestimmung der individuellen Strafverantwortung muss man seine Aufmerksamkeit auch auf die Anwendung der Strafverantwortung der juristischen Person richten, da diese Verantwortungsform bei uns in Finnland nur in sehr geringem Maße angewandt worden ist, wohingegen bei der strafrechtlichen Harmonisierung der EU dieser Verantwortungsform ein ziemlich hohes Gewicht beigemessen wird. Im Zusammenhang mit der Reformierung der Wirtschaftsstrafvorschriften (2003) wurde der Ermessensspielraum, der bei der Verurteilung einer juristischen Person zur Strafverantwortung bestanden hat, reduziert. Auch ansonsten sollte man die besonderen Züge der Unternehmensdelikte sowie das Verhältnis zwischen gemeinschaftlicher und individueller strafrechtlicher Verantwortung bei diesen Delikten erwägen. Die in den Forschungsprojekten zum Corpus Juris und den Europa-Delikten gemachten Vorschläge zu Vorschriften über die Regulierung der strafrechtlichen Verant-

22 Siehe näher Riihijärvi, Criminal Liability of Corporations - Finland, in: de Doelder / Tiedemann (eds), La Criminalisation du Comportement Collectif, 1996, S. 203 ff. 
wortung von Unternehmensleitern können hierfür beachtenswerte Vorbilder abgeben. ${ }^{23}$

Über die besonderen Züge der Wirtschaftsdelikte wurde bei der Reformierung der Allgemeinen Lehren des Strafrechtes auch im Zusammenhang mit der Ausformulierung der Vorschriften über den Vorsatz und den Irrtum (StGB Kap. $3 \S 6$; StGB Kap. $4 \S \S 1-3$ ) diskutiert. Die Wirtschaftsdelikte wurden in der Reformvorlage bei der Behandlung durch das Parlament als eine typische Deliktgruppe angeführt, für die die Bestimmung des untersten Grades des Vorsatzes in Bezug auf die Tatumstände allein anhand des Wahrscheinlichkeitsbegriffs - wie in der Reformlage des StGB Kap. $3 \S 6$ vorausgesetzt war erhebliche praktische Schwierigkeiten mit sich bringen würde. Im Wirtschaftsleben wird von den Akteuren eine recht weitgehende Pflicht der Informiertheit bzw. des Sich-Informierens über die finanzielle Situation des Unternehmens oder die Risiken der Tätigkeit vorausgesetzt. Die Verurteilung wegen einer vorsätzlichen Straftat sollte in solchen Fällen nicht nur davon abhängig sein, dass der Angeklagte faktisch das Vorliegen der einem Straftatbestand entsprechenden Tatumstände für recht wahrscheinlich gehalten hat, sondern häufig geht es um ein normativ gefärbtes Ermessen darüber, ob man der Ansicht sein kann, dass der Angeklagte auf die Richtigkeit der ihm gemachten Angaben hat vertrauen dürfen oder ob man ihm die besagte Pflicht zuschreiben kann, wenn in ihm ein begründeter Zweifel an der Unrichtigkeit der Angaben aufgekommen ist. ${ }^{24}$

Der Gesetzesausschuss des Parlaments hat aus der Vorsätzlichkeitsvorschrift die Bestimmung über den Vorsatz in Bezug auf die Tatumstände gestrichen, da er der Ansicht war, dass sich diese nur schlecht auf den Vorsatz in Bezug auf die Tatumstände von Wirtschaftsdelikten anwenden lasse und die Vorsatzschwelle anheben könne. Der Vorsatz in Bezug auf die Tatumstände wurde aufgrund der Vorschrift über den Tatbestandsirrtum der Rechtsprechung zur Beurteilung überlassen. ${ }^{25}$ Bis zum Ende des Jahres 2006 wurde nur ein einziges Präjudiz (OGH 2006:64) gefällt, das sich auf diese neuen Vorschriften

23 Siehe Delmas-Marty / Vervaele (eds), The Implementation of the Corpus Juris (a.a.O., Fn 6), Appendix III, Article 12; Tiedemann (Hrsg.), Freiburg-Symposium (a.a.O., Fn 5), Kap. E, Art. 15.

24 Siehe zur dieser Kritik vor allem Koponen, Intent in economic crime (Summary), in: Oikeustiede-Jurisprudentia XXXV (2002), S. 341 f. Vgl. auch zum Entwurf für Europa-Delikte, Freiburg-Symposium (a.a.O., Fn 5), Kap. E, Art. 5.

25 Siehe näher Cornils / Frände / Matikkala, Das finnische Strafgesetz (a.a.O., Fn 1), S. 20 f.; Matikkala, Dolus Nordicus, in: Nuotio (ed.), Festschrift in Honour of Raimo Lahti, Helsinki 2007, S. 221 ff. 
stützt, und bei diesem ging es um die Vorsätzlichkeit und den Tatbestandsirrtum bezüglich der Qualität eines Rauschmittels. Alle Mitglieder des OGH haben - anders als der Referent - auf diesen Fall den Wahrscheinlichkeitsvorsatz angewandt, aber es blieb unklar, welches die Linie des OGH hinsichtlich des Vorsatzes auf die Tatumstände bei andersartigen Straftaten ist und in was für ein Verhältnis der OGH den Wahrscheinlichkeitsvorsatz, den Tatbestandsirrtum gemäß StGB Kap. $4 \S 1$ und die absichtliche Unwissenheit zueinander stellen würde.

Mit der Anwendung der Wirtschaftsstrafvorschriften ist auch in höherem Maße als gewöhnlich die Grenzziehung zwischen dem Tatbestandsirrtum (StGB Kap. $4 \S 1$ ) und dem Verbotsirrtum (StGB Kap. $4 \S 2$ ) verbunden, vor allem da es in dem Gesetz keine Vorschriften über den sogenannten Subsumptionsirrtum gibt. ${ }^{26}$

Ein für Wirtschaftsdelikte kennzeichnender Zug ist der, dass statt einer einzelnen Tat häufig eine ganze Tatserie sowie das zu dieser gehörende Gesamtarrangement und deren Ziele, häufig auch sogar ein gewisses „Systemunrecht“, zu beurteilen sind. ${ }^{27}$ Dies ist problematisch für das Strafrechtsdenken, das die Schuld bei Einzeltaten und das Legalitätsprinzip (die genaue Bestimmung der strafbaren Taten) betont. Bei der gesamtheitlichen (materiellen) Betrachtung von Tatserien kann es zum Beispiel von zentraler Bedeutung sein zu klären, was für wirtschaftliche Veräußerungs- oder sonstigen Handlungen sachlich gesehen vorliegen, wer die faktischen Auftraggeber von Vermögensdisponierungen sind und ob die Vermögenssubjekte wirklich voneinander getrennt sind. ${ }^{28}$ Aus der Rechtsprechung liegen vorläufig nur einige wenige Rechtsfälle vor, die die Einschätzung dieser Fragen klären würden (siehe jedoch OGH 2003:13).

\section{Ist die Reformierung des Wirtschaftsstrafrechts gelungen?}

Aus dem Obigen dürfte hervorgegangen sein, dass, wie bereits im Voraus zu erwarten war, wegen des Inhalts und der Form der Vorschriften mit der An-

26 Vgl. zum Entwurf für Europa-Delikte, Freiburg-Symposium (a.a.O., Fn 5), Kap. E, Art. 5 (2) und Vogel, Voraussetzungen und Ausschluss der subjektiven Zurechnung, ibid. S. 125 ff. (139 ff.). Zur Irrtumslehre näher siehe Tiedemann, Wirtschaftsstrafrecht (a.a.O., Fn 9), § 4.IV.

27 Zur diesen Entwicklung siehe näher Heine, Kollektive Verantwortlichkeit, in: Eser et al. (Hrsg.), Einzelverantwortung und Mitverantwortung im Strafrecht, 1998, S. 95 ff. (96).

28 Vgl. Tiedemann, Wirtschaftsstrafrecht (a.a.O., Fn 9), § 4.II.4: „Schein- und Umgehungshandlungen". 
wendung des Wirtschaftsstrafrechts durchschnittlich mehr Probleme auftreten als normal. Es kommt häufig zu schwierigen Auslegungsproblemen, da die Strafvorschriften von allgemeinerer Natur sind als zuvor und die Tatbestände viele normative Begriffe enthalten. Die Einbürgerung der bei der Anwendung der Vorschriften einzuhaltenden Auslegungen setzt eine mit der Mitwirkung der Rechtsprechung und Rechtswissenschaft erfolgende Entwicklung des geltenden Rechts voraus. Dies braucht seine Zeit.

Bedeutsame Präjudizien des Obersten Gerichtshofes, in denen es um Wirtschaftsstraftaten geht, erhält man nur mit ziemlicher Verzögerung, und die Rechtshinweise, die in ihnen enthalten sind, sind fragmentarisch. Mit anderen Worten: erst auf der Grundlage von zahlreichen Präjudizien, in denen es um dieselben Vorschriften geht, präzisieren sich die Auslegungen dieser Vorschriften. Zum Beispiel was die Schuldnerdelikte betrifft, ergingen bedeutende Präjudizien erst fünf Jahre nach der Reform (OGH 1995:64 und 163). Die ersten Präjudizien betreffend die Auslegung des Tatbestands der Zahlungsunfähigkeit bei einem Steuervergehen wurden desgleichen erst fünf Jahre nach dem Inkrafttreten der einschlägigen Vorschriften gefällt (OGH 1995:137 und 1996:35), und eine besonders bedeutsame Leitentscheidung erging erst nach fast zehn Jahren (OGH 2004:46). Bei den von juristischen Personen begangenen Straftaten haben sich die Prinzipien der Zuweisung der Verantwortung erst auf der Grundlage von Präjudizien, die sich über mehrere Jahrzehnte verteilen, präzisiert, und die Verantwortungsstellung derjenigen Person, die die wirkliche Verfügungsgewalt ausübt, hat sich nach wechselhafter Rechtspraxis in den vergangenen zwanzig Jahren erst durch Entscheidungen des Jahres 2001 klarer abgezeichnet (OGH 2001:85-86) - zwei Jahre bevor dieser Verantwortungsgrund gesetzlich niedergeschrieben wurde (StGB Kap. $5 \S 8$ und Kap. $30 \S \S 9$ 10).

Ab dem Ende der 90er Jahre ist in Finnland das Interesse der Rechtswissenschaft an dem Wirtschaftsstrafrecht gestiegen. In den Dissertationen aus dem Bereich des Wirtschaftsstrafrechtes ist es um allgemeine Fragen aus dem Gewichtswinkel des Strafrechtes und Strafprozessrechtes, um die Straftaten gegen den Wertpapiermarkt und um Betrug in Geschäftsbeziehungen gegangen. Die Grundlagenforschung auf diesem Gebiet hat das methodologische und theoretische Fundament für die Weiterentwicklung dieses Rechtsbereichs bereitgestellt, und Monographien zum Besonderen Teil haben die Wirtschaftsstrafvorschriften systematisiert und interpretiert. ${ }^{29}$ 
Wenn man darüber ein Urteil fällen soll, wie die Reformierung der Wirtschaftsstrafvorschriften in der ersten und zweiten Phase (1990, 1995) gelungen ist, so besteht ein wichtiges Messinstrument darin, wie bald die Überprüfung dieser Vorschriften aktuell geworden ist. Man kann sagen, dass man sehr bald schon Veränderungen hat vornehmen müssen. Zunächst einmal hat sich bei den Missbrauchsfällen im Zuge der Bankenkrise die Vorschrift betreffend den Missbrauch einer Vertrauensposition (StGB Kap. $36 \S 5$ ) als problematisch erwiesen, und zwar wegen der vom Verletzten ausgehenden Klageregelung und der damit verbundenen besonderen Verjährungsfrist. Das Anklagerecht wurde dann auch erweitert, und zugleich wurden die Vorschriften über die Schuldnerdelikte überprüft (317/1994). Eine größere Überprüfung der Wirtschaftsstrafvorschriften wurde aufgrund einer Grundsatzentscheidung der Regierung (1998) in Auftrag gegeben. Allerdings beschränkte man sich dabei auf solche Korrekturen, die am dringlichsten vorgenommen werden mussten, unter anderem auf die Novellierung der Vorschriften über die Buchhaltungsdelikte und die Geldwäsche (61/2003). Gleichzeitig wurde die Regulierung der Strafverantwortung der juristischen Person (im Kapitel 9 des StGB) geändert, um ihre Anwendung zu effektivieren. Nach Finnlands Beitritt zur Europäischen Union im Jahre 1995 haben sich die Vorschriften der EU vor allem auf die Regulierung der Geldwäschedelikte und die Straftaten gegen den Wertpapiermarkt stark ausgewirkt. Der so genannte Gemeinschaftsbetrugsvertrag der EU (1998) hat zu einigen Änderungen an den Vorschriften über die Subventionsdelikte und den Steuerbetrug geführt (814/1998).

Der Gesetzesausschuss des Parlaments hat bei seiner Behandlung der Vorlage zu der ersten Phase der Gesamtreform des Strafrechtes geäußert, dass „das Strafrecht seine Aufgabe selbst über Jahrzehnte hinweg mit relativ wenigen Änderungen erfüllen soll, und zwar trotz der Wandlungen in der Gesellschaft und in den Lebensbedingungen der Menschen“. Das Tempo der Veränderungen im Wirtschaftsstrafrecht war jedoch viel schneller, als man sich bei der Niederschrift des obigen Satzes hatte vorstellen können. Damals hatte man auch noch nicht das Anwachsen der international- und europarechtlichen Kriminalisierungsverpflichtungen voraussehen können.

keuden yhtymäkohdassa (Abstract: Economic crime at the crossing point of criminal law and criminal procedure), 2004; Tapani, Petos liikesuhteessa (Zusammenfassung: Betrug beim Austauschverhältnis), 2004; und Häyrynen, Arvopaperimarkkinoiden väärinkäyttö (Summary: Market abuse), 2006. 


\section{Schlussfolgerungen}

Die Formen, in denen die Wirtschaftskriminalität auftritt, sind immer vielfältiger, verwickelter und internationaler geworden. Diese Besorgnis erregende Entwicklung stellt für die Behörden und ihre Zusammenarbeit untereinander sowie für die internationale Kooperation in Rechtssachen eine große Herausforderung dar. Materielle Gesetzgebung wie das Strafrecht muss dazu bereit sein, sich in einem schnelleren Takt als früher zu erneuern, damit man in der Lage ist, in Missbräuche zu intervenieren, auch wenn es natürlich immer noch so ist, dass legislative Reformen stets mit einer gewissen Verzögerung erfolgen. An den Qualitätsforderungen, die an die Strafgesetzgebung zu stellen sind, muss man indes ebenso festhalten wie an der Gründlichkeit der Gesetzesausarbeitung.

Die beschriebene Entwicklung stellt auch die rechtswissenschaftliche, empirische und kriminalpolitische Forschung im Bereich des Wirtschaftsstrafrechtes vor eine Herausforderung, da es gilt, den gesetzgebenden Organen, den Gesetzeshütern und den Justizbehörden zeitgemäße juristische Instrumente in die Hand zu geben, mit denen sich verdächtige und zu verfolgende Tatweisen beurteilen und klären lassen. Wenn man von den Herausforderungen spricht, vor die die zukünftige Erforschung der Wirtschaftskriminalität und des Wirtschaftsstrafrechtes gestellt werden, so ist es wichtig, die besonderen Züge dieser Forschung herauszustellen: ihre Inter- und Multidisziplinarität. Dies ist verständlich, da der Rechtsbereich eng an den Begriffsapparat und damit an die Auslegungen der materiellen (wirtschaftlichen) Gesetzgebung - des Vermögens-, Unternehmens- und Steuerrechts sowie des Insolvenzrechtes, eines neuen Rechtsbereichs - gebunden ist. Desgleichen setzt das Verständnis der juristisch zu beurteilenden wirtschaftlichen Transaktionen, der komplexen Arrangements und sonstiger Handlungen wirtschafts- und verhaltenswissenschaftliche Kenntnisse sowie Kenntnisse der Buchhaltungsprinzipien und des Tätigkeitsumfelds des Geschäftslebens voraus.

Mittels Forschungsarbeit sind vor allem auch die Allgemeinen Lehren des Wirtschaftsstrafrechtes weiterzuentwickeln, die sich - gemäß der Natur der Allgemeinen Lehren der Rechtsbereiche - überhaupt nur zum Teil durch Gesetzgebung bestimmen lassen, da sie einer tieferen Struktur der Rechtskultur angehören, weswegen der sie betreffende legislative Wandel besonders langsam ist. Das Wirtschaftsstrafrecht bildet einen Teil des modernen Strafrechts, über dessen allgemeine und besondere Lehren auch auf internationaler Ebene 
nicht sehr viel wissenschaftliche Diskussion geführt worden ist. ${ }^{30}$ Der Jubilar Klaus Tiedemann hat als Bahnbrecher der wirtschaftsstrafrechtlichen Forschung in der internationalen Wissenschaftsgemeinschaft sowie als Schlüsselperson in den genannten Forschungsprojekten zum Corpus Juris und zu den Europa-Delikten eine ganz zentrale Position eingenommen. Da die Harmonisierung des Strafrechtes vor allem im Bereich des Wirtschaftsstrafrechtes erfolgt, ist die Zusammenarbeit zwischen den Wissenschaftlern und Entscheidungsträgern in der Europäischen Union und darüber hinaus immer wichtiger geworden. Die genannten europäischen Projekte sowie als jüngstes Vorhaben der unter der Leitung von Bernd Schünemann ausgearbeitete alternative Vorschlag ${ }^{31}$ stellen grundlegende Dokumente für die weitere Arbeit dar.

30 Vgl. jedoch besonders Madrid-Symposium für Klaus Tiedemann, Bausteine des europäischen Wirtschaftsstrafrechts, 1994; Tiedemann (Hrsg.), Freiburg-Symposium (a.a.O., Fn 5).

31 Schünemann (Hrsg.), Ein Gesamtkonzept für die europäische Strafrechtspflege (a.a.O., Fn 16). 



\title{
Über die strafrechtliche Verantwortung der juristischen Person und die Organ- und Vertreterhaftung in Finnland ${ }^{1}$
}

\author{
1. Die Einführung der strafrechtlichen Verantwortung der \\ juristischen Person als ein Beispiel der Verstärkung und \\ Differenzierung des Wirtschaftsstrafrechts
}

In Finnland wurde in den Jahren 1972-2003 eine Gesamtreform des Strafrechtes verwirklicht, bei der das Wirtschaftsstrafrecht einen zentralen Teil gebildet hat. Von der Gesamtreform steht die Überprüfung einiger Vorschriften des Besonderen Teils des Strafgesetzes sowie die gesamte Kapitelsystematik des Besonderen Teils noch aus, aber ansonsten konnte die Rekodifizierung des aus dem Jahre 1889 stammenden Strafgesetzes im Jahre $2003 \mathrm{zu}$ einem faktischen Abschluss gebracht werden. ${ }^{2}$ Die Wirtschaftsstrafvorschriften wurden in den Jahren 1990, 1995 und 2003 in drei Gesetzgebungspaketen reformiert. Die grundlegenden Vorschriften über die strafrechtliche Verantwortung in der Form der echten Kriminalstrafbarkeit juristischer Personen finden sich im 9. Kapitel des reformierten StGB (GB1. 743/1995). Die wichtigsten den Allgemeinen Teil des Strafrechts betreffenden Vorschriften wurden in 2003 novelliert.

Die Ziele, Wirkungen und Grenzen des Wirtschaftsstrafrechts haben auch die Regelung der strafrechtlichen Verantwortung juristischen Personen beeinflusst. Die Ziele des reformierten Wirtschaftsstrafrechtes sind vor dem Hintergrund der allgemeinen Ziele der Gesamtreform des Strafrechtes zu sehen. Die wichtigste Aufgabe, die der Reformarbeit des Strafrechtskomitees gestellt worden

1 Eine frühere Version dieses Artikels ist auf Japanisch erschienen: Lahti, Comparative Law Review (Waseda University, Japan) Vol. 48, No. 3, 2015, S. 187 ff. Siehe auch Lahti, Über die Regelung der strafrechtlichen Verantwortung der juristischen Person. In: Ayşe Nuhoğlu (Ed.), Sanktionen gegen juristische Personen, Max-Planck-Institute for Foreign and International Criminal Law and Bahçeşehir University Joint Research Group, Volume T 2, 2013, S. 115 ff.

2 Siehe jetzt: Das Finnische Strafgesetz (nach dem Stand vom 1.10.2005). Übersetzung und Einführung von Karin Cornils, Dan Frände und Jussi Matikkala. Max-PlanckInstitut für ausländisches und internationales Strafrecht, 2006. 
war, hat darin bestanden, Überlegungen darüber anzustellen, was strafbar sein sollte und wie streng für die einzelnen Delikte zu bestrafen sei. Für die Bestimmung der Strafbarkeit der Taten und der festzusetzenden Strafdrohungen wurde ein Modell vorgebracht, nach dem zuerst die Nachteiligkeit und Vorwerfbarkeit der Tattypen zu beurteilen und dann die Vor- und Nachteile einer eventuellen Kriminalisierung im Vergleich zu den übrigen Regulierungsalternativen abzuwägen sei. Das Komitee betonte die das strafrechtliche System kennzeichnende Wirkung: die mittelbare Wirkung und die symbolische Bedeutung der Strafdrohungen. Mit den Strafvorschriften wird aufgezeigt, welches die für die Gesellschaft zentralen Ver- und Gebote seien. Durch die Existenz der Strafdrohungen und ihre Anwendung in der Praxis wird die autoritative Missbilligung der Gesellschaft ausgedrückt und somit Einfluss auf die Herausbildung der Rechts- und Moralvorstellungen der Bürger genommen. ${ }^{3}$

Die Vorarbeiten zur Strafrechtsreform spiegeln den begründeten Glauben an die generalpräventive Wirkung des strafrechtlichen Systems sowie an die Wichtigkeit der Prinzipien Gerechtigkeit und Humanität für die Legitimität des Strafrechtssystems wieder. Die Reduzierung der Kriminalität und ihrer Nachteile setzt eine vielseitige und wirkungsvolle Kriminalitätsbekämpfung und ein effektives strafrechtliches Kontrollsystem voraus. Von dem strafrechtlichen Kontrollsystem wird Glaubwürdigkeit und Legitimität erwartet, mit anderen Worten: man muss an die Funktionsfähigkeit des Systems glauben und auf seine Richtigkeit und Billigkeit vertrauen können. Der Schweregrad der Strafdrohungen bzw. der einzelnen Strafen bildet jedoch nur einen Teil der Umstände, die einen Einfluss auf die Funktionsfähigkeit des gesamten Systems haben. Es ist somit offenbar, dass man allein dadurch, dass man die Wirtschaftsstrafvorschriften aktualisiert und deren Strafdrohungen in ein gerechtes Verhältnis zu den Strafdrohungen der konventionellen Vermögensdelikte stellt, die angestrebte Wirksamkeit der Wirtschaftskriminalitätsprävention und -kontrolle nicht erreicht. Die Wirksamkeit des strafrechtlichen Systems ist maßgeblich von dem gesamten Strafprozess, d.h. von den Tätigkeitsvoraussetzungen der verschiedenen Behörden (der Aufsichts-, Polizei- und Anklagebehörden sowie der Gerichte) abhängig, die dafür zuständig sind, die Täter zur strafrechtlichen Verantwortung zu ziehen.

3 Siehe Komiteebericht 1976:72, Kapitel II-IV. Siehe auch im allgemeinen Lahti / Nuotio (Hrsg.), Criminal Law Theory in Transition / Strafrechtstheorie im Umbruch. Finnish Lawyers' Publishing Company, Helsinki 1992; Lahti, Das Wirtschaftsstrafrecht in der Gesamtreform des Strafrechts. Festschrift für Klaus Tiedemann, Carl Heymanns Verlag, 2008, S. $61 \mathrm{ff}$. 
Die mit Strafdrohungen bewehrten Strafvorschriften spielen bei der Bekämpfung und Kontrolle der Wirtschaftskriminalität dennoch eine eigene wichtige Rolle, wie das Strafrechtskomitee die Sachlage ausgedrückt hat. Allerdings hat man bei der Ausarbeitung der Strafrechtsreformen in Finnland, wie auch in anderen Ländern, eine lebhafte kritische Diskussion darüber geführt, ob das strafrechtliche System zur Vorbeugung und Kontrolle des Missbrauchs wirtschaftlicher Tätigkeit oder zur Förderung der Arbeitssicherheit und des Umweltschutzes geeignet sei oder ob dem Strafrecht nur eine rein symbolische Bedeutung zukomme. $^{4}$

Ein spürbares administratives Bußgeld - die Buße für Wettbewerbsverstöße wurde gemäß dem Vorbild des Wettbewerbsrechts der Europäischen Gemeinschaft in einem Gesetz über Wettbewerbsbeschränkungen (GBl. 480/1992) in Gebrauch genommen. Jedoch war es ein großer Mangel in Finnland, dass diejenigen punitiven administrativen Sanktionen, die besonders im Wettbewerbs- und Wertpapiermarktrecht wegen der Vorbildwirkung der EU in Gebrauch genommen worden sind, bei der Gesamtreform des Strafrechts keine reale Beachtung fanden und darum die Vor- und Nachtteile der punitiven administrativen Sanktionen im Verhältnis zu Kriminalstrafen im Gebiete des Wirtschafstrafrechts nicht systematisch erörtert wurden. ${ }^{\mathbf{5}}$

\section{Zur Strafverantwortung der juristischen Person in Finnland}

$\mathrm{Zu}$ den aus rechtsideologischer und internationaler Sicht bedeutenden Reformgedanken des Strafrechtskomitees (1977) hat der Vorschlag über die Einführung der strafrechtlichen Verantwortlichkeit von Kollektiven gehört: Die strafrechtliche Verantwortung müsse man auch dem Kollektiv selbst, der juristischen Person, zuweisen können. Diesem Gedanken folgend wurde im Jahre 1995 die Strafverantwortung der juristischen Person eingeführt (StGB Kapitel 9; 743/1995). ${ }^{6}$

4 Siehe u.a. die kritischen Beiträge im Forschungskolloquium „Finnisches Strafgesetz 100 Jahre“. In: Lahti / Nuotio (Hrsg.), Criminal Law Theory in Transition, a.a.O. (Fn. 3), insb. Kap. II und Hassemer, Kennzeichen und Krisen des modernen Strafrechts, S. $113 \mathrm{ff}$.

5 Siehe näher Lahti, Das moderne Strafrecht und das ultima-ratio-Prinzip. Festschrift für Winfried Hassemer, C. F. Müller Verlag, 2010, S. 439 ff.

6 Siehe auch Riihijärvi, Criminal Liability of Corporations - Finland. In: de Doelder / Tiedemann (eds.), La Criminalisation du Comportement Collectif, 1996, S. 203 ff.; Jaatinen, Corporate Criminal Liability and Neo-Classical Criminal Policy. Turku Law Journal 1/1999, S. 103 ff.; Frände, Strafbarkeit juristischer Personen aus finnischer Sicht. In: Hirsch (Hrsg.), Krise des Strafrechts und der Kriminalwissenschaften? 
Über die in Frage kommenden, bei der Tätigkeit der juristischen Person begangenen Delikte wurden separate Vorschriften erlassen (StGB 9:1.1). Zu solchen Delikten wurden in der Anfangsphase die Bestechungsdelikte (StGB 16:18; 563/1998), die Beihilfedelikte (StGB 29:10), die meisten von den Gewerbedelikten im Kapitel 30 des StGB (StGB 30:13), die Geldwäsche und die sonstigen schweren Hehlereidelikte (StGB 33:8), die Rationierungsdelikte und der Schmuggel (StGB 46:14) sowie die Umweltdelikte (StGB 48:9) bestimmt. Man erachtete den Bedarf dieser neuen Verantwortungsform für am offenbarsten bei der im weiten Sinne definierten Wirtschaftskriminalität, aber nicht alle Deliktstypen dieser Kriminalität - zum Beispiel Steuer-, Buchhaltungs-, Schuldner- oder Arbeitsdelikte - sind in den Kreis der neuen strafrechtlichen Verantwortlichkeit einbezogen worden. In den Begründungen zum Gesetz wird die Bedeutung der Erwägung der kriminalpolitischen Notwendigkeit und des Behutsamkeitsprinzips betont. Seitdem ist der Bereich der strafrechtlichen Verantwortlichkeit der juristischen Person insbesondere aufgrund der Vorschriften der Europäischen Union erweitert und diese Verantwortungsform auch auf Arbeitsschutzdelikte ausgedehnt worden.

Die Rechtsvorschriften über die strafrechtliche Verantwortlichkeit der juristischen Person sind in Finnland nun seit beinahe 20 Jahren in Kraft. Die in den Gesetzesbegründungen geäußerte Annahme, dass man nur selten Körperschaftsgeldstrafen verhängen würde, traf besonders in den Anfangsjahren zu. Damals wurden vor den Gerichten nur einige wenige Fälle der kollektiven Verantwortung gemäß Kapitel 9 des StGB verhandelt. Zum Teil hatte darauf der Umstand einen Einfluss, dass der Staatsanwalt kraft Kapitel 9 des StGB bis zur Gesetzesänderung des Jahres 2003 reichlich Ermessensspielraum hinsichtlich einer sanktionsartigen Verfolgung hatte. Danach ist es häufiger geworden, dass juristische Personen strafrechtlich verantwortlich gemacht werden, und u.a. die Präjudizien OGH (KKO) 2008:22 und 2009:1 des Obersten Gerichtshofs haben diesbezüglich eine steuernde Wirkung ausgeübt.

Als eine Erklärung für die recht gering gebliebene Anwendungspraxis lässt sich behaupten, dass das Kapitel 9 des StGB eine kritikanfällige symbolische Strafgesetzgebung repräsentiere. Zunächst einmal ist bei den in Frage kommenden Deliktstypen ganz allgemein eine strafrechtliche Verfolgung recht selten. Zum zweiten verlangt die Anwendung dieses recht diffizilen Vorschriftenwerks, dass die Verwirklichung der kollektiven Verantwortung zum Schwerpunktgebiet der Tätigkeit der Überwachungs-, Ermittlungs- und Ankla-

Duncker \& Humblot 2001, S. 228 ff.; Tolvanen, Trust. Business Ethics and Crime Prevention - Corporate Criminal Liability in Finland. Fudan Law Yournal 4/2009, S. 99 ff. 
gebehörden gemacht wird. Das würde verlangen, dass man den zuständigen Behörden Schulung über die Prinzipien der neuen Verantwortungsform zukommen lässt und Ressourcen in die Untersuchung der Voraussetzungen der kollektiven Verantwortung und das Ermessen betreffend die Anklageerhebung investiert.

Für den sparsamen Gebrauch der strafrechtlichen Verantwortlichkeit der juristischen Person spricht - außer der schwachen Funktionsfähigkeit der Klärung der Verwirklichung der kollektiven Verantwortung - auch die Entwicklung von alternativen Mitteln für diese. Das Strafrechtskomitee hat in seinem Bericht derartige Mittel behandelt, und zwar als zentrales von ihnen die Effektivierung der individuellen Verantwortung. Neben der Einführung der strafrechtlichen Verantwortlichkeit von Körperschaften sollte man auch eine solche Regulierung entwickeln, die die individuelle strafrechtliche Verantwortung für die bei der Tätigkeit der Körperschaft begangenen Delikte betonen und die Klärung der individuellen Schuld effektivieren würde. Derselbe Standpunkt wurde auch in der späteren Regierungsvorlage hervorgehoben. Obgleich es also möglich sein muss, die strafrechtliche Verantwortlichkeit der juristischen Person selbst zuzuweisen, so müsste man auch diejenigen Prinzipien genauer herausarbeiten, nach denen man die strafrechtliche Verantwortlichkeit einer oder mehreren natürlichen Personen zuweisen könnte, die im Namen und / oder zugunsten einer juristischen Person gehandelt haben.

Es ist angebracht, diesen Ausgangspunkt der Vorarbeiten des Gesetzes weiter zu präzisieren. Eine gesetzgeberische Klärung ist dabei keine ausreichende Maßnahme. Ein zu empfehlendes Mittel besteht darin, dass man die Verantwortungslehre betreffend die in der Tätigkeit einer juristischen Person begangenen Delikte mittels strafrechtstheoretischer Forschung zur kohärenten Anwendung weiterentwickelt. Die gewachsene gesellschaftliche Bedeutung von Unternehmen und allgemeiner von Organisationen hat auch ansonsten den Bedarf verstärkt, die Organisations- oder Körperschaftsdelikte und deren Regulierung zu erforschen. Dieser Entwicklungszug ist ein Beispiel für die Modernisierung des Strafrechts, wie sie für den Wohlfahrtsstaat typisch ist. Das Strafrechtssystem wird bei diesem Wandel nicht in einheitlicher Form erhalten bleiben, sondern es wird eine gewisse Differenzierung eintreten gleich ob man nun mit dem System den juristischen Systemaspekt oder den soziologische Kontrollmechanismus meint.

In der ausländischen Rechtsliteratur hat man entsprechend in zunehmendem Maße die Probleme der strafrechtlichen Unternehmerverantwortung und / oder des Körperschaftsstrafrechts untersucht. Diese Betrachtung ist eng mit dem Wirtschaftskriminalrecht verbunden gewesen, da im Allgemeinen das Augen- 
merk auf in unternehmerischer oder gewerblicher Tätigkeit begangene Delikte gerichtet wurde, bei denen es sich typischerweise um Wirtschaftsdelikte handelt. Bemerkenswert ist der Umstand, dass man bei einer solchen juristischen Analyse parallel zueinander ebenso die Voraussetzungen und Sanktionen der kollektiven wie der individuellen Verantwortung erörtert hat. Man sollte auch in der finnischen Diskussion beide Verantwortungsformen als interaktive Teile eines neuartigen Verantwortlichkeitssystems sehen, die sich auf der Basis eines parallelen strafrechtstheoretischen Denkmodells evaluieren lassen. Und zwar ungeachtet dessen, dass man bei der Verabschiedung des Kapitels 9 des StGB nicht bestrebt gewesen war, die fraglichen Verantwortungsformen systematisch aneinander anzupassen.

Für einen Vergleich ist der schwedische Gesetzesentwurf (1997) über die Einführung der strafrechtlichen Verantwortlichkeit für die juristische Person von Interesse, der nicht verwirklicht worden ist, sondern man hat in Schweden für die juristische Person als eine verhängbare Sanktion eine Sicherungsmaßnahme beschlossen, die mit der Konfiskation vergleichbar ist. Dem besagten Entwurf zufolge wäre die Möglichkeit, eine Körperschaftsgeldstrafe zu verhängen, in erster Linie mit solchen in gewerblicher Tätigkeit begangenen Delikten verbunden, für die man eine natürliche Person aufgrund der Prinzipien über die unternehmerische Verantwortung (die Zuweisung der strafrechtlichen Verantwortlichkeit) verurteilen kann. Die wichtigsten Prinzipien dieser Verantwortung hätte man im Gesetz niederschreiben müssen, und bei weniger schweren Delikten wäre es die erstrangige Verfolgungsalternative gewesen, die juristische Person strafrechtlich verantwortlich zu machen.

Eine solche in Schweden vorgeschlagene Regulierungsweise zur Harmonisierung von körperschaftlicher und individueller Verantwortlichkeit würde auch in der finnischen Gesetzgebung eine Verbesserung darstellen. Sie würde die Anwendungspraxis der Behörden erleichtern und vereinheitlichen. Man könnte eine solche Entscheidung auch mit einem solch gleichartigen grundsätzlichen Aspekt befürworten wie dem finnischen Modell über die körperschaftliche Verantwortung. Die strafrechtliche Verantwortlichkeit der juristischen Person hat somit Berührungspunkte mit den die individuelle strafrechtliche Verantwortlichkeit betreffenden Prinzipien, und die Wahl zwischen diesen Verantwortungsformen müsste man deutlicher als bisher gestalten. 


\section{3. Über die Wechselwirkung zwischen der Verantwortlichkeit von natürlichen und nicht-natürlichen Personen für Straftaten in Unternehmen, Verbänden und anderen Kollektiven ${ }^{7}$}

Gleichzeitig mit der Einführung der strafrechtlichen Verantwortlichkeit der juristischen Person wurden bei der Reformierung des Strafgesetzes (578/1995) in die neuen Kapitel über Arbeits- und Umweltdelikte, in den $\S 7$ des Kapitels $47 \mathrm{StGB}$ und in den $\S 7$ des Kapitels 48 Regeln über die Zuweisung der individuellen strafrechtlichen Verantwortlichkeit (d.h. über die Organ- und Vertreterhaftung) aufgenommen. Bei der Erwägung der Voraussetzungen dieser Verantwortungsform wird das Augenmerk auf Delikte gerichtet, die von einer juristischen Person oder einer mit ihr vergleichbaren Instanz bei unternehmerischer oder sonstiger organisierter Tätigkeit begangen werden. Die Zuweisung der strafrechtlichen Verantwortlichkeit ist in den klassischen Allgemeinen Lehren des Strafgesetzes in erster Linie mit den Grundsätzen über die Teilnahme, die Unterlassungshaftung und die Fahrlässigkeit verbunden.

Die Regulierung der individuellen strafrechtlichen Verantwortlichkeit bei Organisationsstraftaten ist in dem Strafgesetzprojekt - der Projektorganisation des Justizministeriums, die die Gesamtreform des Strafgesetzes ausgearbeitet hat - die letzte Frage der strafrechtlichen Verantwortungslehre gewesen. Die vom Strafgesetzprojekt eingesetzte Arbeitsgruppe hatte zwei alternative Regulierungsvorschläge ausgearbeitet. Dem ersten, siegreich gebliebenen Vorschlag zufolge ist es ausreichend, dass im Kapitel über den Versuch und die Teilnahme eine Bestimmung über das Handeln für einen anderen getroffen wird, während zugleich in das neue Strafgesetz eine allgemeine Vorschrift über die Strafbarkeit der Unterlassung aufgenommen wird. Dem zweiten Vorschlag zufolge sollte man in den Allgemeinen Teil des Strafgesetzes auch eine Gesetzesstelle aufnehmen, die den Rechtsvorschriften der $\S \S$ 47:7 und 48:7 des StGB entspricht und die besonderen Regeln weitgehend ersetzt. Die Rechtsvorschrift (StGB, 5:8), die im Jahre 2003 im Zusammenhang mit der Reformierung des Allgemeinen Teils des StGB in das Strafgesetz aufgenommen wurde, hat den folgenden Inhalt:

Handeln für eine juristische Person.

(1) Wer einem gesetzlich vorgeschriebenen Organ oder der Leitung einer Gesellschaft, einer Stiftung oder einer anderen juristischen Person angehört sowie wer innerhalb einer juristischen Person tatsächlich Entscheidungsbefugnis ausübt oder

7 Vgl. im allgemeinen Yamanaka, Parallele Bestrafung von juristischen und natürlichen Personen. In: Yamanaka, Strafrechtsdogmatik in der japanischen Risikogesellschaft. Nomos 2008, S. 78 ff. 
aufgrund eines Amtsstellungs- oder Dienstverhältnisses oder Auftrags sonst für die juristische Person handelt, kann wegen einer im Rahmen ihrer Tätigkeit begangenen Straftat bestraft werden, auch wenn er die besonderen für den Täter geltenden tatbestandsmäßigen Voraussetzungen nicht erfüllt, sofern die juristische Person diese Voraussetzungen erfüllt.

(2) Ist eine Straftat in dem Geschäft eines Gewerbetreibenden oder im Rahmen einer anderen mit der Tätigkeit einer juristischen Person gleichzustellenden organisierten Tätigkeit begangen worden, so sind die Vorschriften des Absatzes 1 über eine im Rahmen der Tätigkeit einer juristischen Person begangene Straftat entsprechend anzuwenden.

(3) Die Vorschriften dieses Paragraphen finden keine Anwendung, sofern an anderer Stelle gesetzlich etwas anderes vorgesehen ist. ${ }^{\mathbf{8}}$

Im Folgenden ist es mein Ziel, diese mit der Zuweisung der strafrechtlichen Verantwortlichkeit und deren Regelung verbundenen rechtlichen Probleme zu erörtern und ihren Hintergrund zu skizzieren. Im Mittelpunkt der Betrachtung steht der Versuch, das Verhältnis zwischen kollektiver und individueller strafrechtlicher Verantwortlichkeit sowie die Prinzipien, die darauf einen Einfluss habe, zu klären. Ich beleuchte diese Abhandlung anhand von Präjudizien des Obersten Gerichtshofes.

Es ist anzumerken, dass mit der individuellen und gemeinschaftlichen Strafbarkeit von im Rahmen der Tätigkeit einer juristischen Person begangenen Straftaten besondere Züge verbunden sind, die sich weder mit den konventionellen Teilnahmevorschriften noch mit der Lehre über die Unterlassungsverantwortlichkeit handhaben lassen. Die Einführung der echten Kriminalstrafbarkeit der juristischen Person in 1995 hat die Annahme einer neuen Verantwortungsform bei diesen so genannten Unternehmensdelikten bedeutet, weil die individuelle Strafbarkeit traditionell in der Rechtspraxis und Doktrin anerkannt worden ist. In die Kapitel über die Arbeits- und Umweltdelikte wurden besondere, die Zuweisung der individuellen Verantwortung betreffende Vorschriften

8 Die Rechtsvorschrift, für die sich die Minderheit ausgesprochen hatte, lautet wie folgt: „Die Zuweisung der strafrechtlichen Verantwortlichkeit aufgrund einer in der Tätigkeit einer juristischen Person begangenen Straftat

(1. Absatz wie in der von der Mehrheit unterstützen Vorschrift.)

(2) Ist in der Tätigkeit einer juristischen Person oder für diese eine Straftat begangen worden, so wird derjenige als Täter zu einer Strafe verurteilt, dem die Verwirklichung der Straftat durch eine Handlung oder Unterlassung anzurechnen ist. Bei der Einschätzung dessen sind neben den sich aus dem Straftatbestand ergebenden Voraussetzungen auch die Position der betreffenden Person in der juristischen Person, die Art, der Umfang und die Klarheit seiner Aufgaben und Befugnisse sowie seine berufliche Qualifikation zu berücksichtigen.

(3. Absatz wie in Absatz 2 der von der Mehrheit angenommenen Vorschrift.)“ 
(StGB Kap. $47 \S 7$ und Kap. $48 \S 7$ ) aufgenommen. Bei der Reform der allgemeinen Lehren des Strafrechtes (2003) wurde in den Zusammenhang mit den Vorschriften über die Teilnahme eine Vorschrift über das Handeln für eine juristische Person (StGB 5:8) aufgenommen.

Das Problem dieser neuen Vorschrift (StGB 5:8), die auf dem Vorbild des deutschen Strafrechtes (dStGB § 14) basiert, besteht indes darin, dass sie die Prinzipien der Zuweisung der Verantwortung bzw. die Maßstäbe völlig undefiniert lässt, auch wenn man aus der neuen Vorschrift über die Strafbarkeit der Unterlassung und die Teilnahmevorschriften einen ergänzenden Auslegungshinweis erhält. Durch den Erlass des $\S 8$ im Kapitel 5 des StGB ist auf jeden Fall anerkannt worden, dass die mit unternehmerischer Tätigkeit verbundenen (wirtschaftlichen) Straftaten solche mit der Konstruierung der Verantwortung zusammenhängenden besonderen Züge aufweisen, die die Aufnahme einer Vorschrift in den Allgemeinen Teil des Strafrechtes begründen. Diese Vorschrift klärt auf jeden Fall die Bestimmung des Täterkreises und verstärkt die eingebürgerte Rechtspraxis, bei der der faktische Geschäftsführer mit der Leitungsperson in der Organstellung gleichgesetzt wird (siehe OGH 2000:74 sowie OGH 2001:80 und 85-86).

Man sollte theoretisch die besonderen Züge der Unternehmensdelikte sowie das Verhältnis zwischen gemeinschaftlicher und individueller strafrechtlicher Verantwortung bei diesen Delikten erwägen. Gegenwärtig besteht die strafrechtliche Verantwortung des Individuums für im Auftrag oder zu Gunsten der juristischen Person begangene Delikte (d.h. die Organ- oder Vertreterhaftung) parallel zur Verantwortung der juristischen Person. Es besteht die Gefahr, dass diese parallel zur Verfügung stehenden Verantwortungsformen $\mathrm{zu}$ einer tatsächlichen Sanktionskumulation führen können (siehe OGH 2002:39; vgl OGH 2009:1). Man kann auch fragen, ob es prozessökonomisch wünschenswert wäre, dass die Staatanwaltschaft mehr Ermessensraum hätte, um der mehr zweckentsprechenden Verantwortungsform den Vorrang in der Strafverfolgung zu geben (vgl. die Praxis in Dänemark).

Die in den Forschungsprojekten zu dem Corpus Juris und den Europa-Delikten gemachten Vorschläge zu Vorschriften über die Regulierung der individuellen strafrechtlichen Verantwortung von Unternehmensleitern können hierfür beachtenswerte Vorbilder abgeben. 9

9 Siehe Delmas-Marty / Vervaele (eds.), The Implementation of the Corpus Juris I-IV. Intersentia 2000-2001, Appendix III, Article 12; Tiedemann (Hrsg.), Wirtschaftsstrafrecht in der Europäischen Union, Freiburg-Symposium. Carl Heymanns Verlag 2002, Kap. E, Art. 15. 


\section{4. Über die Zurechnungsstruktur der strafrechtlichen Verantwortung der juristischen Person ${ }^{10}$}

Die Zurechnungsstruktur der echten Kriminalstrafbarkeit ist im Kapitel 9 des finnischen StGB nicht ganz klar (siehe auch Anlage). In erster Linie denkt man, dass die juristische Person aufgrund der Tat eines individuellen (in Ausnahmefällen auch anonymen) Täters bestraft wird, aber andererseits ist in der Regelung eine gewisse kollektive, ,gemeinschaftliche“ Schuld oder Zurechenbarkeit erkennbar.

Zunächst einmal ist mit dem Verantwortungsobjekt eine Körperschaft, Stiftung oder sonstige juristische Person gemeint. Als Sanktion für die Straftat kommt nur eine gemeinschaftliche Geldstrafe in Frage. Juristische Personen zur strafrechtlichen Verantwortung zu ziehen ist nur dann möglich, wenn dies im StGB bei dem jeweiligen Deliktstyp gesondert vorgesehen ist. Solche Deliktstypen sind typischerweise solche Wirtschaftsdelikte wie Gewerbedelikte, Subventionsdelikte, Geldwäschedelikte und Umweltdelikte.

Als zweite Grundvoraussetzung für die gemeinschaftliche Verantwortung gilt, dass eine Straftat im Rahmen der Tätigkeit der juristischen Person begangen wurde. Diese Verantwortungsform kommt jedoch nicht in Frage, wenn das Delikt bei der Ausübung öffentlicher Gewalt begangen wurde. Das Delikt gilt als im Rahmen der Tätigkeit der juristischen Person begangen, wenn der Täter im Auftrag oder zu Gunsten der juristischen Person gehandelt hat, wenn er der Leitung der juristischen Person angehört oder zu dieser in einem Angestelltenoder Dienstverhältnis steht oder wenn er aufgrund eines Auftrags gehandelt hat, den er von einem Vertreter der juristischen Person erhalten hat. Es ist jedoch nicht unbedingt notwendig, dass ein solcher individueller Täter ermittelt oder bestraft wird.

Zum dritten setzt die gemeinschaftliche Verantwortung die oben genannte gemeinschaftliche Schuld (durch Identifizierung oder Geschäftsherrnhaftung) voraus. Eine zu einem gesetzmäßigen Organ oder zur sonstigen Leitung der juristischen Person gehörende Person muss an der Straftat beteiligt sein oder die Tat zugelassen haben, es sei denn, dass im Rahmen der Tätigkeit der juristischen Person nicht die gegebene Sorgfalt und Vorsicht zur Verhütung der Straftat gewahrt wurde. Bei einem Ölraffinerieunfall (OGH 2008:33) war die Streitfrage, ob die Angeklagten einer solchen Leitung gehörten, d.h. ob sie

10 Vgl. z.B. Böse, Strafbarkeit juristischer Personen - Selbstverständlichkeit oder Paradigmenwechsel im Strafrecht. ZStW 2014; 126(1), S. 132 ff., 136 ff. 
eine ausreichende selbständige und bedeutende Beschlussfassung in der Aktiengesellschaft ausübten oder nicht.

Zum vierten lagen die Strafverfolgung sowie die Bestrafung der juristischen Person im weiten Ermessen der Strafverfolgungsbehörden und Gerichten. Diese Regelung führte dazu, dass in den ersten zehn Jahren nur ungefähr zehn Fälle in den Untergerichten behandelt wurden. Die strafrechtliche Verantwortung wurde also vorwiegend als eine symbolische gesetzliche Regelung dargestellt. Mit einer neuen Gesetzesänderung (61/2003), die den Ermessensspielraum für die Bestrafung vermindert, bezweckte man die Zahl der Strafverfolgungen zu vermehren, und eine solche Entwicklung ist auch wahrnehmbar.

\section{5. Über die Grundzüge der Regelung der Organ- und Vertreterhaftung}

Welches sind nun die für die Zuweisung der strafrechtlichen Verantwortlichkeit charakteristischen Züge, die möglicherweise von den Grundsätzen des klassischen Strafrechts abweichen? Eine Antwort auf diese Frage setzt die Analyse der inhaltlichen Tatbestände und des Grundgedankens der strafrechtlichen Verantwortlichkeit voraus.

Aus den Gesetzen 47:7 und 48:8 des StGB lässt sich ein solcher Grundgedanke nicht leicht herauslesen. Der Hauptinhalt der erstgenannten Gesetzesstelle wird mit einem Satz ausgedrückt, dem zufolge für eine im Kapitel 47 des StGB als strafbar bestimmte Handlungsweise des Arbeitgebers oder dessen Repräsentanten derjenige zu einer Strafe verurteilt wird, gegen dessen Pflichten die Tat oder Unterlassung verstößt. Entsprechend wird in der zweiten Gesetzesstelle gesagt, dass für eine im Kapitel 48 des StGB als strafbar bestimmte Handlungsweise derjenige bestraft wird, gegen dessen Pflichten die Tat oder Unterlassung verstößt. Beide Gesetzesstellen enthalten zudem einen Hinweis darauf, was bei der Zuweisung der Verantwortlichkeit zu berücksichtigen sei: die Position der betreffenden natürlichen Person, die Art und der Umfang ihrer Aufgaben und Befugnisse sowie ansonsten ihr Anteil an der Entstehung oder der Fortdauer des gesetzwidrigen Zustands.

Aus den Begründungen der Vorschriften geht ihr Zweck hervor. Das Vorbild hat der Absatz 4 (im Gesetz 27/1987) des $\S 48$ des Arbeitsschutzgesetzes (299/1958) abgegeben, welcher sich wiederum auf eine eingebürgerte Rechtspraxis gestützt hat. In den Begründungen des Kapitels über Arbeitsdelikte wie auch des Kapitels über Umweltdelikte wird vorgebracht, dass die Regulierung der Zuweisung der Verantwortlichkeit zur Bestimmung der Verantwortungs- 
subjekte bei Straftaten, die in der unternehmerischen oder sonstigen organisierten Tätigkeit begangen werden, vonnöten ist. Die Arbeitsgesetzgebung bezieht sich typischerweise auf Arbeitgeber in Form von Körperschaften sowie auf interne Strukturen innerhalb dieser, die Umweltschutzgesetzgebung wiederum auf Unternehmen, die Produktionstätigkeit ausüben.

Entsprechend richten sich die Ge- und Verbote in denjenigen Strafvorschriften, die zur Effektivierung der Arbeits- und Umweltschutzgesetzgebung erlassen worden sind, an erster Stelle an diejenigen Personen, die für die besagte Tätigkeit verantwortlich sind - und weniger auf die bei einer solchen Tätigkeit geschehenen einzelnen Taten oder Unterlassungen. Als Hintergrundgedanke in der schwedischen Lehre über die Verantwortung des Unternehmers hat das Bedürfnis gegolten, die strafrechtliche Verantwortlichkeit derjenigen natürlichen Person bzw. denjenigen natürlichen Personen zuzuweisen, die über die besten Möglichkeiten verfügen, die bei der unternehmerischen Tätigkeit vorkommenden Straftaten zu verhindern, indem sie die Tätigkeit in zweckmäBiger Weise leiten, organisieren und überwachen. Somit sollte die Möglichkeit gegeben sein, ausdrücklich die der Leitung des Unternehmens angehörende(n) Person(en) zur strafrechtlichen Verantwortung zu ziehen, und zwar nicht nur für ihr eigenes unmittelbares Handeln, sondern auch für andere bei der Tätigkeit des Unternehmens vorkommende Gesetzesverstöße, die für ihren Teil aus Nachlässigkeiten in der Leitung, der Organisierung und letztendlich der Überwachung der Tätigkeit erwachsen sind. Ein entsprechender, kriminalpolitisch begründeter Hintergrundgedanke über die Wichtigkeit, die „richtigen Personen" strafrechtlich verantwortlich zu machen, geht auch aus den Vorarbeiten der Gesetze 47:7 und 48:8 des StGB hervor.

Als zentrale Frage der strafrechtlichen Zurechnungslehre erhebt sich die Frage, ob man in der Lage ist, die Prinzipien über die Zuweisung der strafrechtlichen Verantwortlichkeit in einer Körperschaft in zufriedenstellender Weise mit den allgemeinen Lehren der herkömmlichen individuellen strafrechtlichen Verantwortlichkeit - in erster Linie mit der Verantwortlichkeit für die Teilnahme, die Unterlassung und die Fahrlässigkeit - in Übereinstimmung zu bringen. In welchem Maße sind diese Zurechnungslehren des herkömmlichen Strafrechts modifiziert oder differenziert worden bei der Bestimmung von Verantwortungssubjekten in Organisationsdelikten? Wo stößt man an die Grenzen des rechtsstaatlichen Strafrechtes?

Die Modernisierung des Strafrechtes kann im Prinzip zu einer zunehmenden Ausdifferenzierung des Straf- und Strafprozessrechtes führen (zum Beispiel danach, ob es sich um die Kriminalität von Einzelnen oder von Organisationen handelt). Man könnte auch meinen, dass es vielmehr die neuen Kriminalitäts- 
phänomene seien, die das klassische Straf- und Strafprozessrecht modifizieren. Zwischen diesen beiden Basisalternativen bestehen unterschiedlich große graduelle Unterschiede, vor allem da der Differenzierungsentwicklung u.a. durch die Menschenrechtsnormen Grenzen gesetzt werden.

Wenn ich nun über die Zuweisung der strafrechtlichen Verantwortlichkeit in einer Körperschaft rede, halte ich es nicht für wichtig, in gründlicher und eindeutiger Weise dazu Stellung zu beziehen, ob die diese betreffende Lehre eine selbständige (mit eigenen Begriffen und Prinzipien) ist oder nicht. Es wäre indes angebracht, diese Frage zu analysieren, und eine solche Erörterung wäre z.B. bei der Erwägung der Notwendigkeit von Sondervorschriften für die Zuweisung der strafrechtlichen Verantwortlichkeit von Bedeutung.

In den Begründungen des Gesetzes 47:7 des StGB wird konstatiert, dass außer dem in dieser Gesetzesstelle Gesagten ebenso die Prinzipien über die Vorsätzlichkeit und Fahrlässigkeit, die Teilnahme und die Unterlassungshaftung wie auch die übrigen allgemeinen Prinzipien der Anwendung der Strafvorschriften einen zentralen Einfluss auf die Zuweisung der Verantwortlichkeit hätten. Es wäre treffender zu sagen, dass die Zuweisung der Verantwortlichkeit außer aufgrund der aus dem betreffenden Straftatbestand hervorgehenden Voraussetzungen auch auf der Basis der herkömmlichen allgemeinen Prinzipien der strafrechtlichen Verantwortlichkeit erfolge, wobei die Lehren über die Teilnahme, die Unterlassungshaftung und die Fahrlässigkeit von besonderer Bedeutung gewesen seien. Mit einer allgemeinen Verantwortlichkeitszuweisungsvorschrift nach Art des Gesetzes 5:8 StGB oder einer besonderen Verantwortlichkeitszuweisungsvorschrift nach Art des Gesetzes 48:7 kann die Präzisierung einer solchen Erwägung oder Ergänzung gemeint sein.

Sind mit der Erwägung des Zur-Verantwortung-Ziehens für Organisationsdelikte (wobei also auf den ersten Blick mehrere Verantwortungssubjekte möglich sind) auch noch andere die allgemeinen Grundsätze der strafrechtlichen Verantwortlichkeit betreffende besondere Probleme verbunden, die den typischen Problemen der Verantwortungszuweisung gleichzustellen wären und aufgrund deren es natürlicher wäre, neutral von der Definierung und Aufzeigung der Haftungsgrundlagen zu sprechen? Man könnte auch fragen, ob man für die Zuweisung der Verantwortlichkeit eine besondere Regulierung benötigt und für welchen Teil.

In der Rechtsliteratur ist ein kritisches Augenmerk auf den in der Praxis zugenommenen Druck gerichtet worden, die Prinzipien der individuellen Strafverantwortlichkeit zu modifizieren, damit diese in einer umfassenderen Weise als zuvor die bei organisierter (kollektiver) Tätigkeit) begangenen 
Gesetzeswidrigkeiten abdeckt. In dieser Kritik ist man der Ansicht gewesen, dass die klassischen Verantwortlichkeitsprinzipien zerbröckeln und dass man sogar dabei ist, neben dem individualistischen Deliktsbegriff stufenweise die kollektive Straftat einzuführen. Bei einer in der Tätigkeit einer juristischen Person begangenen Straftat und der Bestimmung der individuellen Verantwortung ist somit der Bereich solcher Kategorien der Schuldzuweisung wie die Kausalität, das Täterhandeln und die Unterlassungshaftung erweitert worden.

Die allgemeine Tendenz des Strafrechts hat konstant darin bestanden, die Stellung der Tat des Einzelnen als Voraussetzung für die strafrechtliche Verantwortlichkeit zu betonen und eine zurückhaltende Einstellung zum Beispiel zur Erweiterung der Verantwortung betreffend die Teilnahme an den Aktivitäten einer kriminellen Gruppe zu beziehen. Die organisierte Kriminalität ist in der internationalen Kriminalpolitik am deutlichsten dasjenige Teilgebiet gewesen, auf dem man unter Verweis auf Effektivitäts- oder Präventionsargumente Änderungen in der straf- und strafprozessrechtlichen Gesetzgebung gefordert hat. Es ist jedoch eine Tatsache, dass die Einführung der strafrechtlichen Verantwortung der juristischen Person faktisch das Zueigenmachen eines kollektiven, von der individuellen strafrechtlichen Verantwortlichkeit abweichenden Straftat- und Schuldbegriffs bedeutet hat, auch wenn das vom Kapitel 9 des StGB vertretene Zurechnungsmodell Raum für unterschiedliche Auslegungen lässt.

Die Kritik an der Regulierung der Organisationsdelikte hat sich weitgehend auf in gewissem Maße variierende Auffassungen darüber gestützt, welche Grenzen der Differenzierung des Strafrechts vor allem von den fundamentalen Prinzipien der Gesetzlichkeit, des Tatstrafrechts und der Schuld gesetzt werden. Wenn es um die Verantwortung einer natürlichen Person für Gesetzeswidrigkeiten in organisierter Tätigkeit geht, so setzt das Gesetzlichkeitsprinzip voraus, dass sich die Verantwortungsgrundlagen mit hinreichender Genauigkeit aus den (vom Parlament verabschiedeten) Gesetzen ergeben, während das Prinzip des Tatstrafrechts und das Schuldprinzip wiederum voraussetzen, dass diesem Täter oder Mittäter sowohl objektiv als auch subjektiv ein zuzurechnender Anteil an der in der Organisation geschehenen Gesetzwidrigkeit aufgezeigt werden kann.

Somit befindet sich ein solches Zurechnungsmodell nicht in Übereinstimmung mit dem Tatstrafrechts- und Schuldprinzip, bei dem vorausgesetzt wird, dass ein Einzelner für die Tat eines anderen ohne seine eigene, ihm (abhängig von der Tat) als vorsätzlich oder fahrlässig anzurechnende Mitwirkung verantwortlich ist. In Anbetracht dessen bezieht man in denjenigen Ländern - wie etwa in Finnland -, die diese Prinzipien betonen, eine ablehnende Einstellung zum 
Beispiel gegenüber einer solchen strafrechtlichen Unternehmerverantwortung, bei der man nicht zumindest eine dem Unternehmer als fahrlässig anzurechnende Unterlassung seiner Überwachungspflicht verlangen würde.

\section{Nähere Betrachtung der Vorschriften über die Organ- und Vertreterhaftung}

Bei der Gesamtreform des Strafgesetzes ist man im Geiste des Gesetzlichkeitsprinzips bestrebt gewesen, diejenigen Verantwortungsgrundlagen zu präzisieren und zu ergänzen, die angewendet werden, wenn für eine in der Tätigkeit einer juristischen Person (oder in damit vergleichbarer organisatorischer Tätigkeit) begangene Straftat eine Strafe verhängt wird. Die Alternativen, die bei der Ausarbeitung von $\S 8$ Kapitel 5 des StGB zur Sprache gebracht wurden, repräsentierten unterschiedliche Auffassungen darüber, in welchem Maße ein Bedarf an einer solchen Präzisierung durch Sondervorschriften besteht.

Das in das StGB aufgenommene Gesetz 5:8 reguliert nach dem Vorbild von $\S 14$ des deutschen Strafgesetzbuches die strafrechtliche Verantwortlichkeit des Vertreters, wenn auch in einem weiteren Sinne als die Überschrift „Handeln für einen anderen“ nahelegt. Der Zweck dieser Rechtsvorschrift war es, bei Organisationsdelikten die Evaluierung derjenigen teilnahmedogmatischen Haftungssituationen zu klären und zu vereinheitlichen, bei denen der Tätertatbestand der Strafvorschrift in der Weise einschränkend gefasst wurde, dass nur eine in einer bestimmten Position oder in einem bestimmten Verhältnis befindliche Person als Täter strafbar sein kann (sog. Sonderstraftaten). In denjenigen Fällen, wo in der Tätigkeit einer juristischen Person eine solche den Tatbestand erfüllende Straftat begangen wurde und sich die Strafvorschrift wegen des einschränkenden Tätertatbestandes nur gegen die juristische Person als solche richten würde, stellt die neue Vorschrift mit der juristischen Person als Verantwortungssubjekte ihren gesetzlichen Vertreter, ein Mitglied ihres beschlussfassenden Organs oder eine ansonsten für sie faktisch tätige natürliche Person gleich.

Die unmittelbaren Reformwirkungen einer solchen Vertreterverantwortungsvorschrift werden dadurch verringert, dass in denjenigen Fällen, die in der Praxis am wichtigsten sind, entweder der Kreis der Verantwortungssubjekte im Straftatbestand nicht eingegrenzt ist oder der im Ausgang enge Täterkreis vor der Verabschiedung der Vorschrift in den einzelnen Straftatbeständen oder mittels Sonderregelung nicht erweitert worden war (als Beispiele können hier die Buchhaltungs- und Schuldnerdelikte sowie die Arbeits- und Umwelt- 
schutzdelikte angeführt werden; die die letztgenannten betreffenden Spezialvorschriften StGB 47:7 und 48:7 wurden in Kraft gelassen).

Die Vertreterverantwortungsvorschrift StGB 5:8 hat vermutlich in gewissen Maße eine indirekte Auswirkung gehabt, und zwar insofern, als in ihr diejenigen Personen, die für die juristische Person faktisch die Entscheidungsbefugnisse ausüben, als potenziell zu bestrafende Täter genannt werden. Die Rechtspraxis in der Frage, ob der faktische Leiter das Verantwortungssubjekt sein kann, ist schwankend gewesen, und zwar besonders bei Steuerdelikten. In vielen Präjudizien hat man die Steuerdelikte mit den Sonderdelikten gleichgestellt, und zwar auch dann, wenn es um einen solchen Steuerbetrug ging, bei dem der Täterkreis offen blieb (StGB 29:1-3), und als Begründung hat man auf diejenigen Normen verwiesen, die in der steuer- und körperschaftsrechtlichen Gesetzgebung die Verantwortungsposition definieren. Es handelte sich dabei um eine analoge Anwendung der Sonderstraftatlehre, da die strafrechtlichen Normen in den fraglichen Fällen den Kreis derjenigen Täter nicht eingeschränkt hätten, denen die Verantwortung für das Handeln für die juristische Person zuzuweisen sei.

Allerdings hat es in der Rechtspraxis kurz vor der Reformierung der Vorschrift in zunehmendem Maße Fälle gegeben, wo man sich bei der Zuweisung der strafrechtlichen Verantwortlichkeit nicht streng an die Normen betreffend die körperschaftsrechtliche Verantwortungsposition gehalten hat, sondern die faktischen Leiter oder mit ihnen vergleichbare Personen als Täter verurteilt hat. Zur Unterstützung dieses Standpunktes hat man auf diverse, in dieselbe Richtung gehende Gesetzesreformen verweisen können, in denen man die faktischen Leiter mit den Personen gleichgestellt hat, die sich in der Position des Körperschaftsorgans befinden: die Objekte des Geschäftsverbots in dem betreffenden Gesetz und der Begriff des Schuldners im Konkursgesetz.

Eine Schwäche im Inhalt des Gesetzes 5:8 besteht darin, dass es keine Richtschnur für die bei der Erwägung zu berücksichtigenden Umstände über das Wirkungsverhältnis und die Gewichtung zur Aufteilung der strafrechtlichen Verantwortlichkeit unter den potenziellen Verantwortungssubjekten gibt. Bei dieser Erwägung muss man zur Ergänzung der Vorschrift die allgemeinen Prinzipien über die Teilnahme, die Unterlassungshaftung und die Fahrlässigkeit anwenden. Über die Strafbarkeit der Unterlassung und der Fahrlässigkeit wurden im Allgemeinen Teil des neuen Strafgesetzes Legaldefinitionen (StGB 3:3 und 3:7) aufgenommen, und vor allem die erstgenannte Legaldefinition stellt eine bemerkenswerte Auslegungshilfe auch bei der Zuweisung der strafrechtlichen Verantwortlichkeit in Körperschaften dar. 
Zum Beispiel bei Buchhaltungs-, Steuer und Schuldnerdelikten ist für die Täterverantwortung der Umstand von entscheidender Bedeutung, welche Personen in dem Unternehmen oder der Organisation in erster Linie für die Buchhaltung und die Finanzverwaltung sowie die damit verbundenen Pflichten verantwortlich sind. Für einen in einer solchen Verantwortungsposition Befindlichen ist es unerheblich, ob er den Tatbestand des fraglichen Wirtschaftsdelikts durch aktives Handeln oder in Form eines unechten Unterlassungsdeliktes oder teilweise durch aktives Handeln und teilweise durch Unterlassung verwirklicht. In den Vorschriften des Aktiengesellschaftsgesetzes ist den Vorstandsmitgliedern und dem Geschäftsführer der Gesellschaft die erstrangige Pflicht auferlegt worden, für die Gesetzmäßigkeit der Buchhaltung und Finanzverwaltung zu sorgen, und ihre Position begründet auch die Verantwortlichkeit bei einem für die Gesellschaft begangenen Delikt, das der unechten Unterlassung gleichkommt (StGB 3:3.2). Diese Verantwortung kann ungeachtet der Arbeitsteilung, die die Vorstandsmitglieder und der Geschäftsführer untereinander vereinbart haben, erhalten bleiben (siehe OGH 2001:85). Auch die Passivität der Vorstandsmitglieder schließt die Verantwortlichkeit nicht aus, diese kann vielmehr wegen einer Unterlassung gemäß StGB 3:3.2 auch solchen Personen zugewiesen werden, die nicht am Beschlussfassungsprozess teilgenommen haben (siehe OGH 2005:27). Ein nicht selbständiger, angestellter Buchhalter eines Unternehmens, der falsche Bucheintragungen vornimmt, kann sich der Teilnahme an dem Delikt schuldig machen.

Vom rechtsvergleichenden Standpunkt aus kann man den im Betrugsübereinkommen der Europäischen Union (Rechtsakt des Rates vom 26.7.1995, 95/C 316/03) enthaltenen Artikel 3 über die strafrechtliche Verantwortlichkeit der Unternehmensleiter erwähnen. Er drückt recht klar die die erstrangigen Verantwortungssubjekte betreffende Gesetzgebungspflicht aus: Von den Mitgliedstaaten wird verlangt, dass sie ermöglichen, dass Unternehmensleiter oder andere Personen, die im Unternehmen Entscheidungsbefugnisse ausüben, gemäß den nationalen Gesetzen zur Verantwortung gezogen werden in Fällen, in denen eine ihrer Weisungsgewalt unterworfene Person einen im Artikel 1 des Übereinkommens definierten Betrug begangen hat. ${ }^{11}$

11 Vgl. im Allgemeinen Ligeti, Criminal Liability of Heads of Business. Eucrim (The European Criminal Law Associations' Forum) 2015/4, S. 145 ff. 
Ein inhaltlich weitergehendes und von seiner Formulierung her präziseres Ziel für die Harmonisierung der Gesetzgebung der EU-Länder ist in der im Kreise der EU abgefassten so genannten Corpus-Juris-Studie ${ }^{12}$ enthalten:

\section{Artikel 13.}

Strafrechtliche Verantwortlichkeit des Unternehmensleiters. Der Unternehmensleiter oder sonstige Personen, die im Unternehmen Entscheidungs- oder Kontrollbefugnisse ausüben, sind strafrechtlich verantwortlich für eine oben (Artikel 1-8) beschriebene Straftat, die von einer ihrer Weisungsgewalt unterworfenen anderen Person zugunsten des Unternehmens begangen worden ist, wenn sie bewusst die Anordnung dazu gegeben haben, den Verstoß haben geschehen lassen oder die notwendige Überwachung vernachlässigt haben.

Die Delegierung von Kompetenzen und strafrechtlicher Verantwortung ist als Verteidigung nur dann gültig, wenn sie teilweise, exakt und besonders und für die Tätigkeit des Unternehmens unbedingt nötig ist und wenn die Personen, an die die Befugnisse delegiert wurden, sich faktisch in einer Position befinden, in der ihnen die Erfüllung der erteilten Aufgaben möglich ist. Diese Delegierung schließt die Pflichten betreffend die allgemeine Überwachung, Leitung und Personenauswahl nicht aus, und sie betrifft nicht solche für die Unternehmensleitung typischen Gebiete wie die allgemeine Organisierung der Arbeit im Unternehmen.

In der Begründung des Regelungsentwurfs der Studie wird darauf verwiesen, dass der Inhalt der Rechtsordnungen der EU-Länder in dieser Frage recht stark variiert. Der oben erwähnte schwedische Gesetzgebungsvorschlag entspricht im Wesentlichen dem Vorschriftsentwurf der Corpus-Juris-Studie. In das Kapitel des Strafgesetzes über den Versuch und die Mitwirkung wäre eine Gesetzesstelle aufzunehmen, die wie im entsprechenden Absatz 1 des finnischen Gesetzes StGB 5:8 die individuelle Verantwortlichkeit für ein im Namen einer juristischen Person der exekutiven (geschäftsführenden) Leitung zuweist. Im Absatz 2 der Gesetzesstelle würde man die Täterverantwortung gleichfalls der exekutiven Leitung der juristischen Person zuweisen, wenn in der Tätigkeit der juristischen Person wegen mangelnder Kontrolle eine Verletzung der Verantwortungsvorschrift eingetreten ist, und im 3. Absatz würde man recht detailliert die Voraussetzungen für die zulässige Delegierung von Kompetenzen und Verantwortlichkeiten bestimmen.

In den ausländischen Vorschlägen wird etwas mehr als in der finnischen Doktrin die erstrangige Verantwortungsposition der Unternehmensleiter betont wenn auch der Begriff des Leiters recht weit definiert wird. Auf der anderen

12 Siehe Delmas-Marty / Vervaele (eds.), The Implementation of the Corpus Juris I-IV, a.a.O (Fn 9). 
Seite sind diese ausländischen Vorschläge inhaltlich präziser und deutlicher als die finnischen Strafgesetze 5:8 sowie 47:7 und 48:7. Entsprechend dem oben Gesagten sollte der Kreis der in verantwortlicher Position Befindlichen in einer juristischen Person (aufgrund der Zugehörigkeit zu einem Organ oder zur übrigen Leitung) einheitlich definiert werden.

\section{Analyse der Präjudizien OGH 2008:33 und OGH 2009:1}

Die Präjudizien OGH 2008:33 und OGH 2009:1 beleuchten die Zuweisung der strafrechtlichen Verantwortlichkeit in einem Umweltdelikt und in Wertpapierdelikten. In beiden Fällen hatte das Gericht sowohl die strafrechtliche Verantwortlichkeit der juristischen Person als auch die Verantwortlichkeit der im Namen der juristischen Person tätigen Führungskräfte zu untersuchen.

a) OGH 2008:33 (strafrechtliche Verantwortlichkeit der juristischen Person, Umweltdelikt): Aus der Ölraffinerie der Gesellschaft war wegen Fahrlässigkeit ihrer Arbeitnehmer eine große Menge an Öl auf dem Gelände der Raffinerie in den Erdboden und weiter ins Meer gelangt. Die Arbeitnehmer waren wegen fahrlässiger Umweltverschmutzung zu Strafen verurteilt worden. In der Sache ging es darum, gegen die Gesellschaft eine Körperschaftsgeldstrafe zu verhängen.

Kommentierung des Falls:

- Im Fall OGH 2008:33 hatten Gerichte der unteren Instanz die zur individuellen Verantwortung gezogenen Arbeitnehmer kraft StGB 48:4 wegen fahrlässiger Umweltverschmutzung verurteilt. Das erstinstanzliche Gericht war der Ansicht, dass - in aufsteigender Hierarchie aufgezählt - die Unterlassung des Operators (A) erheblich war, aber man hat sie nicht als schwere Fahrlässigkeit eingestuft. Die Fahrlässigkeit des verantwortlichen Betreibers der Abwasseranstalt (B) war laut dem Gericht erster Instanz nicht sehr erheblich, die Fahrlässigkeit des Fertigungsbetriebsleiters (C) war recht geringfügig und die Fahrlässigkeit des Leiters der Produktionsabteilung war ebenfalls nicht sehr erheblich. Da bereits zweimal zuvor beim Umpumpen von Öl wegen eines ähnlichen menschlichen Irrtums Hunderte von Litern Öl in den Erdboden gesickert waren, war es nach der Meinung der Gerichte der unteren Instanz nicht unvorhersehbar, dass das Öl auch ins Meer gelangt.

- Die allgemeine Vorschrift für die Zuweisung der strafrechtlichen Verantwortlichkeit ist StGB 5:8 und die die Umweltdelikte betreffende Sondervorschrift StGB 48:7. Die Zuweisung der strafrechtlichen Verantwortung wird zudem von StGB 3:3.2 bestimmt, die unechte Unterlassungsdelikte reguliert.

- In StGB 48:1-4 ist der Täterkreis nicht eingeschränkt (vgl. z.B. das Arbeitsschutzdelikt, StGB 47:1). Es besteht somit laut StGB 48:4 kein Hindernis dafür 
- wie es die Gerichte der unteren Instanz im Fall OGH 2008:33 getan haben die unterste Arbeitnehmerstufe A, also den Operator, zu verurteilen, der fahrlässigerweise vergessen hatte, beim Umpumpen von Öl ein Ventil zu schließen. Seine Tat, für die die Vernachlässigung der Sorgfaltspflicht wesentlich war, war die unmittelbare Ursache für das verbotene Ablassen von Öl in die Umwelt. Die typische Situation bei der Zuweisung der strafrechtlichen Verantwortlichkeit ist jedoch die, dass eine Person oder Personen zur Verantwortung gezogen werden, die hinsichtlich ihrer Position sowie der Art und des Umfangs ihrer Aufgaben und Kompetenzen der unteren Arbeitnehmerstufe übergeordnet sind, also in erster Linie Vorarbeiter oder in leitender Position befindliche Angestellte und / oder Mitglieder von Leitungsorganen.

- Bei allen in den unteren Gerichtsinstanzen verurteilten Personen konnte individuell die Unterlassung von Pflichten aufgezeigt werden, die in relevanter Weise zur Umweltverschmutzung geführt hatten. In der Fallaufgabe waren die Positionen und Pflichten dieser Personen beschrieben worden. Laut dem Appellationsgericht Turku waren $\mathrm{D}$ und $\mathrm{C}$ dafür verantwortlich, dass man es in der Gesellschaft unterlassen hatte, zur Vermeidung von derartigen Schäden ausreichend schnelle Maßnahmen zu ergreifen. B wiederum hatte die früheren Schäden untersucht, und er hätte faktisch die Möglichkeit gehabt, die Arbeitsverfahren beim Umpumpen von Öl von einem Tank in einen anderen zu ändern, aber er hatte dies unterlassen. Außerdem hat das Appellationsgericht die zusätzlichen Begründungen des Gerichtes der unteren Instanz bestätigt, in denen bezüglich $\mathrm{C}$ dessen Verantwortung für die Funktionen und Bereitschaften der Zentralen Überwachungsstation betont wurde, und bezüglich D dessen Verantwortung für die Einrichtung der Produktion in der Weise, dass über die Verantwortungsbeziehungen keine Unklarheiten bestehen und dass die Organisation auch in der Praxis funktioniert. Dem Gericht der unteren Instanz zufolge konnte man das Eintreten des Umweltdelikts genau auf eine bestimmte einzelne Funktion lokalisieren, weswegen auch in der Organisation der Gesellschaft Fahrlässigkeit und Unklarheit der Verantwortungsbeziehungen aufgetreten waren, aber keine schwere Fahrlässigkeit.

- Die individuelle strafrechtliche Verantwortlichkeit und die strafrechtliche Verantwortlichkeit der juristischen Person werden parallel zueinander angewandt. Es sei dennoch auf StGB 9:4 Absatz 2 Punkt 3 (im Gesetzblatt 61/2003) über das Absehen von Verurteilung einer juristischen Person verwiesen (der die Berücksichtigung der Sanktionskumulation voraussetzt).

- In OGH 2008:33 ist als Objekt des Präjudizes ausdrücklich die Frage, ob die Firma Neste Oil Oyj, die Nachfolgering der Fortum Oil Oy, zu einer Körperschaftsgeldstrafe zu verurteilen sei - anders als man in den Gerichten der 
unteren Instanz gemeint hatte (wo man von einer Verurteilung abgesehen hatte; siehe StGB 9:4). Allerdings war man in allen Rechtszügen der Ansicht gewesen, dass die in StGB 9:2-3 bestimmten Voraussetzungen für die strafrechtliche Verantwortlichkeit der juristischen Person gegeben waren.

- Der OGH untersuchte, ob die Voraussetzungen für die strafrechtliche Verantwortlichkeit der juristischen Person gegeben waren, und betonte, dass entgegen der gegenteiligen Ansicht der Neste Oil Oy die Entscheidung nicht darauf beruhen könne, dass mehrere Arbeitnehmer der Gesellschaft gesetzkräftig für die von ihnen bei ihrer Arbeit begangene fahrlässige Umweltverschmutzung verurteilt worden waren. Der OGH evaluierte, ob die gegen die Umweltgesetzgebung verstoßende Vorgangsweise als eine in der Tätigkeit der Gesellschaft begangene fahrlässige Umweltverschmutzung einzustufen sei (StGB 9:3). Er behandelte zum einen die objektive Tatbestandsmäßigkeit des Umweltdelikts (StGB 48:4) in der oben geschilderten Weise. Auf der anderen Seite bezog der OGH dazu Standpunkt, ob es sich um eine fahrlässige Umweltverschmutzung gehandelt habe, und kam zu einem positiven Ergebnis, da der in der Anklage bezeichnete Schaden und die Schadensgefahr aus der Fahrlässigkeit von Personen erwachsen waren, die im Dienste der Gesellschaft gestanden haben.

- Zusätzlich zu dem Gesagten erwog der OGH nach StGB 9:2, ob man die Handlungen der Angestellten mit der Tätigkeit der Gesellschaft gleichsetzen könne, wie es das Appellationsgericht Turku getan hatte. Der OGH kam hierin jedoch - meiner Meinung nach überraschend - zu einem negativen Ergebnis und konstatierte, dass obwohl D und C in der Ölraffinerie in ihren Tätigkeitsbereichen eigenständige Entscheidungsbefugnisse hatten (sie waren Mitglieder der Direktion, D war für die Verfolgung und Entwicklung der Funktion der Sicherheitssysteme zuständig, und C oblag die Gesamtüberwachung u.a. des Umweltschutzes), sie keine solchen eigenständigen und bedeutenden Entscheidungsbefugnisse gehabt hatten, die die Anwendung des Gleichsetzungsprinzips begründet hätten. Der Begriff „Gleichsetzung“ wird in dem Gesetzestext nicht benutzt, sondern in StGB 9:2.1 ist die Rede von der Zugehörigkeit zu einem gesetzlich vorgeschriebenen Organ oder der sonstigen Leitung. In dem Fall war dennoch die von StGB 9:2 bezeichnete Fahrlässigkeit der Gesellschaft gegeben, mit anderen Worten: in der Tätigkeit der Gesellschaft hatte man nicht die erforderliche Sorgfalt und Vorsicht zur Verhinderung des Delikts walten lassen: Die Ölbeförderungsanlagen waren nicht mit besonderen Sicherungsund Alarmvorrichtungen ausgestattet gewesen, und man hatte es dem Operator, der das Ölumpumpen vorgenommen hatte, erlaubt, sich nach dem Öffnen des Ventils vom Ort zu entfernen, obwohl schon zweimal zuvor beim Um- 
pumpen von Öl Fehler vorgekommen waren, die eine gleichartige Schadensgefahr verursacht hatten. Die Gesellschaft hatte es vernachlässigt, ausreichende Maßnahmen zu ergreifen, mit denen solche Folgen, wie sie durch Nachlässigkeiten beim Umpumpen von Öl entstehen, hätten verhindert werden können.

- Bei seiner Erwägung der Verurteilung zu einer Körperschaftsgeldstrafe zählte der OGH aufgrund des alten Wortlauts des StGB 9:4 (im Gesetzblatt 743/1995; vgl. Gesetzblatt 61/2003) zu den zu berücksichtigenden Aspekten die Schwere des Delikts, die sonstigen der juristischen Person durch das Delikt zugefügten Folgen und die Maßnahmen der juristischen Person zur Verhinderung solcher Delikte. Man hätte das Delikt allein schon aufgrund dessen für schwer halten können, weil eine erhebliche Menge an Öl in den Erdboden gelangt war und die Schäden sich in einem großen Gebiet ausgebreitet hatten. Außerdem hatte man zu berücksichtigen, dass man trotz der in gleicher Weise entstandenen Fehler, zu denen es früher beim Umpumpen von Öl gekommen war, die Sicherheit der Umwelt nach wie vor den Maßnahmen der Arbeiter überlassen worden war, obgleich man zu zumutbaren Kosten ein effektives Sicherheitssystem hätte aufbauen können.

- Die Gesellschaft hatte zur Behebung und Entschädigung der entstandenen Schäden sowie für neue umwelttechnische Investitionen rund 4000000 Euro aufgewandt. Nach dem Geschehnis hatte die Gesellschaft zudem zur Verhinderung gleichartiger Umweltschäden 171000 Euro aufgewandt, und zwar 40000 Euro davon ausdrücklich zur Verhinderung von solchen Schäden, wie sie durch ein offen gelassenes Ventil entstehen können. Der OGH war jedoch der Ansicht, dass diese Investitionen bei der Erwägung der Verhängung einer Körperschaftsgeldstrafe nicht als mildernde Umstände berücksichtigt werden könnten.

- Zusammenfassend war der OGH der Ansicht, dass die Versäumnisse der Gesellschaft und deren Folgen schwer gewesen waren. Auf der anderen Seite waren keine solchen wesentlichen Begründungen dafür zur Sprache gekommen, die Körperschaftsgeldstrafe nicht zu verhängen. Nach der Behandlung der Begründungen zur Bemessung der Körperschaftsgeldstrafe (siehe StGB 9:5-6) verurteilte der OGH die Gesellschaft zu einer Körperschaftsstrafe in Höhe von 500000 Euro; das Höchstmaß wären 850000 Euro gewesen (StGB 9:5; Gesetzblatt 971/2001).

b) OGH 2009:1 (strafrechtliche Verantwortlichkeit der juristischen Person, Wertpapiermarktdelikt, Festsetzung der Strafe, Einzug des Nutzens): A, der Geschäftsführer der C AG und Vorstandsmitglied, sowie B, Vorsitzender des Vorstands derselben Gesellschaft, hatten vor der Emission und dem Verkauf von Aktien der C AG im Notierungsprospekt über das Ergebnis und die Zukunftsaussichten der Gesellschaft 
unwahre und irreführende Angaben vorgebracht und diese beim Verkauf der Aktien als Insider-Informationen ausgenutzt, wodurch sie sich eines den Wertpapiermarkt betreffenden Falschangabedeliktes und schweren Missbrauchs von Insider-Informationen schuldig gemacht haben. In dem Fall ging es um die Festsetzung der Strafen, um den Einzug der durch die Delikte erhaltenen Nutzens und um die Bemessung einer Körperschaftsstrafe.

Kommentierung des Falles:

- Bei den beanstandeten Vorgangsweisen in dem Fall ging es um die Verantwortung von $\mathrm{A}$ und $\mathrm{B}$ sowie der Firma $\mathrm{C}$ AG für Falschangabedelikte im Wertpapiermarkt (StGB 51:4) sowie schweren Missbrauch von InsiderInformationen (StGB 51:4). Da die (objektiven) Tatbestände dieser Wertpapiermarktdelikte in der Tätigkeit der C AG und zugunsten der Firma verwirklicht worden waren, war als nächstes zu erwägen, ob den natürlichen Personen A und B eine individuelle Strafbarkeit und der Firma C AG die strafrechtliche Verantwortung der juristischen Person zuzuweisen sei. Bei Wertpapiermarktdelikten kommt laut einer Sondervorschrift (StGB 51:8) auch die letztgenannte Verantwortungsform in Frage, und die Verantwortungsformen schließen einander nicht aus.

- Bei der Erwägung der individuellen strafrechtlichen Verantwortlichkeit und ihrer Zuweisung wurde die Rechtsvorschrift StGB 5:8 (Handeln für eine juristische Person) berücksichtigt, obgleich bei solchen Wertpapiermarktdelikten der Täterkreis im Tatbestand nicht begrenzt ist. Für den Teil, bei dem die aktive Teilnahme von A und B an den besagten Wertpapiermarktdelikten nicht bewiesen werden konnte, kam die Verantwortung für ein unechtes Unterlassungsdelikt nach StGB 3:3.2 in Frage, und als die darin bezeichnete Folge konnte man ein in der Tätigkeit der juristischen Person begangenes Delikt ansehen. Sowohl A als auch B haben sich in solchen gesellschaftsrechtlichen Positionen befunden (A als Geschäftsführer der Aktiengesellschaft sowie als Vorstandsmitglied und B als Vorstandsvorsitzender), dass - unter Berücksichtigung der Vorschriften 6:2.1 und 17 des Aktiengesellschaftsgesetzes - auch eine strafrechtliche Verantwortungsposition in der von StGB 3:3.2 bezeichneten Weise gegeben war.

- Gemäß dem oben Gesagten hatten A und B aufgrund ihrer Zugehörigkeit zur Leitung der Gesellschaft eine solche verantwortliche Position inne, dass ihnen in den Grenzen ihrer Zurechenbarkeit die Täterverantwortung für die Wertpapiermarktdelikte zukam. Bezüglich der Zurechenbarkeit ist anzumerken, dass für den schweren Missbrauch von Insider-Informationen und das Fälschen des Kurses Vorsätzlichkeit verlangt wird, während bei Wertpapiermarktdelikten ansonsten schwere Fahrlässigkeit ausreicht. Das Appellationsgericht Helsinki 
hatte im Fall OGH 2009:1 unter anderem die Ansicht vertreten, dass die angeklagten Vorstandsmitglieder (bezüglich des Falschangabedeliktes) zu ihrer Entlastung nicht auf die Heranziehung der von ihnen engagierten Sachverständigen bei der Organisierung der Aktienemission verweisen konnten, da sie selbst über das Ergebnis und die finanzielle Lage der Gesellschaft, über die falschen Verbuchungen im Zwischenbericht und über die Haltlosigkeit der Ergebnisprognose Bescheid wussten. Der Irrtum über die richtige Auslegung eines zum Tatbestand gehörenden Merkmals ist ein sog. Subsumtionsirrtum, der bei der Beurteilung der Entlastung dem Verbotsirrtum gemäß StGB 4:2 gleichgesetzt wird.

- Was die strafrechtliche Verantwortlichkeit der Gesellschaft als juristischer Person betrifft, ist zu konstatieren, dass die fraglichen Straftaten in der Tätigkeit der Gesellschaft sowie im Namen und zugunsten der Gesellschaft begangen wurden (StGB 9:1 und 3.1) und dass die natürlichen Personen A und B der Leitung der Gesellschaft angehört haben (StGB 9:3.1). Somit wurde auch die Forderung nach Gleichstellung der Straftäter mit der Gesellschaft (A und B hatten einem gesetzlich vorgeschriebenen Organ der Gesellschaft angehört) gemäß StGB 9:2.1 erfüllt.

- Im Fall OGH 2009:1 wurde die Gesellschaft zu einer Körperschaftsgeldstrafe verurteilt, wobei es in erster Linie deswegen zu einer Diskussion kam, weil zur Tatzeit die Verhängung von Körperschaftsgeldstrafen noch im Ermessen des Gerichts lag, und ebenso hatte das Gericht bei der Bemessung des Betrags der Körperschaftsgeldstrafe sein Ermessen auszuüben (das Endergebnis war eine Körperschaftsgeldstrafe in Höhe von 100000 Euro). A und B wurden zu Freiheitsstrafen von einer Dauer von 2 Jahren und 4 Monaten verurteilt, und außerdem entschied das Gericht, dass sie gesamtschuldnerisch den durch die Straftat erlangten Gewinn in Höhe von knapp 8 Millionen Euro an den Staat abzuführen hatten.

\section{Einige Schlussfolgerungen}

Die finnische Erfahrung zeigt, dass es eine lange Zeit fordert, bis eine solche neue Verantwortungsform wie die echte Kriminalstrafbarkeit der juristischen Person in der Rechtspraxis ernstgenommen wird. In Finnland war die Staatsanwaltschaft lange sehr passiv, und weil bis jetzt nur ganz wenige Fälle vom OGH behandelt worden sind, sind viele strafrechtsdogmatische Auslegungsfragen relativ unklar. Kriminalpolitisch ist auch nicht genügend erörtert worden, was die rechte Sanktionspolitik in der Zukunft wäre: Sollte man eher punitive administrative Sanktionen statt der strafrechtlichen Verantwortung der 
juristischen Person einführen, und wie sollte man das Verhältnis zwischen der individuellen und körperschaftlichen Verantwortung regeln?

Der Vertrag von Lissabon (2009) hat die Zuständigkeit der EU vermehrt, wobei die sich herausbildenden Prinzipien eines europäischen Sanktionsrechts in immer größerem Umfang sich auf die nationalen strafrechtlichen Sanktionssysteme auswirken dürften. ${ }^{13}$ Bei dem Vertrag von Lissabon spielt das sich weiter verstärkende Prinzip der gegenseitigen Anerkennung auch bei der Angleichung der strafrechtlichen Sanktionen gleichfalls eine bedeutende Rolle. Die Stellung dieser administrativen Sanktionen und die Prinzipien ihrer Verhängung sind nun als wichtiger Teil des Sanktionsrechts der EU zu evaluieren.

\section{Anlage: \\ Kapitel 9 (Über die Strafbarkeit juristischer Person) des finnischen Strafgesetzes; GBl. 743/1995 ${ }^{14}$}

\section{Kap. 9 \& 1. Anwendungsbereich}

(1) Wegen einer Straftat, die im Rahmen der Tätigkeit einer Gesellschaft, einer Stiftung oder anderen juristischen Person begangen worden ist, ist auf Antrag der Staatsanwaltschaft eine Körperschaftsgeldstrafe zu verhängen, sofern für die Straftat eine solche Sanktion in diesem Gesetz vorgesehen ist.

(2) Die Vorschriften dieses Kapitels finden keine Anwendung auf eine Straftat, die bei der Ausübung öffentlicher Gewalt begangen worden ist.

\section{Kap. 9 \& 2. Voraussetzungen der Strafbarkeit}

(1) Eine juristische Person wird zu Körperschaftsgeldstrafe verurteilt, wenn jemand, der zu einem ihrer gesetzlich vorgeschriebenen Organe oder sonst zu ihrer Leitung gehört oder innerhalb der juristischen Person tatsächliche Entscheidungsbefugnis ausübt, an der Straftat beteiligt gewesen ist oder die Begehung der Straftat zugelassen hat oder wenn im Rahmen der Tätigkeit der juristischen Person nicht die erforderliche Sorgfalt und Vorschrift eingehalten worden ist, um die Straftat zu verhindern.

(2) Eine Körperschaftsgeldstrafe wird auch dann verhängt, wenn der Täter nicht ermittelt werden kann oder wenn der Täter aus einem anderen Grund nicht verurteilt wird. Wegen eines Privatklagedelikts wird bei fehlendem

13 Vgl. im allgemeinen Tiedemann, Europäisierung des Strafrechts und Sanktionen gegen juristische Personen in der Europäischen Union. In: Ayşe Nuhoğlu (Ed.), Sanktionen gegen juristische Personen, a.a.O (Fn 1).

14 Übersetzung von Cornils, Frände und Matikkala, s. Fußn. 2. 
Strafantrag des Verletzten eine Körperschaftsgeldstrafe jedoch nur dann verhängt, wenn ein besonders wichtiges öffentliches Interesse die Anklageerhebung verlangt.

Kap. 9 § 3. Verhältnis zwischen Täter und juristischer Person

(1) Eine Straftat gilt als im Rahmen der Tätigkeit einer juristischen Person begangen, wenn der Täter im Namen der juristischen Person oder zu deren Vorteil gehandelt hat und er zur Leitung der juristischen Person gehört oder in einem Dienst- oder Arbeitsverhältnis zu ihr steht oder im Auftrag eines Vertreters der juristischen Person gehandelt hat.

(2) Eine juristische Person hat gegen den Täter keinen Anspruch auf Erstattung einer von ihr bezahlten Körperschaftsgeldstrafe, sofern sich nicht ein Erstattungsanspruch aus dem Gesellschafts- oder Stiftungsrecht ergibt. 